Portland State University

PDXScholar

\title{
Scientists, Uncertainty and Nature, an Analysis of the Development, Implementation and Unintended Consequences of the Northwest Forest Plan
}

Gilbert David Miller

Portland State University

Follow this and additional works at: https://pdxscholar.library.pdx.edu/open_access_etds

Part of the Environmental Policy Commons, Forest Management Commons, and the Sociology Commons

Let us know how access to this document benefits you.

\section{Recommended Citation}

Miller, Gilbert David, "Scientists, Uncertainty and Nature, an Analysis of the Development, Implementation and Unintended Consequences of the Northwest Forest Plan" (2019). Dissertations and Theses. Paper 4809.

https://doi.org/10.15760/etd.6693

This Dissertation is brought to you for free and open access. It has been accepted for inclusion in Dissertations and Theses by an authorized administrator of PDXScholar. Please contact us if we can make this document more accessible: pdxscholar@pdx.edu. 
Scientists, Uncertainty and Nature,

An Analysis of the Development, Implementation and Unintended

Consequences of the Northwest Forest Plan

by

Gilbert David Miller

A dissertation submitted in partial fulfillment of the requirements for the degree of

Doctor of Philosophy

in

Earth, Environment and Society

\author{
Dissertation Committee: \\ Craig Shinn, Chair \\ Darrell Brown \\ Max Nielsen-Pincus \\ Robert Scheller \\ Nathan McClintock
}

Portland State University

2019 
(C) 2019 Gilbert David Miller 


\begin{abstract}
The conflict in the Pacific Northwest between competing visions of how federal forests should be managed resulted in a political stalemate in the early 1990s. The Northwest Forest Plan (NWFP) was initiated to resolve the demands for maintaining ecosystem processes and biological diversity with the social and economic needs for timber harvest. The foundation for the plan rested with the development of ecosystem management. The intent of this research is to explore the events which led up to the adoption of the NWFP, how it was implemented by the US Forest Service and Bureau of Land Management and the subsequent reactions to and consequences of the plan. The primary research consisted of thirty-eight semi-structured interviews with individuals responsible for the development of the initial plan, those tasked with implementing the plan and current federal agency personnel from the land management agencies and regulatory agencies. With the use of thematic analysis, key meanings were captured as expressed by the interviewees. The data was analyzed using institutional theory, capturing the organizational relations within the organizational field of the land management agencies.
\end{abstract}

Research findings suggest that the NWFP was unsuccessful in meeting the goal of addressing the social and economic issues as well as the goals for ecosystem management. This dissertation explores the organizational practices and cultural meanings that led to the final instantiation of the plan. It seeks to shed light on the reasons why these goals were not met and how future forest plans can move beyond the current stalemate between conservation and preservation. 


\section{Acknowledgements}

I want to express my gratitude to the thirty-eight interviewees who gave me their time, insights and stories about the Northwest Forest Plan. They provided me with an education and experience that I hope this dissertation captures.

I am indebted to my dissertation committee for their dedication, being a source of academic training and their countless hours spent with me. I want to thank Dr. Rob Scheller, Dr. Max Nielsen-Pincus and Dr. Nathan McClintock for their commitment to me and my research. I want to thank Dr. Darrell Brown for believing in me and providing support for my entrance into the graduate program, changing my life. To my chair, Dr. Craig Shinn, you have provided me with a natural resource social science training, a legacy I am now proud to call my own. Your encouragement, mentoring and commitment were constant and invaluable.

To my PSU friends and colleagues, thank you for your support and encouragement on this journey.

I want to thank my parents and siblings for their love and faith in me. To my children, Olivia and Julian, you inspire me with your love and friendship. To my wife Megan, thank you for your support these last six years. Without your love, caring and understanding, I would not have been able to make it through this process. You never questioned my crazy idea to go back to school and reinvent myself. 


\section{Table of Contents}

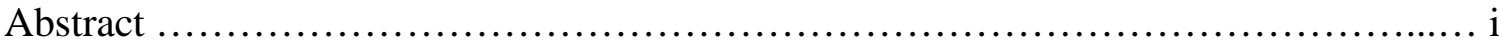

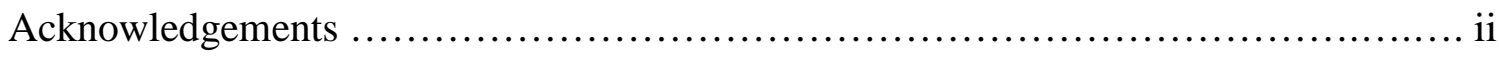

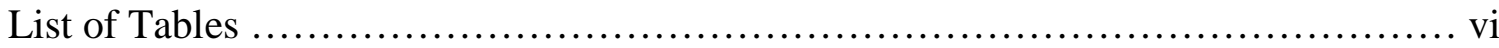

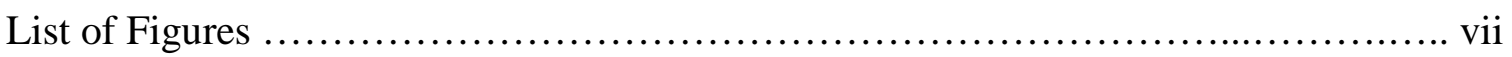

List of Abbreviations ........................................................ viii

Chapter 1: Literature Review

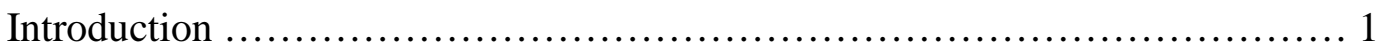

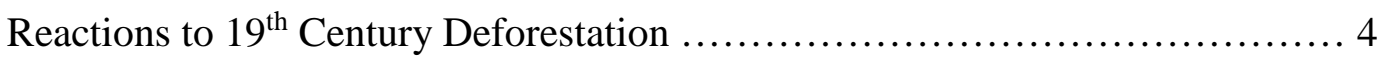

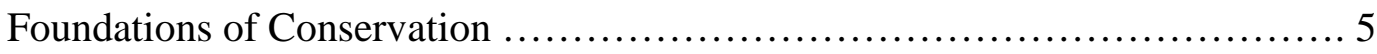

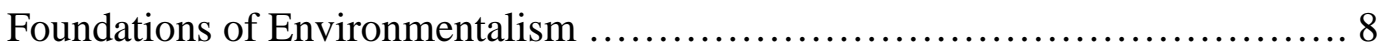

Chapter 2: Research Problem Formulation

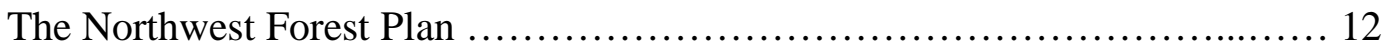

Oregon Endangered Species Task Forces ................................ 15

Listing of the Northern Spotted Owl ..................................... 18

Interagency Scientific Committee to Address the Conservation of the Northern

Spotted Owl ...................................................... 21

The Scientific Panel on Late-Successional Forest Ecosystems (Gang of Four) .. 27

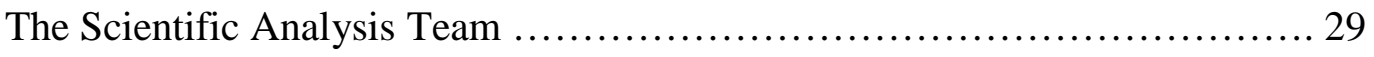

Forest Ecosystem Management Assessment Team ......................... 32

Chapter 3: Research Methodology and Study Design

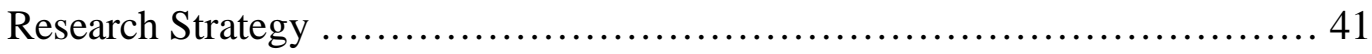


Definition of Study Universe ............................................. 42

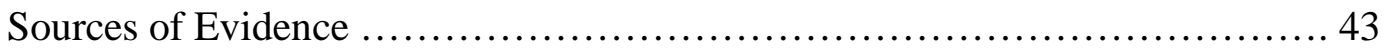

Analytic Design of Research ............................................. 48

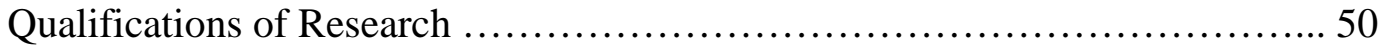

Chapter 4: Research Analysis

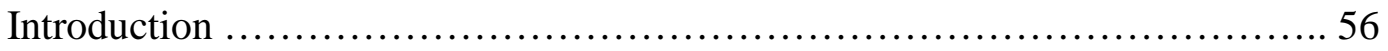

Environmental Community ............................................. 56

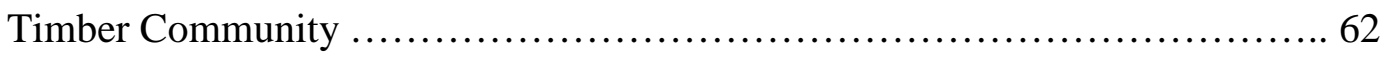

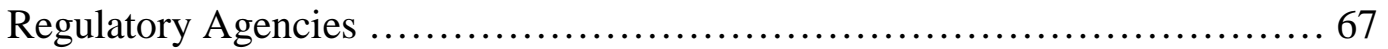

Academic Community .................................................. 72

Bureau of Land Management …............................................... 81

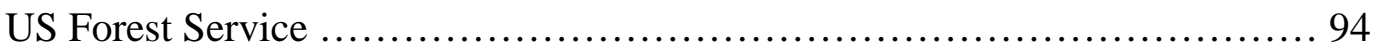

Chapter 5: Discussion of Findings

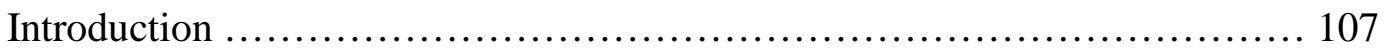

Scientists as Arbiters of Legal Issues and Social Values ....................... 113

The Foundational Meaning of Uncertainty and Certainty ...................... 119

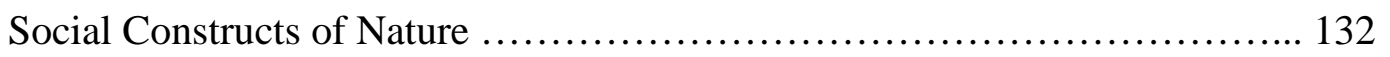

The US Land Management Agencies Moving Forward ...................... 143

Chapter 6: Discussion and Conclusion

Implications of the Research ............................................... 153

Dynamics of Organizational Fields ..................................... 158

Directions for Future Research ............................................ 165 
Conclusion ....................................................... 168

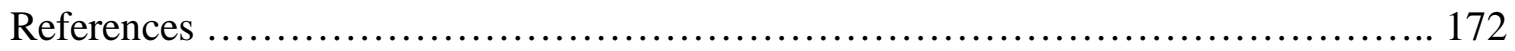

Appendix. List of Interviewees ......................................... 178 


\section{List of Tables}

Table 1. Mythology of the American West ........................................ 10 


\section{List of Figures}

Figure 1. Map of Northwest Forest Plan region ............................... 14

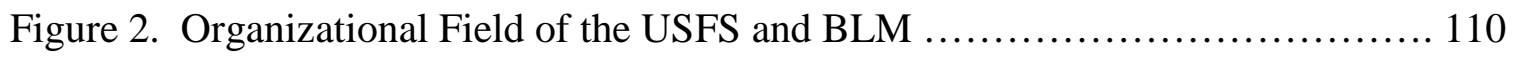

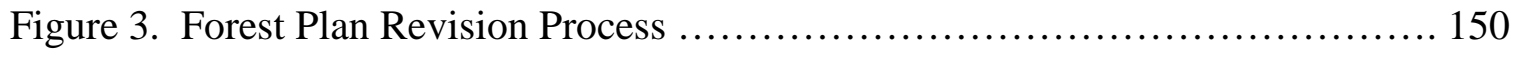

Figure 4. Organizational Field for Land Management Agencies Prior to NWFP ..... 160

Figure 5. Organizational Field for Land Management Agencies at Introduction of NWFP ...................................................... 163

Figure 6. Current Organizational Field for Land Management Agencies ............. 165 


\section{List of Abbreviations}

ACS

BLM

CAA

CWA

DCA

EIS

ESA

FEMAT

FLPMA

HCA

ISC

MOCA

MUSY

NEPA

NOAA

NPS

NWFP

NSO

$\mathrm{O} \& \mathrm{C}$ Act

OESTF

SAT

SEIS

SOHA

RIEC

ROD

USFS

USFWS

USGS
Aquatic Conservation Strategy

Bureau of Land Management

Clean Air Act

Clean Water Act

Designated Conservation Areas

Environmental Impact Statement

Endangered Species Act

Forest Ecosystem Management Assessment Team

Federal Land Policy Management Act

Habitat Conservation Area

Interagency Scientific Committee to Address the Conservation of

the Northern Spotted Owl

Managed Owl Conservation Areas

Multiple Use-Sustained Yield Act of 1960

National Environmental Policy Act

National Oceanic and Atmospheric Administration Fisheries

National Park Service

Northwest Forest Pan

Northern Spotted Owl

The Oregon and California Revested Lands Act of 1937

Oregon Endangered Species Task Force

Scientific Analysis Team

Supplemental Environmental Impact Statement

Spotted Owl Habitat Areas

Regional Interagency Executive Committee

Record of Decision

United States Forest Service

United States Fish and Wildlife Service

United States Geological Survey

viii 
"Environmental issues are linked to the ebb and flow of political life because the origins of natural resources are to be found in society, not in the earth. Unlike nature, the web of human society is woven of myth and rhetoric, of faith and persuasion, which filter and sort the meanings of man and nature. Therefore, environmental crises, like other social problems, emerge when the traditional myths and rhetorics are questioned and new ones compete for their replacement” (Burch 1971).

\section{Chapter 1: Literature Review}

\section{Introduction}

Two federal land management agencies, the US Forest Service (USFS) and the Bureau of Land Management (BLM) have been influenced by of a shift in social values defining the meaning of federal forests in both cultural and economic terms. This shift in social values began in the United States in the 1960s with the development of a greater environmental awareness regarding the impact of management practices of both private industry and federal land management agencies (Yaffee 1994, 10). As a response to this shift, in 1969 Congress enacted the National Environmental Policy Act (NEPA), requiring federal agencies to provide "an evaluation of the environmental impacts of alternative planning scenarios and the use of up-to-date environmental information” (Blumm 1991, 610). Subsequently in the 1970s Congress passed three major pieces of legislation that redefined the management practices of federal land management agencies, the Endangered Species Act of 1973 (ESA), the National Forest Management Act of 1976 (NFMA) and the Federal Land Policy and Management Act of 1976 (FLPMA). 
These legislative actions forced federal land management agencies to include protection of animal and plant species along with their habitat in their land management plans (Hirt 1994, Satterfield 2002). This shift was grounded in the “ecosystem ecology,” taking a "functional view of ecosystems, emphasizing the movement of matter and energy among their constituent parts" and "could highlight and measure the degree to which humans were disrupting the fundamental processes that produced ecological stability” (Skillen 2015, 23). Concurrently, conservation biologists were developing the concept of "biodiversity" as a means to express the loss of species diversity as a result of human destruction of environmental habitats (Tackas 1996). Biodiversity captures the intention of preservation of species on three grounds: (a) biodiversity as a source of raw material for agriculture and pharmacology; (b) human moral and ethical concerns; and (c) for overall evolutionary processes, independent of human interaction (Pottast 1996, 183). Biodiversity incorporates biological and ethical components to maintain existing ecological processes and systems in order to avert loss of future resources and potentially ecological crisis (Tackas 1996, 9).

The sciences of ecology and conservation biology influenced both the Congressional legislation of the 1970s and the manner in which social and cultural preferences for environmental protection are expressed. The ESA, NFMA, FLPMA and NEPA redefined the manner in which the USFS and BLM operate as land management agencies and their relationship with other federal agencies such as the US Fish \& Wildlife Service (USFWS) and the National Oceanic and Atmospheric Administration Fisheries (NOAA). The changes brought about by this new legislation to the USFS and BLM were 
defined by their respective agency cultures and histories, the result of federal court rulings, and shifting social values in relation to the priorities for federal forests.

Changing social values in the 1970s as evidenced by the release of the Congressional Bolle Report critical of the clear-cut timber harvesting in the Bitterroot National Forest expressed a changing set of meanings for the American public regarding federal forest management (Freeman 2002, 634). In the Pacific Northwest, the confluence of shifting public attitudes, new Congressional legislation and active legal proceedings initiated by environmental organizations led to an eventual halt in timber harvesting on federal lands in 1989. The solution to the ongoing legal issues regarding timber harvest on federal lands by the land management agencies and the federal government was to look to a group of scientists. The solutions provided by these scientists were modified through successive instantiations of scientific panels and interpreted by the USFS and BLM through their political and economic interests as well as their organizational history and practices. The landmark Northwest Forest Plan approved in 1994 was meant to be the solution to balancing the interests of all stakeholders and to provide a legally defensible plan to meet the court's interpretation of federal land management legislative requirements.

This research explores the events which lead up to the adoption of the Northwest Forest Plan, how it was implemented by the USFS and BLM and the subsequent reactions to and consequences of the implementation. This research employs the insights from the "cognitive" branch of Institutional theory, which as defined by Scott "stress[es] the centrality of cognitive elements of institutions: the rules that constitute the nature of 
reality and the frames through which meaning is made” (Scott 1995, 40). The focus of analysis rests at the organization level as opposed to understanding social behavior in terms of an individual rational actor model. Organizations comprise symbolic systems and cultural rules external to the individual and provide a context for understanding individual actor behavior (Scott 1995, 41). Organizations exist within a larger social sphere - an organizational field. An organizational field is comprised of a number of related organizations that "constitute a recognized area of institutional life: key suppliers, resource and product consumers, regulatory agencies, and other organizations that produce similar services or products” (DiMaggio and Powell 1991, 64-65). The focus of this research will be with the organizational field as constituted by the USFS, the BLM, federal regulatory agencies, the academic community, the timber community, and the environmental community.

\section{Reactions to $19^{\text {th }}$ Century Deforestation}

Throughout the $19^{\text {th }}$ century and up until its end, forestry management in the United States was based on laissez-faire private ownership practices. Private timber companies practiced a severe cut-and-run practice, whereby entire forests were clear-cut and abandoned, and timber companies moving on to new forested lands when exhausted. Forested lands in the southeastern and Midwestern United States were quickly harvested (Hirt 1994, 28). Groups such as the American Forestry Association looked to the federal government to set aside forest reserves. The American Forestry Association was comprised "primarily of botanists, landscape gardeners and estate owners...emphasized 
arboriculture, an aesthetic appreciation of forests, and the study of individual trees” (Hayes 1959, 27). In addition, the National Irrigation Congress sought federal action to "reserve particular watersheds as national forests to protect them from commercial use, and to prevent timber cutting and grazing within them” (Hayes 1959, 23). Both of these groups advocated the conservation of water resources and forested lands through the establishment of federal reserves that would restrict commercial activities.

\section{Foundations of Conservation}

During the administration of Theodore Roosevelt at the beginning of the $20^{\text {th }}$ century, Gifford Pinchot proposed a Conservationist policy for the nation's forests to address this same short sighted waste of forest resources based on the idea of the efficient use of forest resources or "sustained yield." The efficient use of forest resources "strove to encourage the greatest possible production of material goods at the lowest possible cost” (Hayes 1959, 126). Pinchot argued for setting aside federal forest lands, similar to the Preservationists, but with a different objective in mind. "The significance of the new

public lands program...lay not in the method of public ownership, but in the objective of efficient, maximum development” (Hayes 1959, 69).

The 1897 Forest Service Organic Act defined the role of the US Forest Service to manage the federal forests to promote the Conservationist goals to promote the rational commercial harvest of timber based on the idea of sustained yield while at the same time promoting stable timber communities that relied on federal timber supplies (Hoberg 1997). The cut-and-run activities of the timber industry could not sustain local 
communities and the policy of sustained yield sought to stabilize the economic base of rural communities (Hoberg 1997, 49).

This highlights two threads of forest management policy that continues today. First is the conflicting goals of Preservation and Conservation. The former seeks a stewardship of federal forests to preserve watersheds and trees, removing commercial activity from these lands. Conservation seeks to exploit the timber resource of the federal forest in an efficient manner in order to maximize these resources. The second thread focuses on the use of federal authority to claim federal ownership as opposed to private development. Pinchot's position was that the rational management of forests, and maintaining rural communities, could be better met by federal management as compared to the unregulated economic behavior of private ownership.

Pinchot believed that through scientific management, public forests could provide an efficient source for timber, superior to cut and run practices of past timber harvesting. This also covers other resources that the federal forests could provide, such as water and hunting game. The concept of "multiple use" is implicitly defined in the Forest Service Organic Act of 1897 in relation to the management of federal lands for maintaining watersheds and timber supply. At the time the government "recognized livestock grazing, wildlife habitat and recreation as legitimate values or uses of public forests (Hirt 1994, 35). The history of the US Forest Service shows that multiple use did not mean equal weighting. Timber production was determined to be the dominant use. After the end of World War II timber production dramatically increased on federal lands as demands for housing drove timber demand (Hirt 1994, 245). Political interests sought to 
include managing for recreation, water and streams, wildlife preservation as priorities for the US Forest Service, but economic and political demands for timber outweighed these other concerns.

With the development of a larger middle class after World War II demands for recreation and wildlife preservation grew. The Multiple Use-Sustained Yield Act of 1960 (MUSY) and the NFMA sought to limit the discretion of the US Forest Service to manage primarily for timber. The increased influence of environmental groups and public opinion elevated concerns for environmental protection over timber interest in the Congress, lead to the passage of the NFMA (Hoberg 1997, 52). Hoberg outlines the major changes brought about by the NFMA. First, it moved policy decisions away from the appropriations committees dominated by industry and regional interests to authorizing committees more in line with environmental concerns. Second, the act required the USFS to create forest plans which required greater emphasis on multiple use, away from a dominant focus of timber harvest to include protection of water sources, fish and wildlife. The act did not restrict agency discretion but did require that the agency to include public participation to comment on forest plans (Hoberg 1997, 52-53). The trend of increasing environmental concerns placed more pressure on the USFS after the passage of the NFMA. In the late 1980s, conservation biology was becoming increasing influential along with the development of ecosystem management (Hoberg 1997, 54). Ecosystem management can be understood as "a system of making, implementing, and evaluating decisions based on the ecosystem approach, which recognizes that ecosystems and society are inexorably linked and always changing. 
Ecosystem management is based on the understanding that ecosystems are constantly changing independently of society and human influence” (Maser 1994, 309). Ecosystem management began to have an influence on USFS personnel regarding environmental concerns as a result of the stream pollution, stream temperature warming and soil erosion associated with the clear-cutting of federal forests. These environmental changes were highlighted by agency personnel but continued pressure to maintain timber harvests meant that efforts by agency personnel to incorporate ecosystem management was thwarted (Hirt 1994, 288).

\section{Foundations of Environmentalism}

Conservation management is based on a model of nature as comprised of resources. In contrast, contemporary Environmentalism is founded on the Preservationist ideas of nature originally influenced by the Transcendentalist tradition of Emerson, Thoreau, Whitman and Muir. Transcendentalism starts with the idea of the self-sufficient individual who rejects the commercialism of society and focuses on the cooperative and conscious relations between members of society and with nature (Burch 1971, 104). This tradition arises out of the $18^{\text {th }}$ century idea that the self-reliant individual can only find freedom outside of the restrictions of social life in nature since nature is conceived as separate from society (Burch 1971, 70). Burch points out that nature is a central metaphor for Western social thought that provides a means to provide a "place" for individuals independent of the demands placed upon them by society and "in its totality is the prime illustration of unity formed from diversity” (Burch 1971, 74). 
For Burch, the frontier of the American West symbolizes the stage for the struggle Western thought has created with the self-sufficient individual and a nature separate from society. "The tribesman looks into nature and sees himself, but Western man consistently looks into nature to find himself. For him, morality is not simply a given that exists, has existed, and will always exist; rather it is something that each individual must struggle to attain anew, for he, rather than society, is the only reality” (Burch 1971, 71). Burch identifies three American myths associated with this anti-urban and anti-bourgeoisie idea of the self-sufficient individual separate from society. The first is that of Primitivism, which he identifies as "freedom without equality." Here the individual rejects the rules governing the social system and seeks to find an identity with the "predetermined laws of nature” (Burch 1971, 76). This mythology is consistent with the cowboy of the American West or any variation where an individual seeks to discover their "true self". The second is that of the Yeoman or "equality without freedom.” This mythology is closely associated with the Jeffersonian ideal of expansion and settlement of the West with independent, self-sufficient farms. The Yeoman myth establishes a sacred relationship between man and the land and that farming (or ranching) was a "way of life" unlike urban life. The third, the Transcendentalist myth Burch describes as the source of ecological thinking. Here the focus is on the individual who recognizes that personal accumulation leads to self-destruction. The individual must act in a manner of communal welfare and takes a long-term perspective so not to degrade, waste or amass resources. "In America the metaphors of nature tend to follow three distinct directions. The ruggedindividualist theme, in an existentialist mood, rejects the reality of society. The yeoman- 
equality theme views homogeneous conformity as the appropriate solution; society is the only reality. For the transcendentalists, the only reality is that society is part of nature and must build its unity accordingly” (Burch 1971, 105-106).

\section{Mythology of the American West}

\begin{tabular}{|c|c|c|}
\hline & World View & "Reality" \\
\hline Primitivism & Freedom over Equality & Rejects Society, only Nature \\
\hline Yeoman & Equality and Conformity & Only Society \\
\hline Transcendentalist & Communal Welfare & Society as part of Nature \\
\hline
\end{tabular}

Table 1. (Adapted from Burch 1971)

For Burch (1971), the mythology of the American West provides a means to explore the relations established in the Western tradition between the individual and society, society and nature, and the individual and nature. The mythology provides a context in which to view contemporary organizations and social movements in their relation to their idea of nature and how that directs their actions. The contemporary Environmental community has its roots in the Transcendentalist tradition and can only be understood in relation to the other traditions.

Cronon (1995) makes a similar argument as Burch and specifically focuses on nature as wilderness. Coming from the same historical tradition of Emerson and Thoreau, Muir in the second half of the $19^{\text {th }}$ century expresses the Preservationist ideal of protecting wilderness as a means to escape the confines of an artificial modern urban life (Burch 1971, 92). The frontier of the American West after the Civil War had become a tamed wilderness after the violence with Native American resistance. The wilderness was viewed as virgin, uninhabited land although it had been formed and managed by 
Native Americans for centuries. Cronon points out that wealthy Americans began building estates and ranches as a means to "safely enjoy the illusion of seeing a nation in its pristine and original state” (Cronon 1995, 15). In summation, wilderness is a construct established as a means for the individual to escape from the inauthentic restrictions of society and to reestablish the true self.

The purpose of this discussion is to provide a framework for the conflict that lead to the Northwest Forest Plan. That conflict was based on the fundamental ideas of what a forest should be and more importantly, what a public forest should be. The ideas of conservation as expressed through scientific management dominated federal forest management from the beginning of the twentieth century until the shift in environmental thinking began its ascent in the latter half of the century. This conflict took place over decades and was never fully settled although the Northwest Forest Plan was supposed to provide a compromise solution. 


\section{Chapter 2: Research Problem Formulation}

\section{The Northwest Forest Plan}

The story of timber harvesting in the Pacific Northwest and the conflict which began in the 1970s regarding the harvesting of old-growth forests on federal lands has been written about by many authors (Hays 2007, Satterfield 2002, Yaffee 1994). These authors seek to explain the shift and repercussions that occurred regarding the management of federal forests from political, social, historic, legal, economic or scientific perspectives. The federal forests provided a much needed supply of timber starting with the housing boom after the end of World War II (Hayes 2007). The federal land management agencies, the USFS and the BLM, faced a new set of challenges with the ESA, the NEPA, FLPMA and the NFMA in regard to managing for environmental priorities. These laws passed in the 1970s required that the USFS and BLM realign their dominant use land management paradigm of timber harvest and consider the issues of biodiversity and ecological processes in federal forests as part of their mission. These new requirements were in contradiction to the timber harvest focused institutional structures of the USFA and BLM. The ensuing court cases brought by environmental organizations against the management policies of the USFS and BLM finally brought the sale of timber from federal lands in the Pacific Northwest to a halt in the early 1990s. The Northwest Forest Plan was expected to be the solution to the economic, social and legal disruptions and conflicts of the time.

The Northwest Forest Plan (NWFP) is defined within a Record of Decision and subsequent Standards and Guidelines that was signed by the Secretary of Agriculture and 
the Secretary of the Interior in 1994 as an amendment to the to the nineteen National Forests and seven Bureau Land Management Districts (USDA 1994). The NWFP was the outcome of a one-day Forest Conference held in Portland, Oregon headed by President Clinton shortly after he was inaugurated into office in April 1993. The Record of Decision was based on Option 9 of the Forest Ecosystem Management Assessment Team (FEMAT) report. The FEMAT report was the result of team of over 600 persons of "Federal, State, private, and university specialists in many fields including ecology, biology, economics, sociology, forestry, silviculture, fire ecology and other areas” (Marcot 1997, 11). FEMAT had been asked to provide forest management alternatives that "attain the greatest economic and social contribution from the forests of the region and meet the requirements of the applicable laws and regulations” (FEMAT 1993, 4)

The FEMAT report was compiled in ninety days and the team was led by Jack Ward Thomas, Chief Research Wildlife Biologist for the USFS, Pacific Northwest Research Station. FEMAT was the culmination of a series of earlier scientific reports led principally by Thomas. The beginning of these scientific teams goes back to 1973 with the start of the Oregon Endangered Species Task Force (OESTF). The twenty year period between the OESTF and FEMAT saw a number of scientific efforts to address the requirements of the ESA, NEPA and the NFMA using the developing disciplines of landscape ecology and conservation biology. These efforts started with the targeted requirements for maintaining the viability of the Northern Spotted Owl (NSO) in Oregon, Washington and California. Later efforts recognized the importance of expanding the focus to all species associated with old-growth forests based on both regulatory 
requirements and the underlying principles of ecosystem management. This chapter will outline the history of these scientific teams, the court directives that either brought about their genesis or the issues they were seeking to address, and some of the underlying principles of conservation biology and landscape ecology behind their thinking.

\section{Map of the Northwest Forest Plan Region}

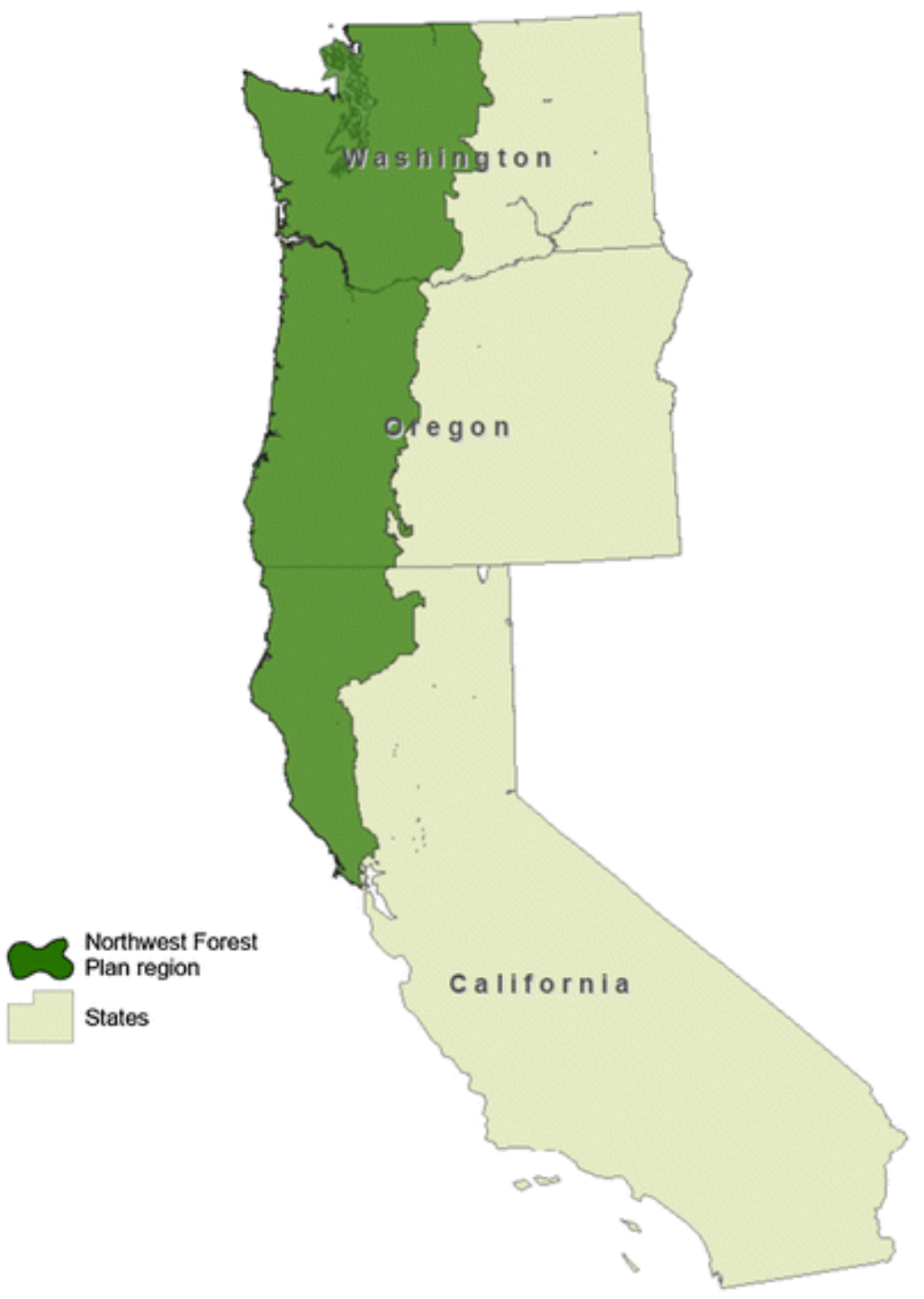

Figure 1. Map of Northwest Forest Plan region from Charnley (2008) 


\section{Oregon Endangered Species Task Force}

The history of scientific panels formed to address conflict between management objectives for land management agencies in the Pacific Northwest begins in the early 1970s with the northern spotted owl (NSO). The research by Oregon State University (OSU) graduate student Eric Forsman and his advisor, Howard Wight showed that the NSO population in the Pacific Northwest was threatened as a result of management actions in harvesting old-growth forests. Forsman had identified thirty-seven pairs of NSO inhabiting old-growth stands (Yaffee 1994, 15). Wight led the Oregon Cooperative Wildlife Research Unit, a division of the USFWS and in July 1972, he sent letters to the Washington, D.C. headquarters of the USFWS and the regional offices of the USFS and BLM to inform them of the threat to the NSO and to recommended caution in harvesting old-growth NSO habitat (Yaffee 1994, 15). The research on the NSO at this point in time was limited to the early work Forsman had begun and he had estimated that a pair of NSO would require 300 acres of old-growth habitat per nesting site (Yaffee 1994, 21). As old-growth timber was a valued commodity for federal land management agencies, they were not eager to begin setting aside habitat.

The NSO was included in the publication of the USFWS “Red Book” of 1973, a predecessor to the national endangered species list. As a result, John McKean, Director of the Oregon Game Commission, formed the Oregon Endangered Species Task Force (OESTF) in order to address endangered species, the NSO in particular (Meslow 1993, 34). The OESTF was composed of representatives from the Oregon State Game Commission, the BLM, the USFS, the USFWS and Oregon State University (Yaffee 
1994, 21). The OESTF identified three courses of action: (1) recognized the importance of old-growth habitat for associated species and the need for additional research on oldgrowth dependent species; (2) establish the interim guideline of set-asides of 300 acres for each owl pair location where timber harvest would cease until further research; and (3) call for mapping old-growth forests and NSO sites (Yaffee 1994, 22). The USFS and the BLM rejected the OESTF's recommendations, there was little support in the agencies for the NSO and setting aside habitat from timber harvest. As Yaffee (1994) explains, “A lack of basic information about 'what was out there' hampered the development of management recommendations in 1973, and amazingly continued to limit productive discussions...land managers had little idea of what nongame animals resided on their lands, and more fundamentally, what their land base consisted of” (Yaffee 1994, 24-25).

The work of the OESTF continued over two years mapping NSO sites but doing little in the way of mapping old-growth habitat. Research efforts on the NSO continued but the management plan expected by December 1975 did not materialize (Yaffee 1994, 29). The task force went two years without meeting and with the insistence of the BLM, was restarted in November 1976. The BLM had started its next planning process and required guidance on "sensitive species” after losing a number of lawsuits on NEPA violations (Yaffee 1994, 31). In December 1976 the OESTF put forth an interim plan based on the premise that with a minimum of 400 pairs of NSO on federal lands in Western Oregon, the species could survive. In addition, it requested that the USFS and BLM protect NSO nest sites until a final management plan set for January 1978 could be finalized (Yaffee 1994, 33). The land management agencies agreed to abide by the 
interim plan and in October 1977 the final OESTF plan was ratified. The Oregon Spotted Owl Management Plan assigned responsibility for 90 pairs of owls to the BLM, 290 to the USFS and 20 to others (Yaffee 1994, 34). The plan identified habitat management areas in order to maintain NSO population viability. As expressed in the ISC report, "The plan recommended habitat management areas that included clusters of three to six pairs, with a minimum of 1200 acres of contiguous habitat per pair. Each pair was to have a core area of at least 300 acres of old growth or the oldest available contiguous habitat, if 300 acres of old growth did not exist. At least 50\% of the remaining 900 acres were to be covered by forests older than 30 years. Core areas for clustered pairs of owls were to be no more than 1 mile apart, as measured from center to center. Management areas were to be a maximum of 8 to 12 miles apart for multiple-pair habitat areas, less for single pairs” (ISC 1990, 52).

The plan was a first step in providing guidance for habitat based on the early science behind the NSO. Support for the OESTF plan was not consistent, with some USFS line officers protecting NSO sites and the BLM ignoring protective measures (Yaffee 1994, 44).

There are a number of issues raised as a result of the OESTF efforts which highlight future issues to bring the recommendations of a scientific panel to bear on management planning. First, the level of scientific research on the NSO (and other oldgrowth dependent species) was limited. The ability of the land management agencies to evaluate and contextualize this new information posed an issue. The recommended 
habitat areas were considered large at the time and considered a threat to the agencies (Yaffee 1994, 24). Second, the land management agencies did not have a comprehensive understanding of the amount and location of old-growth habitat nor the range of nongame species on the lands they managed. Without the organizational knowledge of oldgrowth and non-game species, the recommendations could not be placed in a proper context. Third, and most important, the land management agencies were not willing to change their land management practices both from an economic and silvicultural standpoint. The proposals from the OESTF, however conservative they were in hindsight, were generally not followed because the political and economic pressures from Congress and the timber industry out-weighed the growing social backlash against the harvesting of old-growth forests and concerns for biodiversity with the NSO. The organizational structures and cultures of the USFS and BLM did not have the ability to integrate the recommendations of the OESTF.

\section{Listing of the Northern Spotted Owl}

As a result of radio-telemetry studies conducted by Forsman in 1980 for his $\mathrm{PhD}$ dissertation, the 1977 Oregon Spotted Owl Management Plan was modified to incorporate the findings that a minimum 1000 acres of old-growth forest be maintained for each pair of NSO. This was an increase from the original 300-acre recommendation (ISC 1990, 53). These new recommendations were submitted to the USFS and BLM in

Oregon. The USFS agreed to incorporate the new standard if further research confirmed 
these new findings. The BLM rejected the recommendation and maintained the 300 -acre old-growth forest guideline (ISC 1990, 53).

In 1984 the USFS issued the final Regional Guide for the Pacific Northwest (Freeman 2002, 635). Forest planning was to follow the 1981 Oregon Spotted Owl Management Plan (ISC 1990, 54). Environmental groups filed suit against the USFS citing that the standards and guidelines were inadequate and that it violated NEPA and NFMA (ISC 1990, 54). The USFS was directed to prepare a supplemental Environmental Impact Statement (EIS) and the final SEIS was completed in late 1988 (Freeman 2002, 635). The SEIS proposed a Spotted Owl Habitat Area (SOHA) network plan for the 13 Oregon and Washington National Forests. The ISC report describes the SOHAs as follows:

“Standards and guidelines differed for physiographic provinces. Amounts of habitat to be provided in SOHAs varied from 1000 acres in southern Oregon to 3000 acres on the Olympic Peninsula. Habitat was to be identified within 1.5 miles of the center area in Oregon and 2.1 miles in Washington; SOHAs containing three or more pairs were to be no more than 12 miles apart, and single-pair SOHAs were to be no more than 6 miles apart” (ISC 1990, 57).

In Seattle Audubon Society v Robertson, March 1989, the Seattle Audubon Society brought suit against the USFS in District Court of Western Washington claiming that the 1988 Regional Guide violated NEPA and NFMA (Blumm 1991, 614). The Court issued a preliminary injunction that blocked 135 timbers sales of NSO habitat based on the 
premise that old-growth forests could not be replaced (Blumm 191, 614). The Seattle Audubon Society agreed to a stay as the USFWS was in process of listing the NSO (Rule 2000, 218).

Concurrent with the development of the USFS SEIS, in 1987, the environmental groups GreenWorld, and later that year, the Sierra Club Defense Fund, petitioned the USFWS to list the NSO as an endangered species under the ESA (Bonnett 1991, 125). The USFWS denied the petitions and sought to address the issue of the NSO with a plan to work with the USFS, BLM and National Park Service (NPS). The result of this interagency cooperative effort was the creation of the Interagency Scientific Committee to Address the Conservation of the Northern Spotted Owl (ISC). As a result of the USFWS action to deny the NSO endangered status under the ESA, environmental groups filed suit in Federal District Court, Northern Spotted Owl v Hodel (1988) (Blumm 1991, 617). The environmental groups sought to show that the USFWS in rejecting the NSO for listing had, first,

"failed to articulate a rational connection between the administrative record and its decision. Second, the USFWS allegedly did not base its listing decision solely on the best scientific data available, as the ESA mandates, but instead considered economic and other factors. Third, the suit alleged that the USFWS improperly relied on its informal interagency memorandum as a substitute for its duties under the ESA. Finally, the plaintiffs alleged that the USFWS neglected to consider the listing of the owl as threatened rather than endangered, even though twenty-nine 
organizations had specifically petitioned that the owl be given that status” (Bonnett 1991, 126).

The Court found that the USFWS had violated the ESA by not following the recommendations of its scientists and found the decision by the USFWS to be " arbitrary and capricious' and 'contrary to law'” (Bonnett 1991, 126). The agency was ordered to provide the scientific evidence for its original decision and later in April 1989 informed the court that the NSO would be listed (Bonnett 1991, 128). On June 26, 1990 the NSO was listed as a threatened species. The result of this action meant that the USFS and BLM would now need to seek approval from the USFWS before any management action effecting the habitat of the NSO (Blumm 1991, 617).

\section{Interagency Scientific Committee to Address the Conservation of the Northern}

\section{Spotted Owl}

The ISC was formed in 1989 arising out of an agreement between the BLM, USFS, USFWS and NPS in August 1998 to "work toward a common goal of ensuring population viability for the spotted owl throughout its range” (ISC 1990, 56). The directive for the Scientific Committee was to “develop a scientifically credible conservation strategy for the northern spotted owl” (ISC 1990, 47). The Scientific Committee was composed of six members: Jack Ward Thomas (lead), Chief Research Wildlife Biologist USFS; Eric Forsman, Research Wildlife Biologist USFS; Joseph Lint, District Wildlife Biologist BLM; E. Charles Meslow, Leader Oregon Cooperative Wildlife Research Unit USFWS; Barry Noon, Research Wildlife Biologist USFS; and 
Jared Verner, Chief Research Wildlife Biologist USFS. Working with agency personnel from the USFWS, USFS, BLM and NSP, the ISC was able to finalize a report in April 1990. The ISC proposed a shift in management strategy "from the protection of isolated individual owl territories (circles) to protection of large reserves for multiple owl pairs spaced at regular intervals. It also broke important ground in recommending that federal forest areas between reserves (the matrix) be managed so as to improve the potential for successful dispersal of owls” (Franklin 1995, S-77). The ISC brought two important concepts into their NSO management plan, fragmentation and adaptive management.

The network of SOHAs implemented by the USFS and BLM at the time were established based on the plan developed by the OESTF. SOHAs were reserves for one to three pairs of NSO where logging was prohibited. “A circle approximating the annual home range of a pair of spotted owls was used to bound areas within which SOHAs on USFS lands were delineated. These circles ranged from 1.5 to 2.1 miles in radius and amounts of prescribed suitable habitat ranged from 1000 to 3000 acres, depending on physiographic province” (ISC 1990, 17). SOHAs within the circles are forest stands of suitable NSO habitat, the circle itself is not the SOHA boundary. As a result of timber harvest and disturbances, SOHA habitat was fragmented both at the SOHA scale and at the landscape scale of the SOHA network (ISC 1990, 17). Continued timber harvest within the circle and not identified as a SOHA further increased the fragmentation between established NSO habitat. Simulation modeling conducted by the ISC on the SOHA network structure on NSO population dynamics led the committee to conclude that "the persistence of the owl is imperiled in significant portions of its range by 
continued loss and concomitant fragmentation of its habitat. This loss has included much habitat that was likely to have been superior for the owl, especially at lower elevations. Loss of superior habitat has led to the fractioning of a formerly more continuous population into smaller, more isolated demographic units. Many of these units are at risk of local extinction because of demographic factors and environmental phenomena (ISC 1990, 23).

The ISC sought to improve on the SOHA network model with a conservation strategy that focused on large blocks of habitat that could contain multiple pairs of owls. These blocks of habitat were termed Habitat Conservation Areas (HCAs) and expected to be placed throughout the range of the NSO and close enough to allow for migration between areas (ISC 1990, 23). The conservation strategy was based on five principles of reserve design:

- "Species that are well distributed across their range are less prone to extinction than species confined to small portions of their range.

- Large blocks of habitat, containing multiple pairs of the species in question, are superior to small blocks of habitat with only one to a few pairs.

- Blocks of habitat that are close together are better than blocks that are far apart.

- Habitat that occurs in less fragmented (that is, contiguous) blocks is better than habitat that is more fragmented. 
- Habitats between blocks function better to allow owls to move (disperse) through them the more nearly they resemble suitable habitat for the species in question (that is, blocks that are well connected in terms of habitat are better than blocks that are not)" (ISC 1990, 23).

Standards and guidelines were developed that mapped to the five principles above, what was termed the "rule set."

- "All portions of the range of the northern spotted owl in the United States were included in the conservation strategy.

- Ideally, HCAs should contain 20 or more pairs of owls. HCA size was determined by selecting areas known to contain, or that were estimated to contain, 20 or more pairs of owls.

- Distances between HCAs were set at no more than 12 miles at the nearest separation for HCAs containing 20 or more pairs and no more than 7 miles for HCAs with 2 to 19 pairs.

- Adequate portions of the forested areas between HCAs must be in appropriate structural condition to provide at least marginal foraging habitat for dispersing owls. This need is addressed by requiring that $50 \%$ of the forest matrix outside the HCAs be covered with stands of trees averaging 11 inches or more in d.b.h., and with at least $40 \%$ canopy closure. 
- At least 80 acres of suitable owl habitat should be designated as HCAs around activity centers of up to seven known pairs of owls per township in the forest matrix. These HCAs may provide core areas for nesting and foraging and allow reoccupation of these sites by owls in 50 to 80 years after harvest of the surrounding stands" (ISC 1990, 28-29).

The 1977 final OESTF plan called for maintaining 400 pairs of NSO on federal lands. In 1986, the Audubon Society released the results of a Blue Ribbon Panel of six scientists that recommended a minimum of 1,500 pairs of NSO in Oregon, Washington and California covering all land ownership types (Yaffee 1994, 99). The ISC considered the Audubon recommendation as a yardstick for the network of HCA reserves. The HCA network on federal land was known to contain 925 pairs of NSO and the ISC estimated a total of 1,465 pairs due to incomplete survey of the HCA lands. The ISC estimated that as a result of the proposed halting of old-growth harvest and future growth of suitable old-growth habitat, a total of 1,750 pairs of NSO would be inhabiting the HCA network on federal land by the year 2100 (ISC 1990, 32).

In order to address the management issues regarding timber harvest with the HCA network, the ISC proposed an initial conservative approach that protected NSO and an “adaptive management” and monitoring process to inform compatible timber harvest strategies. "Adaptive management is a process that can improve management practices incrementally by implementing plans in ways that maximize opportunities to learn from experience” (ISC 1990, 345). The goal for an active adaptive management process 
would be to quickly identify management practices that meet the goals of the conservation of NSO habitat and timber harvest. The ISC was forthright in stating that they did "not know how to schedule timber harvests safely in and around habitats occupied by spotted owls” (ISC 1990, 345). In addition, silvicultural techniques that produce suitable NSO habitat should be explored as part of the adaptive management strategy (ISC 1990, 347). The ISC report concludes with a cautionary reminder that the conservation strategy for the NSO is but one aspect of a broader, landscape perspective that is required to address "water quality, fisheries, recreation, soils, stream flows, scenic values, biodiversity and other species of wildlife” (ISC 1990, 45).

With the release of the ISC report, initially the USFS and BLM accepted its recommendations (Thomas 2004a, 8). The USFS issued a directive "to operate 'in a manner not inconsistent' with ISC guidelines rather than to adopt the ISC guidelines per se” (Marcot 1997, 4). As a result, the USFS was issued an injunction in May 1991 by U.S. District Judge William L. Dwyer, halting timber sales. The USFS was ordered to develop an EIS for an NSO conservation management plan consistent with NEPA and the ESA (Marcot 1997, 4). The BLM later withdrew its support for the plan and put forth its own plan, the Jamison Plan, named for the BLM Director Cy Jamison. In response to the action, in February 1992 the Portland Audubon Society and others sued the BLM for issuing an inadequate conservation management strategy that did not meet NEPA and ESA requirements (Marcot 1997, 4). 


\section{The Scientific Panel on Late-Successional Forest Ecosystems (Gang of Four)}

In May 1991 the Agricultural Committee and the Merchant Marine and Fisheries Committee of the U.S. House of Representatives requested that a scientific panel report to them on the status of late-successional forests in the Pacific Northwest and provide management alternatives for these forests (Johnson 1991, 1). The panel was the “Scientific Panel on Late-Successional Forest Ecosystems” (Gang of Four) and led by John Gordon, Jerry Franklin, K. Norman Johnson and Jack Ward Thomas. The goals for the panel were:

- "Identify, map, and classify the ecologically significant LS/OG [late-successional/old-growth] forests on federal lands within the range of the northern spotted owl as the basis for establishing a LS/OG reserve system;

- Develop options for management of lands outside of reserves;

- Develop and evaluate different alternatives for protecting LS/OG ecosystems and associated species;

- Quantify the effect on each LS/OG reserve system and associated management option for lands outside of reserves on sustainable harvest levels;

- Considered potentially endangered fish species and stocks;

- Conducted a risk analysis of alternatives as they related to retaining over the long term a functional LS/OG network, to ensuring viable populations of northern spotted owls, and to 
providing habitat on federal lands for marbled murrelet nesting, for other LS/OG-associated species, and for sensitive fish species and stocks; and

- Analyzed effects on timber-based employment and income associated with each alternative” (Johnson 1991, 1).

The panel focused on the late-successional/old-growth forests on 18 National Forests and 7 BLM Districts in Washington, Oregon and northern California (Johnson 1991, 2). These federal lands comprised a total of 5.7 million acres (Johnson 1991, 5). In addition to the NSO that was the focus of the ISC report, the panel investigated the viability of all vertebrate species and at-risk fish species associated with latesuccessional/old-growth forests (Marcot 1997, 4). Like the ISC plan, the panel proposed a reserve system for late-successional/old-growth forests that "should be managed to maintain and /or enhance their ecological integrity” (Johnson 1991, 5). In regard to the management of federal lands outside of the reserves, the panel proposed three options based on the 50-11-40 rule developed with the ISC plan (Johnson 1991, 6). The panel proposed 14 major alternatives "ranging from current National Forest and BLM plans, through extensive protection of all remaining LS/OG forests, spotted owl habitats and key watersheds for fish” (Marcot 1997, 5).

The panel provided some concluding observations that the Forests Plans at that time did not "provide a high level of assurance (low risk) for maintaining habitat for oldgrowth-dependent species” and that “there is no 'free lunch' - that is, no alternative provides abundant timber harvest and high levels of habitat protection for species 
associated with late-successional forests” (Johnson 1991, 15). The House committees did review some of the alternatives, but this did not result in any legislation (Marcot 1997, 5). In a memoir by Jack Ward Thomas, he recalls the upcoming testimony to the Congressional committees on the finding of the Gang of Four. He writes that the panel will point out that "the Forest Service has been living with the myth of potential timber harvest that is dramatically exaggerated, and that was clearly understood, at least at the national forest and BLM district level. I know that various forest supervisors have tried to call attention to that fact and failed. Then, like good soldiers, they shut up and tried their best to 'get the cut out'” (Thomas 2004b, 40).

\section{The Scientific Analysis Team}

In 1991 U.S. District Judge William L. Dwyer stopped timber harvests on USFS land as a result of the USFS not fully adopting the guidelines of the ISC plan (Marcot 1997, 3). In 1992, the USFS issued a Final EIS in response to Dwyer’s order of 1991 which proposed guidelines based on the ISC plan recommendations (Marcot 1997, 10). The Seattle Audubon Society challenged the new USFS EIS on the grounds that it violated NEPA by neglecting to include new information on the impact to the NSO and other old-growth related species from timber harvest in old-growth forests (Marcot 1997, 10). The court agreed with the Seattle Audubon Society and enjoined further USFS timber sales (Marcot 1997, 10). As a result of the 1992 court ruling, the Chief of the USFS Robertson requested a scientific team address the concerns from Judge Dwyer on 
the Final EIS (Thomas 1993, 8). The Scientific Analysis Team (SAT) was formed with scientists from the USFS and USFWS headed by Jack Ward Thomas.

The questions the SAT were asked to research were as follows:

- "Does the May 15, 1992, decision by the Endangered Species Committee to allow cutting of 13 timber sales prepared by the Bureau of Land Management and judged by the Fish and Wildlife Service to cause "jeopardy" for the northern spotted owl necessitate changes in spotted owl viability assessments of the alternatives in the Final Environmental Impact Statement?

- Does any information that has become available since the publication of the Forest Service's Final Environmental Impact Statement necessitate revision of the standards and guidelines of the selected alternative in the Final Environmental Impact Statement or change the probabilities of maintaining viable populations of the northern spotted owl that were assigned to the alternatives in the Final Environmental Impact Statement?

- Would the Forest Service's implementation of the selected alternatives in the Final Environmental Impact Statement (the Interagency Scientific Committee’s Conservation Strategy) lead to the extirpation in the Forest Service planning areas (National Forests) of any of the 32 species identified in the Final 
Environmental Impact Statement as being closely associated with late-successional and old-growth forests?” (Thomas 1993, 8).

In response to the first question, the SAT found that the BLM's preferred alternative to their Draft Resource Management Plans would provide a higher level of risk for maintaining the viability for the NSO when compared to the USFS's adoption of the ISC plan. As a result, the SAT recommended that mitigation measures be implemented on federal lands managed by the USFS (Thomas 1993, 12). After a review of the literature of the NSO since the publication of the ISC plan, the SAT found that new research did not impact the fundamental assumptions behind the ISC plan. With the addition of the additional mitigation measures addressed in the first question, the SAT recommended that the Final EIS would provide a high level of protection for the NSO (Thomas 1993, 18). The SAT expanded the analysis for old-growth related species beyond the 32 identified in the ISC plan to include plants, invertebrates and fish species for question three. The Gang of Four had included fish species as part of its analysis and the SAT built upon that to include additional populations as a means to approach an “ecosystem management” perspective (Thomas 1993, 18). The SAT identified 667 species associated with old-growth forests. These included 35 species of mammals, 38 birds, 21 reptiles and amphibians, 112 fish, 149 invertebrates, 122 vascular plants and 190 nonvascular plants and fungi (Thomas 1993, 19). The SAT concluded that the ISC plan enabled "482 of the 518 (93 percent) plants and vertebrates closely associated with old-growth forests can be considered to have a low risk for extirpation or extinction. The remaining risk to the other species is impossible to assess” (Thomas 1993, 22). 
The SAT report reaffirmed the HCA reserve network strategy from the ISC plan. In addition, it built upon the work of the Gang of Four to include fish species, beginning to work towards an ecosystem management approach, recently embraced at that time by

the USFS (Thomas 1993, 18). The survey of 667 old-growth forest related species was a step in the direction to expand the focus of old-growth forest management beyond the NSO. The charter of the ISC was specifically related to the success of maintaining NSO populations. However, the team identified the necessity to look beyond the NSO to an ecosystem conservation approach (Marcot 1997, 10). The SAT was the platform that provided the beginnings of an "ecosystem management" approach to federal forest land management.

\section{Forest Ecosystem Management Assessment Team}

The publication of the SAT report provided the response to the specific questions from Judge Dwyer but it did not answer the ongoing conflict regarding management of old-growth forests on federal land. With the failure of the Congress to take any action after the report of the Gang of Four, the issue remained within the federal courts. After the presidential election of 1992, President Clinton convened the Forest Conference in Portland, Oregon on April 2, 1993, following up on a campaign promise to find a solution to the conflict (FEMAT 1993, 3). An interagency working group, the Forest Ecosystem Management Assessment Team (FEMAT) was created and tasked to provide in ninety days a "balanced and comprehensive policy that recognizes the importance of the forest and timber to the economy and jobs in this region, and how can we preserve our precious 
old-growth forests?” (FEMAT 1993, 3). The conservation and management assessment was to identify alternatives for the federal forests of the USFS, BLM and USNPS to "attain the greatest economic and social contribution from the forests of the region and meet the requirements of the applicable laws and regulations” (FEMAT 1993, 4). The working group was directed to apply an ecosystem management approach with emphasis on maintaining late-successional and old-growth forests, biodiversity and sustainable levels of timber production (FEMAT 1993, 4).

Previous scientific task forces sought to address the legal issues from federal court actions regarding compliance with FLPMA, NFMA, NEPA, and the ESA for the USFS and BLM. The directive for the FEMAT team was to work as an interagency team comprised of federal land management agencies and federal regulatory agencies to provide management options that meet these legal requirements. The FEMAT team was clear that its mandate was not to "interpret the applicable laws and regulations or to indicate whether a particular alternative satisfied those regulations or requirements” (FEMAT 1993, 10). The FEMAT team saw its mission as to "'include alternatives that range from a medium to a very high probability of ensuring the viability of species' and that the analysis 'should include an assessment of current agency programs'” (FEMAT 1993, 10). The team was directed to meet the following objectives:

- "maintenance and/or restoration of habitat conditions for the northern spotted owl and the marbled murrelet that will provide for viability of each species - for the owl, well distributed along its 
current range on federal lands, and for the murrelet so far as nesting habitat is concerned;

- maintenance and/or restoration of habitat conditions to support viable populations, well distributed across their range, of species known (or reasonably expected) to be associated with old-growth forest conditions;

- maintenance and/or restoration of spawning and rearing habitat on Forest Service, Bureau of Land Management, National Park Service, and other federal lands to support recovery and maintenance of viable populations of anadromous fish species and stocks and other fish species and stocks considered "sensitive" or “at risk" by land management agencies, or listed under the Endangered Species Act;

- maintenance and/or creation of a connected or interactive oldgrowth forest ecosystem on the federal lands within the region under consideration...” (FEMAT 1993, 10).

Following the management proposals from the ISC, the Gang of Four and the SAT, FEMAT proposed a system of reserves in order to maintain species viability. These reserves would preclude all or almost all timber harvest with timber harvest limited to the Matrix areas outside of the reserves (FEMAT 1993, 12). Unlike the reserve systems proposed from the scientific teams listed above, FEMAT proposed two types of reserves, "Late-Successional Reserves (LSR), encompassing older forest stands, and 
Riparian Reserves, consisting of protected strips along the banks of rivers, streams, lakes, and wetlands, which act as a buffer zone between the water and areas where cutting is allowed" (FEMAT 1993, 12). FEMAT proposed ten options each with varying sizes for the LSR and the management activities allowed within each LSR and for Riparian Reserves where in all but one option, no timber harvest was allowed (FEMAT 1993, 14). These ten options approximated the work proposed by the SAT (Thomas 2006, 281).

For forest land outside of the LSR, FEMAT defined three other categories. First, timber harvest would be limited to the Matrix, outside of the reserves. Each option defined, sometimes by geographic area, requirements for the retention of green trees and rotation cycles (FEMAT 1993, 15). The second category refers to Managed LateSuccessional Areas, "areas that fall between Late-Successional Reserves and the Matrix in terms of permitted management activities. In these Managed Late-Successional Areas, cutting of trees can occur with less constraint than in Late-Successional Reserve Areas, but the primary objective remains the maintenance of late-successional forests on a landscape scale” (FEMAT 1993, 16). One option, option 9, included Adaptive Management Areas, ten areas ranging from 84,000 to 400,000 acres to "be used for the development and testing of technical and social approaches to integration and achievement of desired ecological, economic and other social objectives. The overarching objective is to improve knowledge of how to do ecosystem management” (FEMAT 1993, 16). The Clinton White House selected Option 9 and this option estimated a "probable sale level" for federal forests in the range of plan to be 1.2 billion board feet per year for the first ten years (FEMAT 1993, 55). This was a lower timber 
production goal than the 5 billion board feet per year harvested from federal lands west of the Cascade Range prior to the halting of sales by court injunctions (Tuchmann 1996, 3).

There are 24.3 million acres of federal lands within the range of the NSO (FEMAT 1993, 23). Within these lands, the FEMAT team performed biological assessments for the listed species of the NSO and marbled murrelet as well as over 1000 other species associated with old-growth forests over a period of 100 years (FEMAT 1993, 30). This was an increase from the previous assessment performed by the SAT of 667 species. In addition to the biological assessment, the FEMAT team "assessed the likelihood of maintaining a functional, interacting late-successional and old-growth forest ecosystem on federal lands...Leading experts, well-versed on the ecology of respective groups of organisms, were recruited from state and federal agencies, universities and research organizations” (FEMAT 1993, 30). The goal of the assessment was to identify an $80 \%$ likelihood that these species would meet the viability requirement of the NFMA of "well-distributed, viable populations" (FEMAT 1993, 32). As explained in the FEMAT report:

"We conducted 14 separate assessment panels for the status of species associated with late-successional forests during late April and again in June 1993. Evaluations were conducted for 82 species of vertebrates and 21 species of fish, 102 species of mollusks, 124 vascular plant species, 157 species of lichens, 527 species of fungi, and 106 species of bryophytes. In addition, 15 functional groups of arthropods that may include 10,000 species were evaluated. More than 70 experts served on 
the panels...The rating process was a subjective evaluation of the sufficiency of the amount and distribution of late-successional and oldgrowth habitat on federal lands under each option to support the species or group of species over the next 100 years. For most species, the information necessary to precisely quantify the response to changes in the quality and pattern of their environment simply does not exist. Our evaluations, therefore, should not be viewed as precise analyses of likelihoods of persistence or extinction; they represent the Forest Ecosystem Management Assessment Team's judgement as to the sufficiency of habitat on federal lands to support viable populations of the species examined (emphasis mine)” (FEMAT 1993, 33).

The FEMAT team provided the assurance that a landscape solution based on the size and configuration of the reserves would meet the requirements set forth by the federal court. In addition to terrestrial species, FEMAT addressed aquatic ecosystems in regard to four key areas: “(1) at-risk fish stocks and species; (2) stream, riparian, and wetlands habitat; (3) water quality; and (4) nonfish species of aquatic and ripariandependent organisms” (FEMAT 1993, 41). As a result of "degradation and ecological stress" of the aquatic systems in the range of the NSO, 314 stocks of anadromous salmonid at the time were seen as at risk (FEMAT 1993, 41). FEMAT developed options for the management of aquatic and riparian ecosystems based on the following elements:

- “A network of 162 Key Watersheds to protect at-risk fish stocks or basins with outstanding water quality. 
- Riparian Reserves to maintain ecological functions and protect stream and riparian habitat and water quality.

- Watershed analysis (which is also significant to welfare of terrestrial species) is a procedure for planning further protection or management, including restoration practices within a basin.

- Restoration to speed ecosystem recovery in areas of degraded habitat and to prevent further degradation.

- No new road construction in designated road less areas in Key Watersheds to prevent further effects of roads as sources of sediment and flood flows” (FEMAT 1993, 42).

FEMAT added a new dimension to ecosystem management with the inclusion of riparian reserves on federal lands. The team identified three classes of streams: “(1) fishbearing streams and lakes; (2) permanently flowing nonfish-bearing streams and wetlands greater than 1 acre; and (3) intermittent streams and wetlands smaller than 1 acre” (FEMAT 1993, 43). The size of the riparian reserve was defined for each class of stream. For the first class, reserves on both sides of the stream need to be a minimum of 300 feet or "two site potential tree heights." Streams of the second class require a minimum of 150 feet or "one site potential tree height" on each side. For the third class of stream in Tier 1 Key Watersheds, a 100 feet reserve or “one potential tree height” is recommended (FEMAT 1993, 43).

The implementation strategy for the FEMAT plan is based on three concepts: ecosystem management, adaptive management and interagency coordination. Ecosystem 
management is an "imprecise concept," that "directs the attention of land managers and others to understanding ecosystems and developing appropriate site-specific management to achieve overarching ecosystem management objectives” (FEMAT 1993, 93). The FEMAT plan is the means to define ecosystem management through recognizing "our understanding of the underpinnings (supporting science, ecological constructs, legal interpretation and societal acceptance) of natural resource management is in rapid flux" (FEMAT 1993, 93). This translates to mean that natural resource management was based on evolving and sometimes conflicting management concepts and the recognition of the limits to the understanding of ecological processes. The species-focused conservation management perspective of the time was rooted in laws such as the ESA and NFMA. The goal for FEMAT was to move from the species-focused conservation management approach to ecosystem management which "leads to the development of a single conservation strategy with multiple phases to accommodate the various species and ecosystems (e.g., riparian and old-growth) of concern” (FEMAT 1993, 93).

The second concept underlying FEMAT's plan is adaptive management allows the science informing forest management to develop to fill in the gaps of ecosystem knowledge. FEMAT defines adaptive management as "a continuing process of planning, monitoring, researching, evaluating, and adjusting management approaches” (FEMAT 1993, 95). Adaptive management is a process by which fundamental assumptions regarding the functioning of ecosystems can be monitored, tested and evaluated to better inform forest management planning. The FEMAT team recognized "the current shortage of 'science"” and "the uncertainty of our predictions" (FEMAT 1993, 96). With the 
addition of new technologies and new research, management concepts and planning can be improved over time to better meet social and ecological objectives.

Finally, the FEMAT plan recognizes the central role federal regulatory agencies play in the development of forest planning and management. Agencies such as the USFWS and NOAA are tasked with oversight and decision making over management actions based on federal law including the ESA and Clean Water Act as examples. In order to accommodate the need for federal interagency coordination, FEMAT recommends the creation of "regional/provincial coordinating groups, which includes representatives of the primary participants in land management planning. These groups should be responsible for such tasks as ensuring adequate participation and timeliness in planning, monitoring, guiding, analyzing new information, and providing a forum for deliberating questions” (FEMAT 1993, 101). 


\section{Chapter 3: Research Methodology and Study Design}

\section{Research Strategy}

The research carried out here explores the history, development and implementation of the NWFP and the influence the plan continues to have on the USFS and the BLM. It is important to see the NWFP within the context of the economic, legal, social and scientific forces that shaped the plan as well as the federal land management agencies themselves. This study focuses on those forces and the impact they have on the ongoing project of how the federal land management agencies define and are “constructed out of a complex process of negotiation and contestation over cultural meanings” (Mohr 1998). This project uses institutional theory to analyze two major types of evidence, documents related to the science, legal mandates and historical context of the NWFP and interviews of relevant actors across the environmental community, the timber industry community, the academic community, federal regulatory agencies, the

USFS and BLM. By using an institutional theory framework, this study "considers 'how and why meanings and forms and procedures come to be taken for granted'” (Shinn 1996, 32). The previous chapters offered a textual analysis of USFS, BLM and USFWS documents and review of the relevant literature. The following chapters focus on qualitative data collected through semi-structured interviews. These individuals who were interviewed were either directly involved with the development of the NWFP, implemented the NWFP or are today revisiting the plan twenty-four years later. 


\section{Definition of Study Universe}

The dissertation's primary research is comprised of semi-structured interviews with individuals involved in some manner with the NWFP. Thirty-eight in-person interviews were held between February 27, 2017 through September 17, 2017 with candidates located between Corvallis, Oregon and Seattle, Washington, primarily in Portland, OR. There were five interviews conducted via telephone with individuals outside of the Pacific Northwest. All interviews were recorded and transcribed. Interview candidates were sought out to provide a wide-range of perspectives on the topics and situated in the analysis as representatives of their organizations. Eleven of the individuals were retired. An institutional perspective directs the analysis of the interviewee not as an individual, but within the contexts of the organizations they represent. The textual research provided a foundation for the policy, management, science and legal topics surrounding the historical efforts to manage the habitat of the NSO, the NWFP and the federal laws that most pertain to the land management agencies.

The scope of this research is limited to the NWFP and how the USFS and BLM were influenced by the forces that led to the development of the plan and the plan itself. The focus is on the scientific panels, changing social values, institutional rules and legal mandates of the land management agencies that shaped the development and implementation of the NWFP. The research will employ an institutional theory framework to understand the meanings of nature, timber production and biodiversity that have been created within these federal agencies over time and how these meanings have changed over time. 


\section{Sources of Evidence}

The sources for this research were obtained through documentation analysis and semi-structured interviews of individuals familiar with the NWFP. These would include land management agency individuals who developed the FEMAT plan, those who were responsible for implementing the plan, those who today operate under the plan. The methodology used for choosing sources of evidence and the analysis of data is based on grounded theory. The methodology of grounded theory seeks to "develop a wellintegrated set of concepts that provide a theoretical explanation of social phenomena under study” (Corbin and Strauss 1990, 5). Data collection is defined as a process and encompasses interviews, observation, and documents. This process is termed theoretical sampling and is "the process of data collection whereby the researcher simultaneously collects, codes, and analyzes the data in order to decide what data to collect next” (Coyne 1997, 625). Through the data collection and analysis process the researcher identifies initial concepts which form the basic unit of analysis (Corbin and Strauss 1990, 7). In the research process the researcher begins to identify concepts that guide further sampling. Corbin and Strauss express the development of emerging theory from analysis as follows: “Every concept brought into the study or discovered in the research process is at first considered provisional. Each concept earns its way into the theory by repeatedly being present in interviews, documents, and observations in one form or another - or by being sufficiently absent...Requiring that a concept's relevance to an evolving theory (as a condition, action/interaction, or consequence) to be demonstrated is one 
way that grounded theory helps to guard the researcher bias. No matter how enamored the investigator may be of a particular concept, if its relevance to the phenomena under question is not proven through continued scrutiny, it must be discarded. Grounding concepts in the reality of data thus gives this method theory-observation congruence or compatibility” (Corbin and Strauss 1990, 7).

Sampling then emerges through the analysis and is "controlled by the needs of the emerging theory not a list of variables” (Coyne 1997, 626). Sampling is then purposive, not random (Miles and Huberman 1994, 27). Categories represent a higher level of abstraction than concepts and are the ““cornerstones’ of a developing theory” (Corbin and Strauss 1990, 7). Categories are groups of related concepts and provide a classificatory means to provide a level of abstraction that "provide a means by which a theory can be integrated" (Corbin and Strauss 1990, 7). The iterative process of sampling, coding, and analysis provides a means for hypothesis development; and "a key feature of grounded theory is not that hypotheses remain unverified, but that hypotheses are constantly revised during the research until they hold true for all of the evidence concerning the phenomena under study” (Corbin and Strauss 1990, 11).

Patton (1999) addresses the issue of credibility in qualitative analysis. He defines credibility as a function of three factors. The factor first pertains to "rigorous techniques and methods for gathering high-quality data that are carefully analyzed, with attention to issues of validity, reliability and triangulation” (Patton 1999, 1190). The 
second factor is a function of the credibility of the researcher, based on their training and experience. The third factor is the "philosophical belief in the value of qualitative inquiry, that is, a fundamental appreciation of naturalistic inquiry, qualitative methods, inductive analysis, purposeful sampling, and holistic thinking” (Patton1999, 1190). Similar to the process outlined above by Corbin and Strauss, Patton writes that "qualitative analysis depends from the beginning in astute pattern recognition” and has "a technical side to analysis that is analytically rigorous, mentally replicable, and explicitly systematic” (Patton 1999, 1191).

Patton develops what he terms the "logic of triangulation," a system of validation "based on the premise that no single method ever adequately solves the problem of rival explanations... because each method reveals different aspects of empirical reality” (Patton 1999, 1192). Patton outlines four types of triangulation that contribute to "verification and validation.” The first type of triangulation he labels "methods of triangulation," whereby the researcher can check the "consistency of findings by different data collection methods” (Patton 1999, 1193). The second type of triangulation is regarding sources, "examining the consistency of different data sources within the same method" (Patton 1999, 1193). The third type is "analyst triangulation,” whereby multiple researchers are engaged in the analysis of the data. The fourth one concerns application of multiple theories or perspectives to analyze the data. This research will concern itself primarily with the triangulation of qualitative data sources.

Patton reminds us that with the triangulation of qualitative data sources, the researcher should not look to multiple sources to yield similar results. As mentioned 
above, "different types of inquiry are sensitive to different real world nuances” (Patton 1999, 1193). Patton continues, "Finding inconsistencies ought not to be viewed as weakening the credibility of the results, but rather as offering opportunities for deeper insight into the relationship between inquiry approach and the phenomena under study" (Patton 1999, 1193). From an analytical perspective, Patton points out that this type of triangulation will not provide the researcher with a "consistent picture," and that "the point is to study and understand when and why there are differences” (Patton 1999, 1195).

In regard to sampling, the intent is cast a wide enough net to cover the range of interests and perspectives associated with the development and implementation of the NWFP. In total, thirty-eight (38) interviews were held, this compares to the expected number of twenty from the dissertation proposal. Interviews were halted when the saturation point was reached, no or little additional data was being added with incremental new interviews. The semi-structured interviews took place on a one-on-one basis. Of the thirty-eight interviews, five were performed over the telephone. The majority of the interviews were approximately one hour and were held at the office of the interviewee or their designated location. The interviews were recorded and were transcribed for analysis purposes. The interviewees can be classified into seven major categories based on their institutional affiliation: environmental community, timber community, academic community, regulatory agencies, Bureau of Land Management, US Forest Service and Other. 
The analytic focus of the interviews was to identify key themes regarding the goals, methods, results and unintended consequences from the NWFP. These themes form the foundation for developing an understanding of the manner in which meanings are constructed and negotiated for the institutions found in each of these seven categories. The questions asked in the interview were meant to provide a beginning point for the conversation with follow-up questions as appropriate during the course of the interview. There was a set of questions that was asked of all interviewees. The questions provided a common set of inquiry across all interviewees and follow-up questions were asked as a result of comments made by the interviewee or inquiry resulting from previous interviews.

Thematic analysis "is a method for identifying, analyzing, and reporting patterns [themes] within data” (Braun and Clarke 2006, 79). The development of themes is based on researcher judgement and Braun and Clarke (2006) identify two approaches to thematic analysis, inductive and theoretical. The inductive approach codes the data without any "pre-existing coding frame," while the theoretical approach is framed within the researcher's theoretical or analytic interest. Given the initial proposed analytic framework in this research proposal, the thematic analysis will take the second approach focusing on a more detailed analysis of coding the data. In addition, Braun and Clarke identify two levels of themes, essentially tied to the two approaches listed above. The first level is termed the semantic or explicit, whereby the researcher focuses on the surface level meanings of the data. The second is the latent level where the researcher "starts to identify or examine the underlying ideas, assumptions, and conceptualizations 
that are theorized as shaping or informing semantic content” (Braun and Clarke 2006, 84).

There are potential issues with qualitative data collection and analysis. First, the research study needs to be comprehensive enough to address the research question. The research proposition provides an initial direction for directed questions; however, the direction and depth the series of interviews will reveal itself in the interview process. In addition, the researcher needs to be aware of the intentions of the interviewee, potentially to provide socially desirable responses to interview questions. The researcher should be cognizant of potential responses which do not address conflicting or sensitive questions and probe with follow-up questions. This is a potential fruitful area for the researcher to explore contradictions in the models of the interviewee. Further, the researcher needs to be aware of researcher bias with the subjective analysis and interpretation of the responses (Nishishiba, 2014, p. 293-294). The researcher needs to be aware of the assumptions going into the research and reevaluate them as the narrative of the interviews unfold. Institutional Review Board (IRB) approval was granted prior to the start of the interview process, protocol \#164018.

\section{Analytic Design of Research}

The original research objective was to explore the research proposition that the management strategy instituted for the recovery of the NSO was based on the assumption that recovery can be accomplished by instituting a "no-management” or "passive” approach once the conditions believed for survival were identified. The research 
proposition, like the course of development for the NWFP itself, started with the NSO and expanded to encompass broader questions about the NWFP. After the first seven interviews, the original research question was not yielding the depth of research material as expected. Some of the issues raised during these first seven interviews were captured with the eighth interview when the comment was made that the land management agencies could not implement the NWFP as given to them. This comment put the issues raised in the first seven interviews in context and the focus of the research question moved on to the institutional issues and thinking that lead to the development of the original FEMAT plan, the subsequent EIS/ROD, and the actual implementation by the land management agencies. These three different phases were born out by the interviewees responsible for the development of the FEMAT plan and land management agency responsible for the implementation of the NWFP as defined by the final EIS/ROD and Standards and Guidelines.

The direction for who should be interviewed was further defined by the evolution of the research question. Interviewees were asked to suggest appropriated candidates for future interviews based on the evolving topics of the development and implementation of the NWFP. It was important to ensure representation of each of the phases for the NWFP. This resulted in identifying individuals currently retired from their previous employers. In total, ten of the thirty-eight interviewees were directly or indirectly involved with the development of the FEMAT plan representing the environmental community, the academic community, the land management agencies and the Clinton White House. 
As part of the method defined by grounded theory, the original research question was a "guide" to asking further questions either for interviews or additional documentary analysis. It was expected in the original dissertation proposal that the research question could change as new questions and analysis develop with further research. The original research question presented in the proposal was posited not as a final statement of this research but only as a starting point for providing a direction on interview sampling, questions and further documentary research and analysis. Kirk and Miller (1986) address the importance of beginning with an initial proposition, for "data ... can only be reported in terms of some explicit or implicit theory $(1986,50)$.

\section{Qualification of Research}

Creswell and Miller (2000) address the question of validity in qualitative research. They define validity as "how accurately the account represents participants' realities of the social phenomena and is credible to them" (Creswell and Miller 2000, 124). In addition, they point out that "validity refers not to the data but to the inferences drawn from them” (Creswell and Miller 2000, 125). Like the "logic of triangulation” developed by Patton, methods will identify "aspects of empirical reality." The method by which these inferences can be drawn differ between quantitative research and qualitative research. In quantitative research "researchers are most concerned with specific inferences made from test scores on psychometric instruments ... and the internal and external design validity of experimental and quasi-experimental designs (Creswell and Miller 2000, 125). However, in qualitative research, the qualitative researcher proceeds 
with the "use [of] a lens not based on scores, instruments, or research designs but a lens established using the views of people who conduct, participate in, or read and review a study” (Creswell and Miller 2000, 125). They specify three types of lenses in qualitative research. The first lens is that of the researcher. Here, researchers "determine how long to remain in the field, whether the data are saturated to establish good themes or categories, and how the analysis of the data evolves into a persuasive narrative" (Creswell and Miller 2000, 125). A second type of validity is "the participants' in the study ... and the importance of checking how accurately participants’ realities have been represented in the final account” (Creswell and Miller 2000, 125). The third lens of validity can be "individuals external to the study ... not affiliated with the project" (Creswell and Miller 2000, 125).

Maxwell (1992) proposes a definition of validity differing from the positivist, instrumentalist approach for qualitative research based on what he defines as the "realistic" alternative. This is "a realistic conception of validity that sees the validity of an account as inherent, not in the procedures used to produce and validate it, but in its relationship to those things that it is intended to be an account of' (Maxwell 1992, 281). This position of "realism" is based on the premise that "assumes that we can have no direct knowledge of the objects of our accounts and thus no independent entity to which to compare these accounts” (Maxwell 1992, 283). Maxwell continues:

"The applicability of the concept of validity presented here does not depend on the existence of some absolute truth or reality to which an account can be compared, but only on the fact that there exist ways of 
assessing accounts that do not depend entirely on features of the account itself, but in some way, relate to those things that the account claims to be about” (Maxwell 1992, 283).

Maxwell elaborates this concept of validity to by proposing that "validity is always relative to, and dependent on, some community of inquirers on whose perspective the account is based. Validity is relative in this sense because understanding is relative ... it is not possible for an account to be independent of any particular perspective” (Maxwell 1992, 284). Maxell defines three categories of "understanding” relative to three corresponding types of validity for qualitative research. $^{1}$

The first type of validity addresses the concern for the accuracy of the report provided by a researcher of what was heard or observed. This is termed “descriptive” validity, accounts described by the researcher that "refer to specific events and situations. No issue of generalizability or representedness is involved” (Maxwell 1992, 286). Maxwell points out that descriptive validity is dependent on theory, but that "descriptive validity is free from disagreement about the theory in question (emphasis original)” (Maxwell 1992, 287). Maxwell is making the case for a level of valid observation, focusing on acts, that is free as possible from theory and can be addressed in a value-free manner.

\footnotetext{
${ }^{1}$ Maxwell address two additional types of validity, generalizability and evaluative. They are beyond the scope defined by grounded theory.
} 
The second level of validity refers to "interpretive" validity, which Maxwell defines as "inherently a matter of inference from the words and actions of participants in the situations studied" (Maxwell 1992, 290). Here the focus is on what behaviors or acts mean to the people under study. Interpretive validity focuses on the meaning of events and these "accounts of meaning must be based initially on the conceptual framework of the people whose meaning is under study” (Maxwell 1992, 289). It is important for the researcher to recognize that participants can distort, censor or rationalized their actions or views and it is incumbent on the researcher to incorporate this into their analysis. Maxwell notes that "the meanings and construction of actors are part of the reality that an account must be tested against in order to be interpretively as well as descriptively valid" (Maxwell 1992, 290). In addition, interpretive validity "also pertains to the unconscious intentions, beliefs, concepts, and values of the participants” (Maxwell 1992, 290).

The third type of validity is "theoretical" validity. Descriptive and interpretive validity are based in the concrete accounting of, and interpretation of the events and concepts of the phenomena under study. Theoretical validity is a level of abstraction over the concrete and "explicitly addresses the theoretical constructions that the researcher brings to, or develops during, the study" (Maxwell 1992, 291). In regard to the idea of validity, "theoretical understanding refers to an account's function as an explanation, as well as a description or interpretation, of the phenomena (emphasis original)” (Maxwell 1992, 291). 
There are two aspects of theoretical validity, "the validity of the concepts themselves as they are applied to the phenomena, and the validity of the postulated relationships among the concepts. The first refers to the validity of the blocks from which the researcher builds a model, as these are applied to the setting or phenomena being studied; the second refers to the validity of the way the blocks are out together, as a theory of this setting or phenomena” (Maxwell 1992, 291). Maxwell recognizes that the distinctions made between these three types of understanding is "not absolute” because "objective 'sense data' that are independent of the researcher's perspective, purposes, and theoretical framework do not exist” (Maxwell 1992, 292).

The research method employed for this dissertation research is based on a qualitative research strategy. Interviews comprised of semi-structured questions were held with recognized leaders in the development of the FEMAT plan and subsequent management and implementation of the 1994 NWFP. The interviewees' responses will remain confidential. Limitations of the research as designed are focused on two levels. First, the interviewees may have rewritten history in their own lives. Here, secondary research will help guide the interviewer when analyzing the responses from the interviewees. However, this limitation provides insight into the object of study, the interviewees. The second level refers to the subjectivity of the researcher and the ability to provide an adequate analysis of the research questions. There will always be some subjective bias on the part of the researcher. The interpretation the researcher brings to 
the interviews and analysis of the interviews are recognized as a condition of the research. 


\section{Chapter 4: Research Analysis}

\section{Introduction}

Thirty-eight interviews were conducted during the Spring and Summer of 2017. The interviews are classified by community, representing an organization or group of like organizations. The interviewees within each community share common values and goals, but their individual histories and perspectives provide enough variation amongst them. The intent here is to identify what, as a community, they articulate as the meanings and goals of the NWFP, how the plan was implemented by the federal agencies and the plan's successes and failures. From a methodological standpoint, the interviews were coded employing a thematic analysis with the purpose of capturing those meanings.

\section{Environmental Community}

Five interviews were conducted with environmentalists, individuals currently or in the past actively promoting environmental protections through fundraising and legal action through the courts. Three of these individuals participated in the early court challenges to the management actions of the USFS, the BLM and the USFWS regarding protections to the NSO on federal lands. These court actions brought the timber harvest on federal lands in the Northwest to a halt. The other two individuals work for organizations that were active during this same time.

The NWFP was initiated in order to bring a resolution to a social controversy with socio-economic and ecological foundations in order to establish a sustainable supply to timber harvest and protections for old-growth dependent species on federal lands. 
Coming off the decisions of the District Court in Western Washington, the goal of the plan was to be "legally defensible, biologically relevant and socially acceptable" (Interviewee R). The plan was required as a result of the federal agencies' failure to convince the court that their plans would protect the NSO and other species because they were "playing fast and loose with the science" (Interviewee E) and not meeting the requirements of the NFMA, NEPA and the ESA. The Court saw the management actions and plans of the land management agencies as a "remarkable series of violations of environmental laws" (Interviewee E). Although the ESA would play an important role in defining the future actions and role of the USFWS once the NSO was listed as a threatened species, the importance of the viability language in the NFMA and procedural requirements of NEPA were instrumental in defining the standards for the Court's decisions (Interviewee C). Court actions brought by environmental organizations against the USFS were primarily based on the premise "that under the National Forest Management Act there's a regulation that says you have to maintain any viable population of a species" (Interviewee O).

The goal of the environmental community at the time of the NWFP was to "protect all remaining old growth forest" (Interviewee C). In order to accomplish this goal and to address the "stranglehold on the USFS and BLM" (Interviewee E) by the timber industry, a number of environmental organizations sought to prove to the District Court in Western Washington that the science behind their management plans was insufficient to meet the goals for maintaining NSO and other species populations in oldgrowth forests. One interviewee recalls how a USFS biologist testified in one court 
session that the USFS directed their biologists to "provide absolute bare minimum protection for the NSO in order to maximize logging" (Interviewee E). The success of the environmental organizations in proving the inadequacy of the science behind the approach to NSO and other species management by the USFS and BLM became an important benchmark for the developers of the original FEMAT plan coming out the Clinton Forest Conference in 1993.

The development of the FEMAT plan as directed by the Clinton Forest Conference was viewed positively by the environmental community. The plan was developed by scientists from academia, the federal regulatory agencies and the federal land management agencies. The FEMAT plan was based on new conservation biology principles which sought to provide sufficient ranges for NSO with corridors for population movement. This was viewed as a breakthrough both in terms of the science applied to defining reserves for old-growth forest species and shifting the scale of the reserves beyond anything previously proposed by the land management agencies. The late-successional reserves defined in Option Nine chosen by the Clinton Administration set aside an additional 7.4 million acres or $30 \%$ of the federal land in the range of the NSO, in addition to the existing Congressionally Reserved Areas of 7.3 million acres and newly proposed Riparian Reserves of 2.6 million acres. In total, all but 4.0 million acres, defined as the Matrix, or $16 \%$ of federal land in the Pacific Northwest within the range of the NSO was set aside for activities other than timber harvest (Tuchmann 1996, 78).

The environmental community had the objective to stop all harvest of old-growth forests. One issue they had with the Matrix as defined by FEMAT was that in these 
harvest acres, there remained old-growth stands that could be harvested according to the plan. These old-growth stands contributed to the 1.2 billion board feet proposed in order to meet the economic and social goals of the plan. Environmental groups sought to stop old-growth timber harvest in court actions against the land management agencies. Their position was that logging of old-growth is "politically unacceptable and socially unacceptable to a vast majority of people" (Interviewee R). These actions to stop land management agency actions combined with later rulings by regulatory agencies and the Survey and Manage program implemented by the USFS and BLM stopped all old-growth stand harvest in the Matrix. In regard to old-growth stands in the Matrix, "not much of it has actually been logged in the last 20 years because it turned out that when all was said and done, and this thing fully played out, the political momentum in the Northwest turned against logging old-growth" (Interviewee E).

As an alternative to logging old-growth stands, environmental groups have championed thinning of young plantations planted by the USFS and BLM after logging previous old-growth. These densely populated forests are typically in the fifty- to sixtyyear range. Mature or old-growth forests are typically defined as at least eighty years old. Thinning is viewed as an acceptable type of harvest because it contributes to the acceleration of old-growth forest conditions. Thinning is accepted as a restoration mechanism in order to create old-growth forest structure. One interviewee makes the argument that there are enough acres of plantations in the Umpqua and Willamette forests to provide "thirty to forty years of thinning at today's current rate of management" (Interviewee O). For the land management agencies thinning has become the "path of 
least resistance" and they have received the "bulk of their volume from the past fifteen years for thinning and there has been less controversy about logging in the last fifteen years" (Interviewee D).

One of the consequences of the implementation of the NWFP was the decline in timber harvest that supported many mills in rural Oregon. As a result, most mills without their own timber supply did not survive. As a result, mill workers lost good paying jobs and in rural communities, few opportunities were available to them. In addition, the USFS and BLM were large employers in these rural communities and when the output from federal forests declined so precipitously, many of these logging related positions were eliminated. Job losses were viewed by one interviewee as inevitable given the combination of steady automation in logging and milling, combined with the dwindling supply of old-growth forests (Interviewee O). The loss of timber jobs was viewed as an inevitable consequence of the change in social value for federal environmental protections over federal timber harvest. Support to rural Oregon counties was seen as misplaced, under-funded and misused. Counties that did not diversify their economy have suffered as the federal payments have ended and timber harvest has remained low. The opinion was expressed that the counties bear some of the blame for not bringing new business and industry to replace the loss of the timber industry (Interviewee E).

The environmental community is happy with the status quo regarding how the NWFP was implemented (Interviewee R). Initially they were concerned with the status of old-growth forests as defined by FEMAT. However, the combination of the loss of social license to harvest old-growth, the inability of the land management agencies to 
change riparian reserves and the addition of Survey and Manage to the implementation of the NWFP have contributed to the halting of old-growth timber harvest. The declining populations of the NSO is a topic that is loosely addressed by the interviewees. It is couched in terms of the long-range predictions for the recovery of the NSO. The NWFP "anticipated continued decline in the owl's population over the next fifty years...we are still in the time period of predicted decline" (Interviewee E). The environmental community remains focused on maintaining the boundaries for late-successional reserves and the matrix. There is a focus on maintaining the status quo regardless of the potential consequences associated with wildfire or degradation of forest conditions. The environmental community does not trust the land management agencies to engage in active management in mature and old-growth forests. As soon as the forest reaches 80 years old, "we are sort of very trusting in natural processes taking over and sort of moving it from 80 years to 200 years without much intervention" (Interviewee D). This rejection of active management goes beyond the level of mistrust which the environmental community has for the land management agencies; it is a fundamental belief that nature is the better steward.

The environmental community, along with the federal courts, influenced the dynamic shift in the organizational field for the land management agencies leading up to the NWFP. With the implementation of the environmental laws of the 1960s and 1970s, the environmental community was able to bring court challenges to planned management actions of the USFS and BLM, thereby halting timber harvests by convincing the court of NEPA, ESA and NFMA violations by the land management agencies. The 
environmental community was able to bring to bear a preservationist perspective to the federal courts, already open to the arguments in favor of increased environmental protection, in regards to the contestation of meaning regarding the role of federal forests and the interpretation of the environmental laws. The preservationist perspective was found in the voice of the social protests over the clear-cutting of federal forests and the perceived "sacredness" of old-growth forests. The environmental community was able to find financial support from these social protests and give voice to these issues through the court. The environmental community found a court that was focused on the scientific work of the academic community and regulatory agencies focusing on habitat and biodiversity protection as opposed to the land management agencies, whose position was questioned by the court. The environmental community was fully aware of the social and economic costs associated with rejecting parts of the FEMAT plan and their court actions. However, their rejection of the commercial value of federal forests which they saw as primarily benefiting the timber industry was reinforced by the idea of sacred value of old-growth as articulated by the preservationist philosophy.

\section{Timber Community}

The five interviewees from the timber community represent varied interests through their industry association, timber company or natural resource organization. In these interviews, the multiple interests expressed within this community become apparent. However, there are a number of consistent issues these individuals have regarding the NWFP and its implementation. First, the fundamental starting point for 
this community is the idea of resources. The forest provides timber resources which have economic and social value to businesses and communities. Along with this is the idea that active management of forests is essential to harvest timber and also to provide stewardship for the interaction between human communities and forests. Second, where the environmental community see a satisfactory outcome from the NWFP, the timber community finds the status quo a failure for the goals of the NWFP and the economic and social dislocation brought on by the plan on rural towns dependent upon federal timber supply.

The goal of the NWFP as set out by the Clinton Administration was to provide the greatest possible economic and social contribution from federal forests and at the same time meet the requirements as articulated by the Court to meet the requirements of the ESA, NFMA and NEPA. The Option 9 plan chosen by the Clinton Administration provided by the FEMAT team estimated an annual production level of 1.2 billion board feet from federal lands. This was a reduction from the 2.4 billion board feet harvested from these forests from the early 1990s (FEMAT 1993, 55). Although the 1.2 billion board feet target was not a promise as some of the interviewees suggested, it would not be “subject to lawsuit, and it won't be subject to administrative review...it will just happen. And there has not been a single year when the combined federal timber harvest has been more than 500 million board feet” (Interviewee AD).

The result of reduced timber harvest on federal lands meant the closure of mills dependent upon federal supply and subsequent job losses. Some rural Oregon towns were dependent upon both federal timber to supply the local mill as well as employment 
with the USFS and BLM. Most of the interviewees viewed this as a failure to maintain rural employment in regard to county services and cultural values (Interviewee AI). One interviewee expressed frustration with federal forest policy being determined by “communities of interest” such as national environmental organizations, Congress and the USFS in Washington, DC, who "have an interest, but they have no place. They are not stuck with living and managing, and having a livelihood, and a business and family...in the town of John Day, or Canyonville” (Interviewee AG). This idea of place is expressed by another interviewee when they suggest that the firsthand knowledge of the complexity of an ecosystem is best understood by those who live and work in that place, as opposed to scientists. "If you want to know how the forest ecosystem on the Olympic peninsula works... talk to a logger. They know, because they go back to pick berries. They go back to cut firewood" (Interviewee AF).

One of the results of the NWFP according to many of the interviewees in the timber community has been the shift in responsibilities for the USFS away from a focus on active timber management. The USFS found itself without the means to control its own destiny and as a result finds itself with "no clear direction for what they want to do and are stuck in the middle of a continuing divisive environment between folks that want to see more harvest and more economic activity and people who want to see more protection, and we can't seem to resolve that debate” (Interviewee AJ). The litigation brought by environmental organizations has limited the scope of active forest management to focusing on thinning plantations planted in the 1950s and 1960s. The threat of litigation has created "a mindset...to put your effort into where you're not going 
to be sued" (Interviewee $\mathrm{AD}$ ). This is limiting the scope of management activity not just with timber harvest but also managing for fuels reduction in forest stands over 80 years of age. The failure of the USFS to actively manage federal forests was described as resulting in increasingly fire-prone forests (Interviewee AD) and overall degradation of old-growth NSO habitat (Interviewee AG/AJ). One interviewee was quite blunt with his summary of the USFS. "You know, I think basically that the forests have been shut down, and if restoration means doing nothing, then they're doing a great job" (Interviewee AI).

The timber community addressed a number of issues related to the implementation of the NWFP. One issue had to do with the ESA and the approach this piece of legislation takes to species management. The ESA does not address the concept of ecosystem management. The NWFP was founded on the principle of managing at the landscape level as defined by ecosystem management. The ESA applies a "fine filter" to species management by singling out individual species rather than taking a more "coarse filter" to the landscape as a whole. As a result, "if we want to have an ecosystem [approach], we're really looking at a coarse filter...the laws are very fine-filtered and that's probably leading us down the wrong road" (Interviewee AD). An associated issue had to do with the conservative positions taken by the regulatory agencies in regard to management activity. The regulatory agencies, USFWS and NOAA, are viewed as defaulting to an extreme conservation positions limiting management actions. The agencies have been described as having "authority without responsibility” (Interviewee 
$\mathrm{AG}$ ) and "raising the bar for the ecological conditions that need to be in place to allow them to sign off on some sort of management activity" (Interviewee AJ).

The idea that the NWFP would provide a solution to the conflict between ecological conservation and timber production does not take into account the fundamental disagreements both the environmental and timber communities had with its conclusions. The timber community has continued to raise the call for active management by the land management agencies to provide for what they see are healthier federal forests and for more timber harvest for the mills and rural timber communities. The general perception of this community is that environmental organizations are "firmly grounded in a belief system...opposed to active management" (Interviewee AJ). There is a level of frustration of the ability of environmental organizations to stop land management agency proposed actions in court based on that belief system. As one interviewee stated, “we haven't figured out a way to convince the courts that the threat of no action can often times exceed the threat of the proposed action" (Interviewee AJ).

The timber community is a complex set of small and large businesses, trade organizations and community based organizations. They do not always have the same interests and do not always agree. However, they all agree on the fundamental principles of conservation; active timber management through sustained-yield practices and sustaining rural timber communities. Conservation has maintained that forest resources have economic and social value through the active management of forests. Preservation principles, as we have seen with the environmental community, reject the necessity to actively manage forests and suggest that natural processes can provide better stewardship. 
Both communities propose an engagement of the forest with people; one has a commercial basis, the other rejects the commercial and insists on a spiritual basis. This explains the comments by some from the timber community that the environmental community is motivated by a belief system. The timber community has its belief system also, one that at its extreme views old-growth forests as “decadent” because of the inefficient use of sustainable resources. This model of extreme efficiency aligns with private interests that are concerned with maximizing profitability. As the interviews in this community show, some private land owners are not this profit driven and maintain their land for both timber and ecological values. This attempt to manage for multiple values goes back to the fundamental precept that federal forests are to be managed for multiple use. The political and social interests for multiple use continue today, now with the preservationist model dominant as compared to earlier times when the agricultural model of conservation dominated. With either case, the excesses of both sides have dominated, frustrating those who seek a more balanced solution.

\section{Regulatory Agencies}

These five interviewees from federal agencies are either NSO biologists or scientists responsible for monitoring and managing NSO populations on federal lands. The documented decline of the NSO in locations throughout its historic range dates back to the scientific literature from the early 1970s.

The initial scientific studies on the NSO, the Interagency Scientific Committee to Address the Conservation of the Northern Spotted Owl (ISC) and later the Scientific 
Panel on Late-Successional Forest Ecosystems (the Gang of Four), were the precursors for the work compiled during the two months FEMAT met in Portland, OR. The stated objective for FEMAT grew beyond just the NSO to include all old-growth related species, including the marbled murrelet and anadromous fish. However, the NSO remained the central threatened species during the development of the NWFP. The final record of decision signed on April 13, 1994 by the Acting Secretary of Agriculture Richard Romminger and Secretary of Interior Bruce Babbitt was titled "Record of Decision for Amendments to Forest Service and Bureau of Land Management Planning Documents Within the Range of the Northern Spotted Owl” (Tuchmann 1996, 35). The range of the NSO extends from the Washington-Canadian border into Northern California. In total, the range of the NSO encompasses 24.4 million acres of public land administered by the USFS and BLM. It includes eighteen National Forests and seven Bureau of Land Management Districts (Tuchmann 1996, 76).

The NSO was listed as a threatened species by the USFWS on June 26, 1990 (USFWS 2011, vi). In 1992 the USFWS issued the Draft Recovery Plan for the NSO. This plan was modeled on the habitat conservation area (HCA) model proposed by the ISC. It remapped the network of HCAs proposed in the ISC plan, replacing them with designated conservation areas (DCAs) for "increasing the biological and economic efficiency of the network” (USFWS 2008, 68). In May 2008 the USFWS issued the “Final Recovery Plan for the Northern Spotted Owl”. In June 2011 the agency issued a “Revised Spotted Owl Recovery Plan” rejecting the network of Managed Owl Conservation Areas (MOCAs) specified in the 2008 plan as a result of scientific peer 
review comments (USFWS 2011, viii). In both the 2008 and 2011 plans, the agency recognizes the critical role the barred owl has on declining NSO populations. In 2013 the agency was able to start an experimental barred owl removal program on Hoopa tribal lands.

At the time of the development of the NWFP, barred owls were known to exist in the northern portions of the range of the NSO. They were a known competitor, but the extent of their threat to the NSO was not understood (Interviewee F). Competition between raptors are known to occur at the individual scale but not at the population scale where one species is extrapirting another (Interviewee Y). However, "where you have invasive species invasions, the native species, if they're already weakened because of loss of habitat, distribution, disease, or some other factor and then you have another impact, they're newly vulnerable or more vulnerable" (Interviewee Y).

Barred owls are a similar owl species to the NSO. They migrated west from the east coast across Canada. The barred owl is recognized as the greatest threat to the NSO now that harvesting of old-growth habitat has been arrested. The barred owl has at this point in time displaced most of the NSO populations from breeding and roosting habitat across the entire range of the NSO. As the NSO have lost their territory, they have become "non-territorial floaters," sourcing food to remain alive but not reproducing (Interviewee B). At one time it was thought there may be a separation of habitats between the two species, the barred owl preferring habitat near water. However, as the barred owl populations have continued to grow, it has been recognized that "there is no niche separation, we have not found anywhere where northern spotted owls do better 
than barred owls" (Interviewee F). The barred owl has adaptive advantages over the NSO. First, it is a generalist, eating a wide variety of prey where the NSO has a much narrower source of food. As a result of its wider food diet, the barred owl has a smaller hunting radius of 300 acres, compared to the hunting range of the NSO for 3,000 acres (Interviewee Y). This means that barred owls are able to colonize with larger populations when competing with the NSO. Second, barred owls reproduce every year, producing two to five offspring. The NSO breeds every couple of years with one or two offspring (Interviewee F). The barred owl has the potential to do more damage than just potentially expirtating the NSO. As a result of its generalist diet, its impact on ecosystem processes could turn out to be profound (Interviewee J).

The USFWS barred owl experiment is based on a removal program on Green Diamond Resource Company land in northern California from 2009 through 2012 (Diller 2013). The original experiment sought to determine how cost effectively barred owls could be removed from NSO habitat and whether NSO were able to successfully return (Diller 2013). The result of the experiment was considered positive for both costeffective and efficient barred owl removal and successful repatriation of NSO to the habitat. The USFWS understood the potentially problematic nature of removing barred owls and prior to starting the experiment enlisted the support of a bioethicist to lead a stakeholder group that included timber industry groups, the Humane Society, the Audubon Society, state agencies and federal agencies, in all about twenty people to educate them on the barred owl and NSO situation (Interviewee F). The USFWS has been unsuccessfully sued for the experiment but the stakeholder group they brought 
together was very supportive of the effort. Barred owls are in $100 \%$ of the range of the NSO and will "wipe out the NSO” if the experiment does not prove successful. It is understood that it will not be possible to remove the barred owl from the entire range of the NSO and "even if we wanted to there is no way we could wipe out barred owls with the techniques that we have now” (Interviewee F). Some interviewees expressed concern "that it's going to be too little too late” (Interviewee B) and if the current experiment is not successful, "there is no Plan B for the barred owl” (Interviewee G). It is understood by the agency that this experiment, if successful, could lead to a barred owl removal program that will remain open ended. One interviewee expressed, "having worked in Hawaii for a number of years, where really our job was killing things from going extinct...that is becoming more and more of a significant part of the field of wildlife management” (Interviewee Y).

The federal regulatory agencies are responsible for the interpretation and implementation of federal environmental laws. These laws, such as the ESA, CAA and CWA, are by definition, based on preservationist principles. They are designed to restore and preserve environmental conditions and ecological processes. For example, the ESA requires that species and habitat decisions are made independent of commercial considerations. NEPA was implemented to address potential environmental degradation due to federal agency actions. The environmental laws of the 1960s and 1970s were established to address the increasing environmental social concerns as a result of commercial activities and the lack of accountability of both commercial and federal land management actions and their externalities. As a result, the role of the federal regulatory 
agencies in the organizational field of the federal land management agencies has been to amplify the preservationist principles and provide a conservative interpretation of the environmental laws as it pertains to federal land management agency actions. These interpretations have been at odds with the federal land management agencies and the federal court has looked to the federal regulatory agency as the expert in matters of scientific expertise. This is due in part as a result of the charter of these agencies, assumed to be free from commercial interests. The original decision of the USFWS to not list the NSO as endangered was questioned by the federal court due to its political basis on economic interests over the objection of USFWS scientists. Their charter also has bearing on the scientists who seek to work at these agencies, as they are drawn to their preservationist mission.

\section{Academic Community}

The necessity for something like the NWFP began with the shut-down of federal timber harvests by the District Court in Western Washington. The court had provided the USFS and BLM opportunities to present management plans to address the listing of the NSO and critical habitat designation by the USFWS. After the 1988 USFS NSO plan was rejected by Judge Dwyer, the G H W Bush Administration and the land management agencies had lost credibility in the eyes Court due to what was seen as the politicization of science (Yaffee 1994, 135). The environmental community had continued to address the need for an NSO management plan that was based on the best science available. The foundation for such a plan would be based on the work of the ISC headed by Jack Ward 
Thomas presented in April 1990. Subsequent work developed by the congressionally convened panel of scientists known as the "Gang of Four" presented in July 1991 outlined options for NSO and other old-growth species, including anadromous fish. The panel headed by K. Norman Johnson (Professor, Oregon State University), Jerry Franklin (Professor, University of Washington), Jack Ward Thomas (Chief Wildlife Biologist, USFS) and John Gordon (Dean, Yale University) expanded the scope of the ISC beyond the NSO to address an ecosystem management approach to address biodiversity and forest management.

The ISC and Gang of Four reports provided the foundation for the FEMAT effort coming out of the Clinton Forest Conference held in April 1993. The FEMAT team was instructed to prepare a plan that would meet future legal challenges and incorporate the "viability" requirements of the NFMA and the protection afforded the NSO and marbled murrelet under the ESA. The FEMAT team comprised 104 natural resource, social and economic experts including federal land management and regulatory agencies from the greater Portland area (Tuchmann 1996, 32). Absent from participation were land management agency planners and line managers. These agency personnel were not included in order to develop a science-based plan without influence of line managers. According to one FEMAT participant, the Team was tasked with answering the question "How much old growth do you need to protect all the species, because we want to create a sustainable timber harvest?” (Interviewee $\mathrm{H}$ ). The plan sought to balance the ecological, social and economic requirements sought from federal forests. 
FEMAT was composed of a number of academic biologists and forestry experts. These participants were influential in developing the earlier ISC and Gang of Four reports. Given their experience with forestry and biodiversity management, these participants came to FEMAT knowing that the science behind the work they were developing was still not robust enough, especially when it came to being able to convince the court that any plan would meet the goal of species viability. The scientific literature on the NSO was fairly extensive but even then, "most of the NSO research that went into the original plan was done by one guy in second growth forest" (Interviewee N). When it came to the over 1,000 plant and animal old-growth habitat species, little was known about them (FEMAT 1993, 30). When it came to developing a plan that would hold up in court regarding species viability, "the biggest barrier was really thin research on almost every aspect of the habitat questions" (Interviewee N).

What is expressed consistently in the academic community regarding the NWFP is the recognition that because of the limited scientific knowledge base for the plan and the complexity of the ecosystem in general, there is the recognition of the uncertainty of planned management actions and the need for a learning component to the plan. It is important to see the applied nature of the FEMAT plan for the academic community as a means to bring sustainability of timber harvest and ecosystem management and resiliency to the federal forests. The uncertainty of planned management actions meant that "the one goal of any kind of forest management, or any kind of management, ought to be learning; there ought to be a formal learning component of every management plan and action" (Interviewee N). As one interviewee expressed, "It was only one of the many 
opportunities in the NWFP for people to make change, because we're a bunch of scientists and we knew very well that we were going to learn things, and circumstances were going to change" (Interviewee X).

The NWFP was intended to be a plan based on ecosystem management. This was an emerging concept at the time and a very different type of approach to forest management the land management agencies had applied up to that point. Ecosystem management meant taking a landscape rather than site specific view of the forest. In addition, there is the recognition of the importance of the disturbance cycles of the landscape. Up until that point, land management agencies had sought to minimize or restore the effects of fire or flooding. Ecosystem management and the goals of FEMAT were to recognize the important role disturbance played in the forests of the Northwest and provide a management plan that worked with rather than against these disturbance cycles. Hence the recognition of the uncertainty of the ecosystem and the need for flexibility when it came to forest management. The intent of the FEMAT plan was a "coarse filter" approach to set aside $80 \%$ of the federal forest lands by designating them as reserves, thereby "covering the needs of the biota" (Interviewee X).

The vehicle for this learning component in FEMAT was the practice of adaptive management, specifically set asides in carved out areas of federal forests known as adaptive management areas. The intent of the adaptive management areas was to provide land management agencies with areas where they could experiment with active management techniques. As one interviewee explained, "the idea that then through the adaptive management areas, and advanced ecosystem research we'd find out what 
actually was going on and respond to that in terms of planning" (Interviewee N). Subsequent to the implementation of the NWFP, adaptive management areas were not utilized as planned. This was viewed as a result of lack of funding, bureaucratic procedures put in place that thwarted the experimental intent and opposition by land management agencies and stakeholders to employ "highly manipulative approaches” through active management. The failure of the adaptive management areas was viewed by one interviewee as a failure in creativity: "We built in a lot of potential for adaptation and nobody wanted it. They lawyers didn't want it. The court didn't want it. The stakeholders didn't want it, whether they were enviros or timber people. Everybody wanted certainty, in terms of outcomes. Certainty doesn't allow for adaptability" (Interviewee X).

One outcome as a result of the NWFP was the change in culture that came about in the land management agencies. The NWFP reoriented the mission of the land management agencies from timber production to ecosystem management, redefining forestry management. The NWFP for the USFS was, "the biggest shock that they've experienced managing the forests out there because the mantra of the USFS is gradual change after due notice, that's right from the original Pinchot letter that the national forests were transferred. And to have this sudden change was a tremendous shock not only a shock in the sense of what their tasks were but just a shock in terms of what good forestry was" (Interviewee H). The change has resulted in a perception among the academic community that the USFS, and less so, the BLM, are "floundering" and have "not equilibrated yet". The USFS is still "kind of floundering to some extent in terms of 
what their purpose is. The BLM is floundering less, they still think their purpose is primarily to generate money for the counties" (Interviewee $\mathrm{P}$ ). It is the requirement for the BLM based on the Oregon \& California Lands Act of 1937 (O\&C Act) to provide the eighteen Oregon and California counties (Blumm 2013, 22) funding from the proceeds of timber sales that has forced the BLM to do "integrated management for environmental and economic values” (Interviewee X).

FEMAT was conceived as a landscape level plan with a focus on ecosystem management. The implementation of the plan by the land management agencies has been influenced by the Environmental Impact Statement (EIS)/Record of Decision (ROD), the regulatory agencies and subsequent court rulings. Interviewees from the academic community recognize that limitations outside the control of the land management agencies have influenced their adaptation of the plan, but they still fault the land management agencies for becoming too conservative and risk averse when it comes to active management. This risk averse approach to forest management is expressed in three categories. First category is the failure to truly implement a landscape level plan and focus on single species management and application of site specific management rules to the landscape level. The second category relates the dynamic nature of the disturbance cycle in the ecosystem and the focus by the federal agencies on maintaining fixed boundaries in federal forests. The third category concerns the perceived lack of creativity of the land management agencies by the academic community.

The implementation of the final EIS and ROD for the NWFP was centered around a coordinated effort by all land management and regulatory federal agencies. This 
coordinated effort was designed to discourage agencies from filing suit against one another as had been the case prior to the NWFP. The USFWS took a central role in defining the overall architecture of the landscape of the NWFP starting with the NSO oldgrowth habitat restoration plan. As one interviewee stated, "the leadership now on landscape planning for the USFS and federal lands has gone to the USFWS and National Marine Fisheries - they are now doing the regional architecture really" (Interviewee H). The focus on maintaining and restoring NSO habitat was a necessity, given the history of depleting old-growth forests. However, the focus on the NSO and old-growth habitat has its unintended consequences. First, "the focus was entirely on preservation and not on ecological management" (Interviewee X). The emphasis on preservation was consistent with the goals of maintaining habitat for the NSO and other old-growth species, but it overshadowed the idea of active management of these late successional forests. Second, the focus on the NSO and other old-growth species in the implementation of the NWFP brought a fine-filter approach to a plan that set out to be a coarse-filter one. The NSO was the central species which through conservation biology defined the habitat architecture, "but the concept of the plan was not single species management, it was ecosystem management but that the single species management never went away" (Interviewee I). Third, the implementation of the NWFP, conceived as a landscape plan, was limited by what is viewed as "small scale" thinking. One interviewee expressed this as follows, "One of the things for me that the NWFP did - it mandated that we move from thinking small scale to a landscape. And so, in doing that you've got to recognize that the way you view this is not the way you view that. And yet what we've done - and it's 
from a regulatory perspective as well, we were really comfortable thinking small” (Interviewee Q).

As was mentioned earlier, the critique of the failure of the land management agencies to engage in active management of all areas of federal forests was associated with the idea of recognizing the central role of disturbance in the landscape. In addition to the absence of active management, many of the academic interviewees spoke about the need for a rethinking of disturbance in relation to assumptions held by the federal agencies. The critique addresses the continued focus on fixed boundaries in regard to reserves and matrix areas. The concept of multiple use has been a forest management principle throughout modern federal forestry management. The idea of "multiple uses" has been conceptualized within areas of distinct spatial boundaries, each identified with a specified "use". These distinct spatial boundaries defined as functional management areas do not always work well with dynamic and disturbance prone ecosystem processes. As one interviewee has noted, "the NWFP came along just at the end of what I would call the Golden Era of zoning type forest planning. Stalinist forest planning if you want to be pejorative. But remember that we had FORPLAN, we had the NMFA and everything was going to be zoned out, planned out and outcomes guaranteed of - that doesn't even work very well with annual agriculture and where you have a lot more control, a lot larger research base. And I don't think there's any chance that it works well for the forests. Yet we are still clinging to that model in many ways" (Interviewee N). The implication here is that management goals need to be developed in a more flexible manner and the land management agencies need to take a landscape perspective based on the fluid nature of 
different habitat types. Another interviewee summarized as follows, "Basically, in an ideal world, you probably wouldn't have a lot of boundaries out there. What you would have is a set of principles, in terms of what your goals are, and you would have a management organization that you would trust to actually follow that as best they could" (Interviewee X).

The composition of the academic community that is part of the organizational field for the federal land management agencies has shifted over time as the demands for environmental management has increased. Conservationist principles dominated academic research with silviculture, economic modeling, forest modeling and game management. The conservationist principles for the efficient use of forest resources provided a foundation for both pedagogy and research at academic institutions with forestry programs. Foresters in both the timber community and the federal land management agencies were trained at these institutions with a common set of assumptions regarding the proper methods for forest management. With the increased social demand for environmental protections in federal forests, the federal land management agencies began to diverge from the private sector to hire "ologists". These scientists were trained in the biological, ecological and social sciences and brought a different ecological perspective to these agencies. Concepts such as landscape ecology, conservation biology and ecosystem management were introduced into the vocabulary of the federal land management agencies. These academic disciplines brought a view of forests as complex systems of ecological processes with an increased perspective of biodiversity and habitat. The academic community shifted from a quite strong 
conservationist position to one more somewhere in the middle between conservation and preservation. The academic scientists involved with the development of the FEMAT plan were seeking a balance from federal forests for both timber harvest for social and economic goals and maintaining ecosystem processes for habitat and biodiversity. These can be viewed as preservationist in nature but where the academic community differs from the environmental community is in the area of active management. The environmental community maintains a position that nature is the best steward for federal forests. The academic community recognizes the need for active management, just one based on seeking to maintain the balance between timber harvest and ecosystem processes.

\section{Bureau of Land Management}

In 1937, the Bureau of Land Management, then known as the General Land Office, was given the responsibility of managing the revested lands in Oregon and California (O\&C lands) under the guidelines set forth by the O\&C Act. For about fifty years the BLM managed these lands under the direction of the O\&C Act with little or no administrative challenges (Blumm 2013, 22). The O\&C Act established a "multiple use” for these lands including sustained yield timber harvesting, watershed and stream protection and providing economic assistance to the O\&C counties from the sale of timber (Blumm 2013, 21). The BLM interpretation of the O\&C Act was one of the “'dominant use' regime that elevated timber production above all other values” (Blumm 2013, 22). Since the implementation of the NWFP, the BLM has been managing the 
O\&C lands under the jurisdiction of the NWFP, currently the Resource Management Plans of Western Oregon, and the O\&C Act. The very different fundamental bases of the NWFP and O\&C Act has provided the BLM with conflicting goals and administrative direction. In the five interviews with BLM employees either currently involved with implementing agency planning and those who were directly involved with the implementation of the original NWFP, all address the conflict between the legal mandates for sustained yield timber harvest and ecosystem management.

The FEMAT plan and the EIS/ROD for the NWFP were developed without the participation of land management planners and managers. This resulted in a plan that required a great deal of translation and confusion when it came to the implementation of the NWFP. The implementation of the NWFP was one of the difficulties the land management agencies faced with the new plan. As one drafter of the original FEMAT plan expressed, "The agency could not implement the NWFP as given to them" (Interviewee H). A contentious part of the plan is the Standards and Guidelines, the rules which define "processes rather than land management, telling us steps to go through before we can take any action, prepare this kind of analysis, do this kind of assessment, have it reviewed by these people" (Interviewee T). It is this focus on process, as opposed to management goals, that made the NWFP very difficult for the land management agencies to implement as they saw fit. The NWFP was "developed at a time, which right or wrong, there was tremendous mistrust of the land management agencies to implement the concepts as they were intended. There are elements of the plan that reflect that 
mistrust and have, I think, crippled the Forest Service and the BLM implementing the plan, even the way that authors of it intended" (Interviewee T).

The interviewees from the BLM view the role of the BLM as defined by the Congressional laws under which they are required to operate. These laws sometimes conflict, but the requirements of FLPMA, the O\&C Act, NEPA, the ESA, the Clean Water Act (CWA) and the Clean Air Act (CAA) define the management space under which the BLM can operate. The intent of the NWFP is to provide a management framework for the federal land management agencies to meet the requirements required primarily by the ESA, NEPA and NFMA, although the BLM is not directly governed by the latter act. FEMAT and the final EIS/ROD both expressed an interpretation of a plan that met the legal requirements under which the land management agencies operated. The interpretation of the EIS/ROD was developed by scientists who did not have working knowledge of the process by which land management agencies arrived at a management decision and how these management actions were implemented. As one interviewee expressed, the NWFP “was way too prescriptive, and it didn't factor in life on the ground" (Interviewee W).

The NWFP was administered by the Regional Ecosystem Office (REO), which is "tasked to facilitate decision-making and prompt interagency issue resolution during the implementation of the NWFP” (REO website). The REO played an important role with the introduction of the NWFP to provide communication and answer questions regarding implementation. The REO as defined by the Standards and Guidelines of the ROD "provides staff work and support to facilitate RIEC [Regional Interagency Executive 
Committee] decision making and prompt interagency issue resolution in support of these standards and guidelines... This office reports to the REIC and will be responsible for developing, evaluating, and resolving consistency and implementation issues with respect to specific topics including, but not limited to, Geographic Information Systems (GIS), pilot watershed analyses, restoration guidelines, Endangered Species Act requirements, adaptive management guidelines, monitoring and research” (USDA 1994, E-16). The REO reported to the RIEC which "consists of the Pacific Northwest federal agency heads of the Forest Service, Bureau of Land Management, Fish and Wildlife Service, National Marine Fisheries Service, Bureau of Indian Affairs and the Environmental Protection Agency. Other participants on this committee include: the National Park Service; Soil Conservation Service; the States of Washington, Oregon and California; and three tribal organizations” (USDA 1994, E-16). The REO is responsible for providing guidance to all federal agencies as a part of the interagency co-ordination on the Standards and Guidelines of the NWFP. The interviewees spoke about some of the issues they had with the REO and the requirement that the BLM seek interpretations from the REO added to the sense of loss of control the agency was experiencing. "Some of the institutional difficulty, I think with implementing the NWFP for us was that we didn't have any control. If we had a question of what does this mean, it had to go to the Regional Ecosystem Office... and they operated independently of the agencies and they had these dedicated employees. You'd submit something to them and it'd be months and months before you heard an answer. And it wasn't our answer. It was an answer given to us. 
Just as the NWFP was given to us. It just felt like we didn't control our own management" (Interviewee T).

A second issue with implementation was the inability of the land management agencies to meet the timber harvest targets expressed in the original FEMAT plan. The chosen Option 9 from the range of alternatives proposed by FEMAT by the Clinton Administration "probable sale" quantity was established at 1.2 billion board feet. There were multiple reasons for the BLM not to meet its portion of the timber harvest goals per the plan. Litigation from environmental organizations was one, but there were two items identified in the interviewees that came directly out of the EIS/ROD and subsequent interpretations by the regulatory agencies. The first of these was Survey and Manage. Survey and Manage is a guideline to address the concern of agency biologists for species that did not have sufficient research as part of the requirement of NFMA that required the USFS to manage federal forests to provide for diversity of native and non-native vertebrate species. The viability standard was held by the District Court in Western Washington as not being met by the original biodiversity plans submitted by the land management agencies which eventually led to the shutting down of all timber harvesting on federal lands within the range of the NSO. It was critical that any new plan submitted to the court by the BLM and USFS coming out of the NWFP meet the court's interpretation of the viability standard.

Survey and Manage was added to the EIS as a precautionary measure as "the NWFP predicted the Plan would provide adequate habitat for nearly 800 latesuccessional forest-associated species including those listed under the Endangered 
Species Act but could not predict the Plan would adequately protect about 400 other latesuccessional related species that were apparently rare or about which little was known. In response to this concern, eight mitigation measures, including Survey and Manage, were added to the final Plan to provide additional benefits for these apparently rare species of fungi, bryophytes, lichens, mollusks, vascular plants, several vertebrates and four arthropod groups” (USDA 2007, 4). Survey and Manage required that any potential management site be surveyed for one of these four hundred species and if found, a management plan would need to be developed, removing the site from management action. From the BLM perspective, Survey and Manage should not have been applied to the agency since the viability clause of the NFMA only applied to the USFS. In addition, the issue for the agency rested with the risk averse nature of the guideline and the level at which it was applied. One interviewee involved with the implementation of the plan noted, "it tried to be an ecosystem management approach and the intent was that these habitat conservation areas would provide benefits to more than just the northern spotted owl. It would be an array of species and plants...But when push came to shove, it appeared to me that we were still dealing species to species from the plan" (Interviewee AL). This addresses the similar issue raised in the earlier section by the Academic Community regarding the appropriate level at which the plan should be applied, the site or at the landscape level. In regard to the intent of the drafters of FEMAT, Survey and Manage is "contrary to the spirit of the NWFP and its conception. They were going for ecosystem management and this is single species management" (Interviewee T). In addition, Survey and Mange takes a more risk averse approach than the ESA. With the 
ESA, "if you don't have affirmative information about a need to list, you don't list. You don't put species on because we don't really know much about them" (Interviewee T).

One BLM interviewee who was involved with the legal issues surrounding the NWFP speaks of Survey and Manage as the "poison pill of the NWFP." One of the important goals of the NWFP was to resolve the viability standards of the NFMA to the satisfaction of the District Court. The scientists behind FEMAT proposed an ecosystem approach to meet this requirement. The team of scientists that developed the EIS/ROD worked with attorneys from the Justice Department to ensure that the final document would meet this hurdle. For most of the well-researched species there was sufficient research to confirm that the plan would meet their needs. However, there were a number of scientists that "were refusing to put their names to document that would say that their species would be viable, unless there was provision for Survey and Manage...The spotted owl, everything was fine. Everything's fine. And then they found - but if they said that their species wouldn't be viable, then the Justice Department wouldn't go back to Judge Dwyer. So, I'm back at this meeting on the $11^{\text {th }}$ hour, and I'm with the Justice Department attorneys. And they were having this difficulty with the fungi and mollusk...but they had told the powers that be, like Katie McGinty and the White House folks, these scientists are going to bolt unless we give them Survey and Manage. Well that's totally contrary to the whole concept of ecosystem management" (Interviewee AK).

The second issue with implementation of the NWFP and the impact to timber harvest was the implementation of riparian reserves. Included in the ROD was The Aquatic Conservation Strategy (ACS) which comprised four elements: riparian reserves, 
key watersheds, watershed analysis and watershed restoration (Tuchmann 1996, 79). This was a novel addition to the management of the federal forests and regarded as a "brilliant” component to the NWFP. The FEMAT plan identifies “(c)ritical issues in management of aquatic resources include: (1) at-risk fish stocks and species; (2) stream, riparian, and wetlands habitat; (3) water quality; and (4) nonfish species of aquatic and riparian-dependent organisms. An estimated 314 stocks of anadromous salmonid stocks have been identified at risk, because of low or declining population numbers” (FEMAT 1993, 41).

The original intent of the ACS was "you would be able to go in and change those buffers at some point in time. That never happened because it was too difficult to do so" (Interviewee AL). The issue expressed by a number of BLM interviewees was that the fieldwork analysis expected by the plan in order to better identify the required buffer widths given the conditions on the ground did not happen as the FEMAT plan had expected. The issue centered around whether to look at the needs of aquatic species or both aquatic and terrestrial species. The decision was to include terrestrial species in the analysis and as a result, the original buffer widths did not change. As a result, "nobody in twenty years, those widths have been what people have managed to, nobody has really changed them. I think if they'd taken a different approach, saying, these riparian zones are here for fish, other species will gain incidental benefits, but we are designing this reserve based on what fish need. I think that process could have worked. But, not if you say every species that benefits is the purpose, because then every acre is needed by something. Then you can't make those choices" (Interviewee T). 
The drafters of FEMAT viewed the NWFP as an adaptive management plan. With the development of the Standards and Guidelines in the ROD, the NWFP became a process focused plan. This has led to a situation as one BLM interviewee asserted, "the NWFP was a great concept, but as we talked about, the flaw was that it was supposed to evolve, and it didn 't' (Interviewee W). The focus on process has led to a situation where making changes to these Standards and Guidelines has been difficult due to the requirement that changes require an amendment to the plan, which requires a NEPA analysis. "One of the things we discovered about the way judges view the NWFP is, if you're going to tinker with it, you've still got to accomplish what it says it's going to accomplish. You can put things in with next to no good information, but if you're taking it out, you need to prove its okay" (Interviewee T). This inability of the land management agencies to convince the courts that the plan requires modification remains one of the major factors for a plan that does not evolve.

One of the original goals of the NWFP was to provide a plan to meet the requirements of the NFMA and ESA as viewed by the District Court. Judge Dwyer did rule that the NWFP met the legal requirements and met all legal challenges (Thomas 2004b, 138). [One interviewee commented that the judges of the ninth circuit court had been discussing the "old-growth controversy" before any cases were before the court (Interviewee AK)]. However, challenges to the plan and the implementation of the NWFP continued. As a result of this, the court remained integral to the on-going implementation of the plan. Two issues come out from the interviews from the BLM community. First, the court is faced with having to make decisions based on scientific 
research and modeling when it is not composed of trained scientists to make independent judgements. As one interviewee suggested, “I would argue the judges aren't looking at the science. They are looking at who do they accept as the expert on the science...At the end of the day the court's not going to disregard the agency that is the expert here and they'll look at the science that supports that agency's position” (Interviewee T). In this case, the expert in the eyes of the court is the regulatory agency. The second issue arises from this situation, namely, that the land management agency is not in control of how to interpret and implement the NWFP. "Instead of having adaptive management and learn and adjust, and adjust through amendments of the resource management plan, what you had were showdowns in court. The court decisions de facto became new prescriptive management that overlaid on the NWFP. It was a court driven process, which means that there was no analysis of alternatives" (Interviewee W).

Up until recently, the BLM was operating under the NWFP. Today, the BLM is operating under a new plan, the ROD for the "Resource Management Plans of Western Oregon” was signed on August 5, 2016. This new planning effort started in 2013 and the BLM's experience with the NWFP informed the manner in which the plan was developed along with the federal regulatory agencies, and to avoid procedural areas with the NWFP that conflicted with management discretion. The new plan the BLM is operating under was developed with three building blocks, two of which were lessons learned from the NWFP. First, the Resource Management Plans of Western Oregon is based on the mandates of the O\&C Act and the ESA. The O\&C Act requires the BLM to maintain a sustainable yield timber harvest to meet the needs of Oregon counties in southwest 
Oregon. That yield coming from the harvest land base is set at currently 205 million board feet. The BLM does not harvest timber with clear cuts but employs an uneven age management regime. The late successional reserves network was built based on the requirements for NSO and marbled murrelet recovery as mandated by the ESA. The reserve network was developed with specific recovery goals in mind as opposed to focusing on a broader goal of developing a reserve network for all late successional and old-growth related species. The reserve network is based on the same fundamental principles from the ISC and FEMAT, "to have large blocks at proper spacing to allow both development of self-sustaining populations and interchange amongst those populations...So, what we did is we took that, how does a forest develop in the absence of timber harvest, how does habitat develop, where can we develop those blocks at the proper spacing if we do no timber harvest. So, that's going back to, as I said, what's the biological capability of our land base. We use that to build our reserve network" (Interviewee T).

The second building block of the new plan was the lesson learned regarding the ambiguous and process-oriented Standards and Guidelines. These process rules do not speak to land management planning and implementation. The new plan addresses what the BLM terms “management direction.” Interviewee T states: "We strove to write as clear, explicit, and defined rules as we could...The ambiguity, the uncertainty in a lot of the rules we had in the NWFP, was exploited to great effect by a lot of our detractors with litigation and was very effective at stopping us from implementing the actions that 
people didn't like...We cannot have a management plan that we can only implement if it meets the approval of potential litigants" (Interviewee T).

The third building block was the recognition that a cooperative effort with the regulatory agencies would build a more robust and legally sustainable plan. The lesson learned regarding the role of science as a foundation for management action in the NWFP was that the courts were going to look to the experts, USFWS or NOAA, as the arbiter of that science. This lesson was as a result of the 2008 BLM ROD termed the "Western Oregon Plan Revision” (WOPR). As a replacement for the NWFP, WOPR sought to increase the level of timber harvest above the levels under the NWFP. At the time the planning for WOPR started in 2004, BLM management believed that from a legal perspective, the mandate of the O\&C Act predominated over the ESA. "There were a lot of very high-ranking people who were very supportive of what I'd call an extremely resource extractive approach...And WOPR did make a pretty good argument that the system could support that level of timber production. The problem is that that effort didn't recognize the role and the power of the courts to dictate the outcomes" (Interviewee W). The 2008 ROD was withdrawn by the Secretary of the Interior in July, 2009.

Early on during the development of their new plan, the BLM recognized the importance of maintaining a relationship with the federal regulatory agencies. "What we learned first of all, I think it's really important to continue the close partnership with the agencies, other agencies, and with the scientists...You are not gonna go anywhere if you don't do that" (Interviewee AL). Now, with this new planning process the BLM 
approached the federal regulatory agencies and asked them to cooperate with them on the development of their new plan, "opened the whole thing up and we were transparent" (Interviewee W). By providing the agencies with the legal mandates that the BLM needs to operate under, the O\&C Act, the ESA, the Clean Water Act, they were able to bring the regulatory agencies into a collaborative situation in order to develop alternatives together. "What I tried to do was get folks in the room and see if reasonable thinking could help find places where they overlap. Where those bubbles overlapped is where we stayed...That's where we stayed for four years" (Interviewee W). One area where this collaborative approach was applied was to the plan's riparian reserve network, working with NOAA, the EPA and USFWS. "We are going to come to an agreement here about what is a good riparian reserve network to accomplish these objectives. We're giving you the objectives, because we're the land management agency what's the best way to go about it.... At the official level, they stand completely behind it. At the staff level of the people who were involved in it, they stand completely behind it. They wrote us a biological opinion that found no jeopardy in there" (Interviewee T).

The O\&C Act provided the mandate for the BLM to manage the O\&C lands with the intent to provide a sustained yield of harvested timber. Although the O\&C Act defined the requirement for multiple-use, like the USFS at the time, timber harvest was the dominant use. The principle of sustained yield timber harvest is fundamental to conservation philosophy. The BLM had the additional responsibility to provide proceeds from the sale of federal timber to the timber counties in Oregon as a result of the agreement the federal government made with the counties once the lands moved to 
federal ownership. This requirement follows the conservation principle of maintaining timber communities as a social responsibility of federal land management agencies. With both payments and employment, the BLM maintained local timber communities along with the sale of timber to local mills. Pressures on the BLM starting with the conclusion of the ISC report to maintain habitat for the NSO and other old-growth habitat species did not fit within the paradigm of conservation principles. The BLM did not have a means to rethink the allocation of federal land to meet the requirements of the ISC within the structure of sustained yield forestry and the agricultural model it is based on, and the pressures the agency received from the timber community and the timber counties. The listing of the NSO began a process where the BLM now needed to work with a federal regulatory agency to allocate land for NSO habitat. However it was not until the NWFP that the BLM was required to re-evaluate the level of timber harvest from the lands it managed and begin the implementation of ecosystem management. The BLM continues to see the O\&C Act and the ESA as in conflict with each other. The conflicting models of conservation and preservation are at play here and the resolution the BLM has sought is a balance of priorities they express as always at the expense of the other.

\section{US Forest Service}

Of the total thirty-eight interviews conducted for this research, seven were associated with the USFS. Four of the interviewees are currently retired from the Service and were instrumental in the initial planning side of the implementation of the NWFP. 
The other three are current members of the Service and have a history in the areas of management and planning.

The federal agency most impacted by the NWFP was the USFS. Federal regulatory agencies began to take on greater influence in federal land management planning, increasing the scope of their agency missions. The USFS saw its mission turned on its head and its position as a leader in federal forest management and timber community involvement curtailed. The NWFP reoriented the priorities of the USFS from a dominance of timber harvest to ecosystem management and all that entailed to define, plan and implement. The loss of timber harvest falling from a high of 4 billion board feet per year in Region 6 to a post NWFP level of 500 million board feet meant a serious reduction in the agency's budget and a decline in employment in timber communities. The USFS was a major employer in these communities and the loss of federal timber harvest contributed to the closure of local mills dependent upon federal timber and the subsequent loss of jobs. Automation advancements in timber harvest and milling also contributing to the loss of jobs. The USFS pre-NWFP controlled its own destiny in regard to forest management and planning. The NWFP required the USFS to collaborate with federal regulatory agencies who now defined the landscape architecture of Region 6 and the recovery plans for listed species. As one USFS interviewee stated, "We just changed the way we operated. It used to be that we drove the bus, we being the management agencies, and it's changed to where we were just a passenger on the bus" (Interviewee U). 
The NWFP set out to be a grand compromise between the social forces advocating federal forest timber production and federal forest old-growth preservation. The USFS was essentially caught in the middle of these social forces, defined from political, economic and scientific perspectives and interests. As a federal agency, the USFS is required to operate within the mandates defined by federal law and the funding directives as defined by the Executive branch and Congress. The timber harvest targets for the agency is set by Congress, and pre-NWFP, the directive to the agency by Congress was to "get the cut out." At the same time Congress passed environmental legislation that defined new mandates for the USFS with the Clean Water Act, the ESA and the NFMA. Similar to the conflict expressed by the BLM, the USFS was making decisions as to which federal mandate it was going to prioritize given their potential conflicts. "On any given day the USFS and the management agencies have to decide which law they're not going to pay attention to because there are so many conflicts among them” (Interviewee U). The environmental community sought through legal actions to require the USFS and BLM to comply with the environmental protections mandated by the ESA and the NFMA. The success of the environmental community to convince the Court that the land management agencies were not taking appropriate management actions, based on current scientific literature, led to the halting of all federal land timber harvest. The NWFP was the new Clinton Administration's effort to provide the land management agencies with a plan that the District Court of Western Washington would approve so that all parties could move forward. 
The NWFP is based on a series of assumptions, both scientific and political. "There were a series of assumptions that were made I believe at the time, and many of them I find exceptionally reasonable. There were assumptions on what was socially acceptable and there were assumptions I believe on what was legally doable" (Interviewee AB). One assumption that the FEMAT team made was that the plan could be developed without the input from land management agency line managers and planners. It is not difficult to see why this assumption was made. The land management agencies were not trusted (Interviewee U), either by the Court or the environmental community. The Court was looking to whom they perceived to be the scientific experts on matters of conservation biology and forestry science, and these were primarily the academic scientists and the regulatory agency scientists. The other assumption made by the FEMAT team was that the plan could be developed without public input. "What the fathers of the plan didn't take into account that they still had, people still had the right to sue and stop whatever was going on" (Interviewee AC). The environmental community did not agree with a number of assumptions from the FEMAT plan, the most critical was the provision that the remaining old-growth forests in the matrix could be harvested as a part of the 1.2 billion board foot harvest goal. The courts agreed that harvest of oldgrowth in the Matrix was in conflict with the recovery of the NSO.

The success of the environmental community to take the USFS to court to stop management actions subsequent to the NWFP has limited the USFS's ability to follow through with the intent of the FEMAT plan and a source of frustration to the agency. "Until we see the courts say that it is okay to do some managing of the national forests, 
we're still going to be in court. As long as environmental groups can get all their costs reimbursed in court when they win, so they can start their next lawsuit, we're still going to see a lot of environmental groups going to court" (Interviewee AC). The environmental community has been successful using the process-oriented ROD as a means to stop agency management actions in court. The issues regarding court actions center around differences of interpretation between the agency and the court as well as high levels of documentation asked of the agency by the court in order to justify management actions. "The documentation increased substantially to be able to show that it met the criteria that was set up in the NWFP...Every time we wrote an EIS to do any kind of management, it took longer and that was a consequence too, unintended consequence, that you spend a lot more time doing paper work than managing the land" (Interviewee AC). As a consequence of continued legal action, the agency has focused on thinning of plantations as a means to meet timber goals, a type of management action the environmental community supports. However, the threat of legal action has had the negative consequence of forcing the agency into more conservative management actions, thereby moving away from the level of creativity in land management expected by the adaptive management ideals of the original NWFP.

The NWFP has been a series of interpretations based on the assumptions of the drafters at each stage of the process. The FEMAT team took the direction from the Clinton Administration and developed a series of options as discussed above. Once the Administration agreed on option nine, the original FEMAT team dropped out of the picture and a second team of scientists from the USFWS, NOAA and the land 
management agencies took to move the plan to the next level. The EIS team was "set up in downtown Portland, it was a mixture of managers and a fair number of scientists involved in actually developing the standards and guidelines. I'd say it was dominated by the scientific viewpoints, and the managers were...the people who worked for the USFS management were there mainly to help get the EIS written in a way that would be legal” (Interviewee Z). In addition to the federal agencies' scientists, “there were a whole bunch of lawyers involved in developing the EIS... and they had an awful lot of strong opinions and not an awful lot of knowledge about land management. So, some of the problems just came from the mix of people who had strong influence on how it was put together" (Interviewee Z). The EIS development was influenced more by the regulatory agency scientists than the scientists from the land management agencies and little participation from planners. "When it [the EIS] was a nearly completed document, we were asked to look at it and identify if there were aspects of it that just couldn't be implemented. We talked about some things that were extremely difficult to implement and some changes got made" (Interviewee Z).

Where the scientists that developed the FEMAT plan saw adaptive management as the solution to a lack of scientific information, the EIS team took a different approach and opted for a solution that applied what has been termed by a number of USFS interviewees as the "precautionary principle." Adaptive management assumes that land management is an ongoing learning process and requires an acceptance of risk and a search for creative solutions. However, the precautionary principle is an attempt to minimize risk and apply the known information to land management in order to achieve a 
highly predictable outcome. It is the opposite of adaptive management in regard to risk and uncertainty. As one interviewee stated, "I think the people who worked on it [the EIS] did the very best they could with the amount of time that they had, and there were certainly areas that didn't have good scientific knowledge, and so the tendency was to take a conservative approach. In the absence of information people would say "well we're pretty sure that this would be helpful, even if it looks like it might be overprotectiveness” (Interviewee Z). In this context the addition of Survey and Manage to the NWFP can be seen as another application of the precautionary principle.

The precautionary principle not only applies to the EIS team but to the courts that have to make scientific determinations based on potentially conflicting interpretations between the federal regulatory agencies and the land management agencies. Between the agencies "there's not necessarily common understanding. I think we're all in favor and support of doing the right thing for the forest...The interpretation of how you do that has taken very different paths...I think some of it actually goes to cultural bent within each agency...My interpretations would be from NOAA you would get the most restrictive answer that kind of worst case scenario. From the USFS you'd get the least restrictive and from USFWS you'd get something in the middle" (Interviewee AH). As a result, court rulings tend to favor a more conservative approach to when it comes to interpreting the final ROD. Where the original framers of FEMAT "set up a landscape scale, strategy, methodology, for protecting the NSO and providing the kinds of social promises that the president and vice-president presumably made to the people of the northwest in general in the timber industry in particular. Which required that there be some flexibility 
in the Matrix area itself. Well along came a number of other folks, and the precautionary principle sets in. And as soon as you've got that, and suddenly the riparian reserves expand, and the judge says any kind of impact on the northern spotted owl through the harvest of old growth, no matter how minuscule it might be, is unacceptable" (Interviewee AB).

A third level of interpretation came with the implementation of the ROD by the land management agencies. The process and procedures codified in the Standards and Guidelines were new to the land management agencies and were not developed in the language and structure of agency planning documents. "So the managers were left with something that was very difficult to implement because of the way it was worded and the way the process procedures were standardized... and the scientists weren't there to help interpret" (Interviewee U). As a result, managers were making it up as the went along and the land management agencies in addition setting up the Regional Ecosystem Office, funded a team of people who would travel around the region providing training and a consistent interpretation of the Standards and Guidelines. The team compiled a compendium of questions and answers called the 'brain book'. "It was challenging to get a consistent understanding of what appropriate implementation of the Standards and Guidelines meant” (Interviewee Z).

The impact of the ROD and the subsequent implementation of it through continued court interpretations has meant that the USFS finds itself in a situation where it is unable to move out of the confines of an unmodifiable plan. This has resulted in two dilemmas for the USFS. One, the level of planning for the NWFP is in conflict with the 
historical USFS planning regime of individual forest plans. The "whole planning structure, within the USFS, is designed for a different type of plan than the NWFP. Its designed entirely for doing planning on a national forest level rather than a dozen national forests at the same time" (Interviewee Z). In addition, because forest planning under the NWFP encompasses multiple national forests, "you end up putting requirements in place that are generally applicable everywhere but probably don't fit well in some places" (Interviewee Z). Second, the application of rules across the landscape means that in some instances, land managers are required to maintain conditions that do not match the conditions of the specific site. The width of riparian reserves is cited as an example by one interviewee: "even though they were set and there was a numerical value, in the field, you'd go out there and you'd go, but that doesn't make any sense. Why are we - but there wasn't really a way to change it, sometimes you would end up doing things that didn't make any sense” (Interviewee AH).

In addition to fixed rules, the implementation of the plan has resulted in fixed boundaries for late successional reserves and matrix areas that have not changed since the implementation of the plan over twenty years ago. The NWFP is a landscape level management plan and by definition, the landscape is dynamic and prone to disturbance. "The challenge of the NWFP and the late successional reserves be fixed on the landscape. Once they burn up, they're gone. Being able to have a mosaic of reserves that moves across the landscape depending upon your current ecological condition is much more important than a fixed boundary reserve because owls don't recognize a fixed [boundary]" (Interviewee AH). The USFS has not been able to address this issue of 
modification of the NWFP with other stakeholders. One interviewee explained, "why is it that you're not more aggressive about moving off fixed land allocations and standards and guidelines which lack flexibility? And the answer to that maybe what folks said to me is, 'They do not trust you. As imaginative as you may be, as well intentioned, we don't trust that future administrations will provide the degree of protection that we believe is appropriate”" (Interviewee AB).

The USFS has been trying to modify the ROD and has not been successful. The process nature of the ROD has meant that the agency needs to provide a NEPA analysis as to why the standards and guidelines are no longer needed. Any change to the ROD has been litigated by the environmental community. This is illustrated by the rejection by the court of the "2007 Record of Decision to Remove the Survey and Manage Mitigation Measure Standards and Guidelines from Forest Service Land and Resource Management Plans within the Range of the Northern Spotted Owl” which was signed by the USFS and BLM (Survey and Manage History and Update Oregon/Washington BLM, www.blm.gov/or/plans/surveyandmanage/history, accessed March 24, 2018). In July 2008, ten environmental organizations filed a complaint against the USFS, BLM and USFWS alleging that the agencies violated NEPA, NFMA, FLPMA and ESA. In December 2009 the District Court for Western Washington ruled in favor of the environmental organizations finding that the 2007 ROD "lacked a true no action alternative, did not disclose enough new information to ensure that public elimination of Survey and Manage is warranted, violated NEPA by not providing high quality information and accurate data and substantive NFMA, FLPMA, ESA claims are not 
abandoned and remain open” (BLM website). In April 2013 the Ninth Circuit Court reversed a settlement agreement from March 2011 between the parties and the District Court for Western Washington issued a new ruling reinstating the 2001 Survey and Manage ROD and Standards and Guidelines along with some project exemptions and accepting later modifications to the species list.

One interviewee described their experience with the frustration of working under the ROD as follows. "I can't tell you how many times, every time we got a new administration or a new regional forester the charge was 'Fix the record of decision. Fix it. Fix those standards and guidelines. Make it easier to implement.' Okay. And over and over again - there were documents and documents and suggestions of what to do. It was all you have to change these channels and get the process out of it. Process and procedures can't be in there. You have to say what you want not how. But if you didn't do a record of decision that opens the whole thing up to appeal and lawsuit and it could have stopped everything and its sort of like, 'Okay, we'll keep muddling through and trying to figure out how to make it work"” (Interviewee U).

The USFS was founded on the principles of conservation and developed a robust agency of silviculturalists and planners focused on the agricultural model for sustained yield forestry. The agency was able to maintain control over the federal forests due to its ability to navigate the requirements set by Congress for "getting the cut out” and economic and political relations with local timber mills and timber communities. As long as the primary goal of the agency was sustained yield timber harvest, it was confident in what it needed to do and was successful. Similar to the BLM, the demands on the USFS 
began to change with the development of environmental concerns from the public of clear-cutting on federal lands and loss of biodiversity. The agency recognized the need to incorporate these public concerns into its management practices but their efforts were deemed insufficient by both the public, through environmental organizations, and the federal court. The agency sought to define the limits of how it would incorporate the requirements from the ESA and NFMA into the dominant agricultural model it operated with. The court admonished the repeated failures of the agency to implement these legal requirements with the best available science, as the court interpreted the science. These failures led to the shutting down of timber harvest in the Pacific Northwest. The USFS had begun to hire "ologists" from the natural and social sciences in order to navigate these new demands, and these new participants began to slowly influence the direction the agency was taking. With the development of the NWFP the agency scientists were becoming a stronger voice, especially as the agency shed positions associated with timber harvest and road building. The agency was forced to align itself with ecosystem management as defined by the NWFP, providing protected habitat for old-growth dependent species and seeking to maintain ecosystem processes. This moved the agency closer to the goals of preservation principles in addition to the social and economic demands for timber harvest. The reduction in timber harvest had a funding impact to the agency. In addition, the requirements of the NWFP and NEPA made management action more difficult to implement as the environmental community was able to litigate proposed actions. Given this set of legal requirements, legal challenges and funding constraints, the USFS continues to find a means to implement ecosystem management 
and maintain levels of timber harvest sought by the NWFP. The new planning process under way to revisit the forest plans of Region 6 will provide the USFS a means to provide a better balance for the goals originally set out by the Clinton Forest Conference. 


\section{Chapter 5: Discussion of Findings}

\section{Introduction}

The thirty-eight interviewees clearly expressed different beliefs as to what constituted the "true NWFP.” Was the true NWFP the directions President Clinton's Forest Conference gave to the FEMAT team, the FEMAT Option 9 that the Clinton White House chose, the Final Environmental Impact Statement/Record of Decision, or the modified version of the plan including all subsequent court rulings and guidelines from federal regulatory agencies? The answer to that was dependent on the outcomes of the NWFP over time and the outcomes the interviewee was expecting from the plan. The further in time the plan moved off the principles of the original Forest Conference, the greater number of interviewees saw the result as not the "true NWFP."

Most of the interviewees would agree with the principles President Clinton tasked the FEMAT team to address: economic assistance, forest management, role of science, timber certainty and interagency cooperation (Tuchmann 1996, 30). The Forest Conference was a listening session from fifty-two individuals that represented a broad cross-section of public interests in the federal forests in the Pacific Northwest (Tuchmann 1996, 29). The goal of the Forest Conference was to develop "a plan that would move forest management decisions out of the courts and back to the managers” (Tuchmann 1996, 28). The decision was made that the plan would be developed in a very short period of time, originally sixty days, and that the plan would be focused on addressing the court's injunction with an ecosystem management plan that "could withstand future 
legal challenges and would require the agencies to integrate the nation's environmental laws” (Tuchmann 1996, 31).

The development of the NWFP was based on a number of assumptions as to how to move federal forest management forward. The central concern was how to meet the court's request for a "scientific plan" to meet the viability clause of the NFMA to maintain species populations. The land management agencies had failed to meet the court's expectations so the Clinton Administration looked to scientists involved with earlier assessments in order to address the problem (Thomas 1999, 13). Two assumptions were made on how to move forward. First, the assumption made was that the solution for a complex socio-economic issue of how to manage federal forests could be limited to the work of a group of scientists without the greater participation of other stakeholders. The second assumption that was made was that a plan could be developed without the participation of other stakeholders that would end future court challenges. These assumptions have a history when it comes to forestry management. Daniels writing on an early scientist panel to address the new regulations of the NFMA concludes that, “(e)ven though forestry’s most intractable dilemmas stem from differences in value hierarchies, debates about them tend to be cast in technical terms. As such, scientists are asked to resolve social questions as fundamental as equity and appropriate rates of economic growth, by focusing on technical natural resource issues that serve as convenient proxies” (Daniels 1992, 130).

The variation of interpretation among interviewees as to what constitutes the "real NWFP” can be viewed as a misalignment between the socio-economic expectations of 
the NWFP and the implementation and subsequent adjudication of the plan. The focus on finding a scientific solution was limited in understanding with regard to what Giddens refers to as the "theory of structuration" in Institutional Theory. Social structures or social relations are continuously constructed and negotiated by social actors (Scott 2008, 431). The USFS or BLM cannot be viewed as fixed institutions acting independently of the larger socio-political context in which they exist. Establishing a set of land allocation rules between reserves and timber production for the land management agency becomes part of the ongoing "complex process of negotiation and contestation over cultural meanings" (Mohr 1998, 350). The land management agencies need to be placed within the "organizational field" in which they exist and are defined. The "organizational field" is defined "as a set of interdependent populations or organizations participating in the same cultural and social sub-system” (Scott 2008, 434). The important aspect of the organizational field is not to view the "organizations in environments but on the organization of the environment” (Scott 2008, 434). The reproduction of the organizational field is a continuous process and defines the interdependent relations between organizations.

The organizational field within which the USFS and BLM are located is a relational structure and Figure 2 represents a model of the organizational field from the perspective of the land management agencies. DiMaggio and Powell state that the organizational field cannot be defined a priori and must be defined with empirical investigation. "The process of institutional definition, or "structuration," consists of four parts: an increase in the extent of interaction among organizations in the field; the 
emergence of sharply defined interorganizational structures of domination and patterns of coalition; an increase in the information load with which organizations in a field must contend; and the development of a mutual awareness among participants in a set of organizations that they are involved in a common enterprise” (DiMaggio 1983, 148).

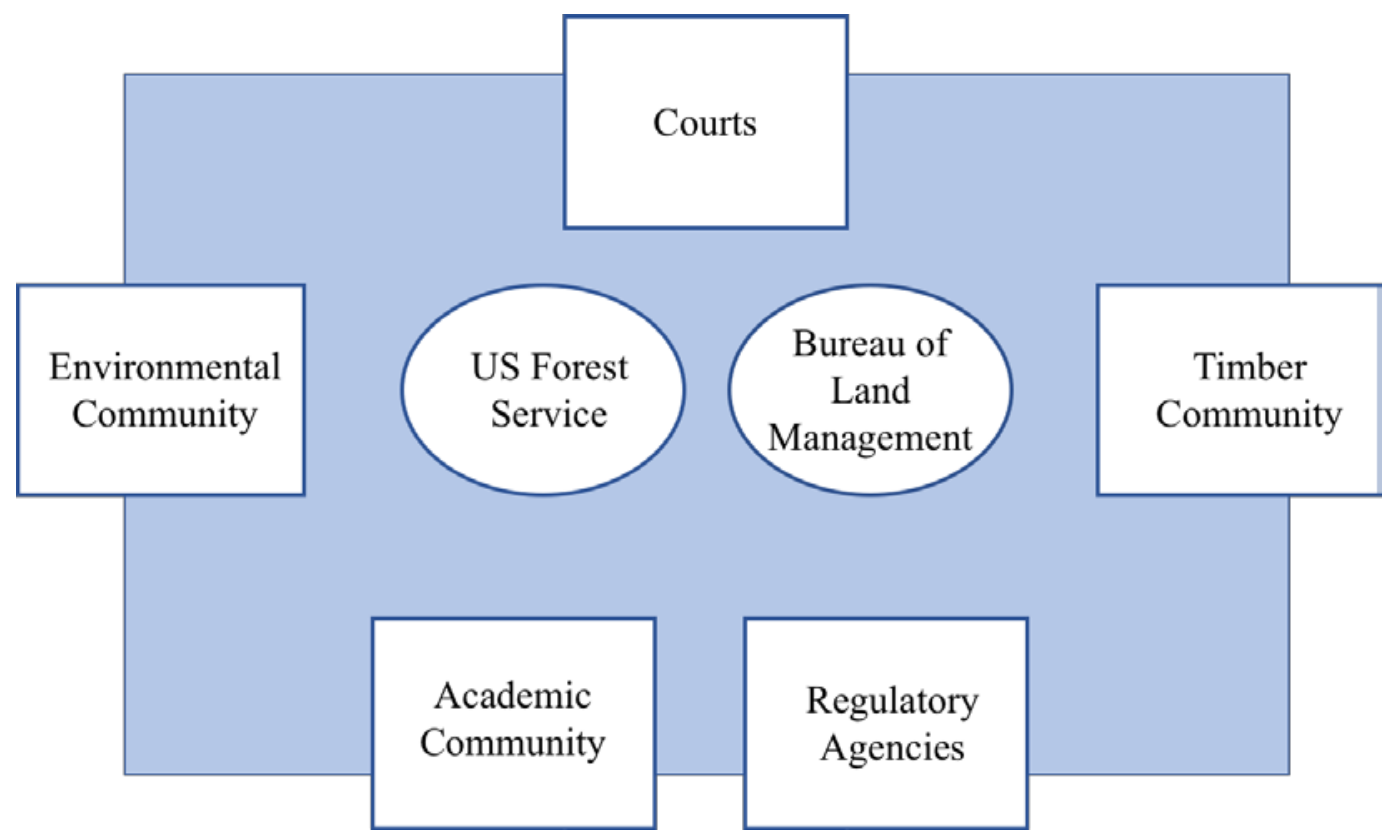

Figure 2. Organizational Field of the US Forest Service and Bureau of Land Management in the Pacific Northwest

Each of the entities as part of the organizational field defined in Figure 2 have either a direct or indirect relation which influence the federal land management agencies. These relations and structure change over time. With the enactment of NEPA and the NFMA in the 1970s, the environmental community was able to address the timber harvesting practices of the land management agencies through the court system, thereby shifting relations and between the agencies and the timber industry. This change took almost two decades but with it came a shift in structure, practices and budgetary funding 
for the agencies. The shift that took place for the federal land management agencies was not the result of any single ideological or scientific change in thinking but a series of events that encompassed all of the participating entities in the organizational field.

Clarke and McCool (1996) provide an organizational theory analysis of federal natural resource agencies prior to the listing of the NSO to "examine what accounts for the performance differences that exist among certain federal agencies...'differentials of power'” (Clarke and McCool 1996, 3). Clarke and McCool (1996) posit the power differentials of the seven agencies they analyze depends on two sources: "(1) the expertise, knowledge, and information an agency has at its disposal, and (2) the clientele and other external support an agency can muster in support of its programs' (Clarke and McCool 1996, 5). From a structural standpoint, they explain that an agency such as the USFS or BLM is part of an "iron triangle" consisting of the agency itself, any responsible congressional committees and associated business interest groups. This iron triangle defines a set of relations as does the organizational field albeit, a more narrow view. Clarke and McCool (1996) suggest that with the growing influence of the federal courts and the environmental community, the historical iron has failed to maintain the power relations that existed prior to the implementation of the NWFP.

With the publication of the Staking Out the Terrain in 1984, Clarke and McCool classify the USFS, along with the Army Corp of Engineers, as a "bureaucratic superstar." The USFS is seen as an agency with a great deal of independence within the Department of Agriculture and the Executive branch. They explain this independence as a result of the agency's history of professional staffing, foundational charter, multiple-use mandate 
and the dominant practice of silviculture. Clarke and McCool refer to the agency's focus on sustained yield forestry as the core practice of the agency thereby bringing both management direction and timber resources for commercial benefit and as a source of funding. Silviculture was the "dominant profession” (Clarke and McCool 1996, 215) within the USFS, defining the re-engineering of the federal forests based on early twentieth century principles of scientific management for sustained yield of timber harvest. Both of the bureaucratic superstars as defined by Clarke and McCool are or were primarily engineering oriented organizations that focused more on the technical practice, as opposed to the scientific research practice. Both agencies were dedicated to a program of "mastery" of Nature. For the USFS that meant replacing “decadent” oldgrowth forests that were not productive in timber growth with new "efficient" monoculture plantations.

The USFS has seen the dissolution of the iron triangle with the agency "shift from providing goods and services to select private interests towards providing more general services to 'the public"” (Clarke and McCool 1996, 224). In addition, the USFWS has seen a shift in its relationship with the federal land management agencies. The USFWS took on three roles in the Pacific Northwest. First, the agency defined the landscape architecture of the range of the NSO, thereby redirecting the role the federal land management agencies had in defining land use options. Second, the USFWS became an integral partner in how management actions were approved in relation to the impact to the NSO population. Third, the USFWS became the de facto expert on scientific topics as it relates to the NSO in the eyes of the court. The central positions that the federal land 
management agencies had occupied in terms of defining federal forest land management practices was shifted into a position of co-operative and in some regard, a secondary status. For some interviewees in this research the USFS in particular, was viewed to have "lost its way" and that it needed to reassert itself in the management direction it once occupied. The set of structural relations in the organizational field that defined the USFS in the past does not exist today. Starting in the 1960s, the USFS was finding it difficult to meet the multiple use demands on the federal forests with a "commodities management approach” (Hirt 1994, 216). The shift in social values that defined the movement away from commodity timber production to forest stewardship was the basis for the environmental laws starting with NEPA. The USFS and BLM continually renegotiate the federal regulations that define their management actions in concert with the other organizations in the organizational field. As with any organization, the federal land management agencies are an expression of the "organization of the environment."

\section{Scientists as Arbiters of Legal Issues and Social Values}

On the morning of June 26, 2018, Region 6 of the USFS held a public presentation on the results of the "Synthesis of Science to Inform Land Management Within the Northwest Forest Plan Area.” The Synthesis consists of twelve chapters reviewing over 2000 peer-reviewed publications and analysis of the 10- and 20-year NWFP monitoring reports covering a range of topics related to the NWFP from the status of the NSO to the socioeconomic issues of rural forest-dependent communities. The Synthesis began in 2016 as the beginning of a new forest planning process for the USFS 
in Region 6 (USFS Region 6 website: www.fs.usda.gov/detail/r6/landmanagement/). The basis for the Synthesis is the requirement from the USFS 2012 Planning Rule that "the best available scientific information” inform management decision making (USFS Region 6 website). The Synthesis is essentially a review of scientific literature that has been published after the literature providing the basis for the FEMAT plan. The assumption here is that new scientific peer-reviewed information will better inform our understanding of how to move the forest planning process forward from the NWFP. We can pose two questions coming out of this research. First, have scientists been asked to arbitrate the legal, social and economic issues arising out of federal land management conflicts? Second, can the issues with the implementation and expectations arising out of the NWFP be resolved with an updated understanding of the ecological and socioeconomic conditions of the federal forests within the range of the NSO?

The growing conflict arising between the federal land management agencies and changing public values regarding of the dominant use of federal forests for timber harvest, especially clear-cutting, and a desire for increased multiple use for recreation and wildlife was addressed by Congress with the Multiple Use Act of 1960 (Hays 2007, 4). This act provided the USFS some guidance on increased multiple use but did not go as far as to set priorities for land use (Hays 2007, 4). The public outcry over clear-cutting in the Bitterroot National Forest in Montana and the Monongahela National Forest in Virginia was influential in Congress passing the 1976 National Forest Management Act (NFMA) (Freeman 2002, 634). The NFMA continued to allow clear-cutting up to forty acres but imposed new restrictions on the USFS by requiring preparation of forest plans, 
requiring public input into the planning process and the requirement to maintain viable populations of native and preferred non-native species (Freeman 2002, 634). The public participation requirement of the NFMA was a "successful mechanism for the gradual, even glacial advance in expression of environmental and ecological forest objectives” (Hayes 2007, 18). The shift in public values would have a significant impact to the federal land management agencies. "Public values shifted. They shifted from the value of cutting timber to the value of preserving habitat and preserving species” (Interviewee U).

The issue of balancing multiple use of federal forests within the USFS goes back to the Organic Act of 1897 that established the service's charter. The Organic Act established two major objectives for the USFS with federal forests, timber production and watershed protection (Hays 2007, 9). The service focused on the former and established a regime of "scientific management" that emphasized a rational production model for the efficient use of forest resources, sustained-yield timber management (Hays 1999, 127). The efficient use of resources demanded the replacement of older forests with a managed, “regulated forest” at the expense of preservation and watershed protection (Hayes 2007, 9). Timber harvest from federal forests remained low up until the end of World War II with the increased demand for wood products for the growing housing industry. The USFS met this timber demand in part by harvesting old-growth forests in the Pacific Northwest with the goal of replacing these forests with an even-aged, monoculture timber harvest regime. The development of these monoculture plantations came at the expense of other public demands from federal forests such as recreation and wildlife preservation. The conflict of social values as expressed as multiple use remains a conflict of two 
different ideas of what is a "forest." Is the value of the forest primarily in its resources for timber production or in its value in its biodiversity and ecological processes? The NFMA and the ESA are laws that seek to address this fundamental issue of the allocation of federal forests between multiple uses to meet these two conflicting ideas of what is a forest. The issue that has been litigated in the courts is how are the land management agencies to interpret and then implement these laws.

Interviewees from the USFS and BLM spoke of the loss of trust the federal land management agencies experienced arising out of the conflict on how to integrate the growing public demand for a greater focus of biodiversity and for maintaining old-growth forests on federal lands. From the perspective of the federal court, the repeated failure of the land management agencies to address the requirements of the NFMA and the ESA in a manner consistent with what the court viewed as the best available science, lead to the loss of trust and damage to the agencies' perceived expertise to implement these laws. The center of expertise shifted from the land management agencies to what were viewed as independent sources, academic scientists and regulatory agency scientists. The federal land management agencies were unable to integrate the recommendations, first of the OESTF and then the ISC, into the dominant timber focused "scientific management" foundation. The series of injunctions halting timber sales by the court was a cycle of increased acceptance on the part of the land management agencies to reluctantly integrate the results of the latest scientific panel into its land management allocation. This culminated with the formation of FEMAT and the subsequent issues as a result of the manner in which the team was formed and the later development of the EIS/ROD. 
The goal of the Forest Conference in 1993 was to resolve the social conflict regarding federal forests in the Pacific Northwest. The interpretation on how to address this social issue was to task a group of scientists to focus on a very specific goal of developing a series of alternatives whose objective was a "balanced and comprehensive policy that recognizes the importance of the forest and timber economy and jobs in the region, and how can we preserve our precious old-growth forests” (FEMAT 1993, 3). The FEMAT team was asked to meet these objectives: (1) maintenance or restoration of habitat to support viable species populations associated with old-growth forests; (2) maintenance or restoration of habitat to support viable fish populations on federal lands and (3) maintenance or restoration of a connected old-growth forest ecosystem (FEMAT 1993, 10). Essentially FEMAT was asked to provide alternative solutions to address the viability clause of the NFMA to meet the guidelines the land management agencies were unable to provide the court. The FEMAT report does contain sections which address the impact to regional employment and the impact to rural communities for each of the options proposed. However, these sections are dependent variables to the primary allocation of federal land between a network of reserves and the Matrix, each option defining a mix of suitable old-growth habitat for maintaining viable species populations and sustainable timber harvest. From the standpoint of meeting the political goals set out by the Clinton Administration, "President Clinton chose Option 9, a compromise between levels of environmental protection that would pass Judge Dwyer's examination; it included a "probable" sale quantity of about 1.2 billion board feet per year" (Thomas 2004b, 55). The Clinton Administration needed to present a plan that provided 
sustainable timber harvest of at least one billion board feet per year in order to meet the expectations of the labor community in the Pacific Northwest (Interviewee M).

It becomes clear that scientists have been tasked to arbitrate the legal, social and economic issues arising out of federal land management conflicts. In the case of the injunctions to halt federal timber sales, the court was saying, "You're not listening to your scientists. You're making a political decision when you should be making a scientific decision” (Interviewee M). The conservation biology modeling establishing the network of reserves for the NSO established by the ISC was the science that was in dispute in the court and later became the foundation for the FEMAT plan. However, the goal of the Forest Conference was not to design the optimal network of reserves for old-growth dependent species. The goals were to resolve the social, economic and ecological issues arising out of the management of federal forests. In the end, the most important goal was to present a plan that would meet Judge Dwyer's approval against plaintiffs of sixteen environmental organizations and nine timber industry co-interveners who brought legal action against the final EIS and ROD in December 1994 (Thomas 2004b, 138).

The resolution of the NWFP was the implementation of an ecosystem management approach to the management of federal forests. The FEMAT team was given the task to define ecosystem management (Thomas 2009, 194). The success of the FEMAT plan was to overcome the inability of previous scientist-lead task forces to integrate their scientific basis of ecosystem management into the planning and management efforts of the federal land management agencies. Yet even now, twentyfour years after the commencement of the NWFP, ecosystem management science is still 
not fully integrated into the planning and management efforts of the land management agencies. The issue today is not a reluctant USFS or BLM that seeks to maintain a rational use tradition of timber harvest. Today the issue is the threat of litigation by the environmental community reluctant to change a successful strategy of stopping active management of federal forests and the manner in which the courts have interpreted the NWFP. As one interviewee aptly put it, "it's an institutional set of arrangements" (Interviewee AB). The lack of trust within the organizational field between the land management agencies and the other organizations hinders the development of active management in the late-successional reserves and the riparian reserves. It seem unlikely that the issues with the implementation and expectations arising out of the NWFP will be resolved with an updated understanding of the ecological and socioeconomic conditions of the federal forests. As the history of previous scientist-led panels shows, "managers therefore have a tendency to believe that if they address the science questions adequately, the value questions will be covered and the management action that follows will be acceptable to most, or enough, of those people who consider themselves affected by the decision” (Gordon 1999, 48).

\section{The Foundational Meaning of Uncertainty and Certainty}

One avenue of exploration regarding the different conceptions of what constitutes the "real NWFP" concerns the manner in which organizations conceive the meaning of "not having enough information.” The way organizations respond to this situation influences in part in the implementation of management actions. The manner in which 
organizations think about and resolve the answer to "uncertainty" had an impact on the translation for the intentions of the NWFP. The fundamental meaning organizations place on the situation of uncertainty has a direct bearing on the actions they take to address future actions. This can be seen with the direction proposed by the FEMAT team and the later direction proposed by the drafters of the EIS and ROD.

The Clinton Forest Conference adopted ecosystem management as the basis for the future management of federal forests (Tuchmann 1996, 32). Jack Ward Thomas explained ecosystem management "requires us to think in three unusual ways: at a landscape scale and across artificial boundaries, at expanded timeframes, and with an underlying objective of maintaining biodiversity, which conceptually evolves into keeping every cog and wheel, which leads us to the maintenance of ecosystem function. Therein lies the assurance of the continuation of the ability to extract the raw materials to support human life” (Thomas 2004b, 142). Thomas further explains that ecosystem management is "a journey and not a destination" and that it "is evolutionary and not revolutionary in approach” (Thomas 2004b, 267). As part of the implementation process of ecosystem management, monitoring and adaptive management play important roles (FEMAT 1993, 9).

Adaptive management is the complement to ecosystem management. If ecosystem management is a "journey," then adaptive management is the road that it follows. Gunderson (1999) defines adaptive management as follows:

"Adaptive management is an integrated, multidisciplinary method for natural resource management...It is adaptive because it acknowledges that 
the natural resources being managed will always change; therefore, humans must respond by adjusting and conforming. There is and always will be uncertainty and unpredictability in managed ecosystems, both as humans experience new situations and as these systems change through management...Active learning is the way in which this uncertainty is winnowed. Adaptive management acknowledges that policies must satisfy social objectives but also must be continually modified and flexible for adaptation to surprises...The process of adaptive management includes highlighting uncertainties, developing and evaluating hypotheses around a set of desired system outcomes, and structuring actions to evaluate or 'test' these ideas” (Gunderson 1999, 35).

Adaptive management recognizes both the uncertainty of complex ecosystems and the limitations of our knowledge of these ecosystems. A number of academic scientists who participated in the development of the FEMAT plan expressed regret that the principles of ecosystem management and adaptive management were not followed in the EIS and ROD and subsequent implementation and adjudication of the NWFP. In regard to the landscape-scale focus of ecosystem management, one interviewee stated: "One of the things for me that the NWFP did - it mandated that we move from thinking about a small scale to a landscape. And in doing that you've got to recognize that the way you view this is not the way you view that. And yet what we've done - and it's from a regulatory perspective as well, we were really comfortably thinking small. So therefore, all we have to - we can take the rules that we use to think small and apply it to 
the big. You see? And we haven't recognized that to think big you've got a whole new set of rules and expectations. The agency has not - not just the USFS and BLM, the regulatory agencies haven't recognized that” (Interviewee Q). The FEMAT team addressed landscape scale thinking by applying a "coarse filter” approach, "whereby oldgrowth stands were assumed to contain associated species” (Thomas 2004a, 12). A “coarse filter” approach to maintaining biodiversity starts with the habitat and the associated ecological processes as the goal for management, the assumption being that maintaining adequately connected habitat and processes will provide for the maintenance of the species associated with that habitat. The late-successional reserve network was deemed to be sufficient to maintain the population of the NSO and associated old-growth species in order to meeting the "diversity clause" of the NFMA.

With the translation of the FEMAT plan to the EIS and ROD and the implementation of the NWFP, the idea of applying a "coarse filter" approach to federal forest management gave way to a "fine filter" approach focusing on managing individual species. There were two explanations for this shift, one external to and, the other internal to the federal agencies. First, the federal agencies are bound by the regulations of the ESA. The ESA was drafted at a time prior to the development of ecosystem management concepts and takes a species-specific approach to biodiversity management (Thomas 1999, 17). With the listing of the NSO, USFWS provided a draft recovery plan for the species in 1992 based on the ISC proposed network of reserves. The land management agencies viewed their primary goal to meet the requirements of the ESA and the recovery plans put forth by the USFWS in 2008 and 2011 (Interviewee T). 
The primary cause for the shift from a "coarse filter" approach to a "fine filter" approach came with the addition of Survey and Manage to the final ROD. The addition of Survey and Manage resulted from "(s)pecies experts assisting in the preparation of the Northwest Forest Plan predicted the Plan would provide adequate habitat for nearly 800 late-successional forest-associated species including those listed under the Endangered Species Act, but could not predict the Plan would adequately protect about 400 other latesuccessional forest related species that were apparently rare or about which little was known. In response to this concern, eight mitigation measures, including Survey and Manage, were added to the final Plan to provide additional benefits for these apparently rare species of fungi, bryophytes, lichens, mollusks, vascular plants, several vertebrates and four arthropod groups” (USDA 2007, 4). This addition was added at the last minute after the completion of the EIS and was incorporated in order to meet the needs of some of the agency scientists who specialized in the rare 400 late-successional species.

Survey and Manage required that the land management agencies survey prior to any proposed management action, and if a species on the list was discovered, a management plan for protecting that specific population was required. Species were on the list specifically because little was known about them and from management standpoint, this was a very risk averse approach to uncertainty. One BLM planner expressed the problematic nature of the approach:

"A lot of the species on the Survey and Manage list were there because we had very little information about them. Well, that's a much more risk averse approach than the Endangered Species Act. The Endangered 
Species Act, if you don't have affirmative information about a need to list, you don't list. You don't put species on because we don't really know much about them. That was problematic. Then the approach of saying we're going to manage these species at their sites at an individual level, not a population level, was problematic again...The Forest Service had hired a bunch of mollusk specialists, so, we had all these lists of species we don't know much about, because we haven't studied them yet... Okay, so what law was this necessary to comply with? Well, it wasn't a law, it was a regulation of maintaining viability and distributed populations of all native and desired non-native vertebrate species. So, where do we start legally here? We took a regulation that applies to the Forest Service and applied it to the BLM...Second, we took a regulation that, by its terms, refers only to vertebrate species and decided to apply it to all species. Invertebrate animals, plants, mosses, liverworts, okay. And then, we build it not around population but around the individuals" (Interviewee T).

Survey and Manage had three significant impacts to the NWFP. First, it shifted the focus of conservation of biodiversity from a landscape scale "coarse filter" to a species-by-species "fine filter" approach. Second, the cost "was just breaking the bank" (Interviewee Y). Third, the impact to agency ground operations for timber harvest was significant. Survey and Manage, along with the inability to modify riparian reserves, are two NWFP aspects which significantly changed the level of timber harvest to meet the 1.2 billion board feet level. The procedural requirements for Survey and Manage were 
not only costly, but also burdensome for the land management agencies as litigation was brought against any timber harvest proposal. A retired USFS employee remarked, "It didn't evolve into survey and manage, it was survey and avoid. And pretty soon, your forest management devolved to the weakest link. And a lot of NEPA decisions had done that too. You proposed one thing, by the time you went through survey and manage, by the time you went through lawsuits, appeals, and everything, you were down to doing something very different" (Interviewee $\mathrm{AB}$ ). Jack Ward Thomas identified the problems Survey and Manage brought to the NWFP: "FEMAT members pointed out the Survey and Manage protocols would prove extremely expensive and render any harvest of old growth allowed in the plan extremely difficult and most likely impossible" (Thomas 2009, 197). He faulted the Clinton Administration for accepting the protocols and not adjusting timber harvest levels down to reflect these changes (Thomas 2004a, 13).

A term frequently used in the interviews when referring to the issue of uncertainty of information is "the precautionary principle." This was a term used by land management interviewees to describe the behavior of actors in reference to Survey and Manage. It refers to taking a conservative position to overcompensate what is perceived to be an issue at risk. Where the FEMAT team identified an experimental, learning approach, others associated with the development of the EIS and ROD, the agency legal personnel and courts themselves, typically applied a solution that seemed at the time to be safe and conservative. An example of the precautionary principle is the addition of Survey and Manage to the final NWFP ROD. As a retired USFS employee described, the FEMAT team had "set up a landscape scale strategy, methodology, for protecting the 
Northern Spotted Owl, and provided the kinds of social promises that the President and Vice-President presumably made to the people of the northwest in general and the timber industry in particular. Which required that there be some flexibility in the matrix area itself. Well along came a number of other folks, and the precautionary principle sets in. And as soon as you've got that, and suddenly the riparian reserves expand and a judge says any kind of impact on the northern spotted owl through the harvest of old-growth, no matter how miniscule it might be, is unacceptable. Those things add up to the thing being completely diverted from where it had intended to go" (Interviewee AB).

Another example of the precautionary principle in addition to Survey and Manage was evident in the development of EIS and the ROD. The team of agency scientists that worked on the EIS developed a series of Standards and Guidelines, Attachment A to the ROD. Attachment A develops management direction, "the rules and limits governing actions, and the principles specifying the environmental conditions or levels to be achieved and maintained" (USDA 1994, A-6). One retired USFS planner who was asked to review the ROD prior to its submittal explained that the team that developed the EIS was "dominated by the scientific viewpoints and the people who worked for the USFS management were there mainly to help get the EIS written in a way that would be legal. I think the people who worked on it did the very best that they could with the amount of time that they had, and there were certainly areas that didn't really have good scientific knowledge, and so the tendency was to take a conservative approach...in the absence of information people would say 'well we're pretty sure that this would be helpful, even if it looks like it might be overprotectiveness'” (Interviewee Z). 
The "rules and limits governing actions" defined in the Standards and Guidelines provide a blueprint for the processes the land management agencies need to follow. As has been established, the participation of land management managers and planners was limited with the development of the Standards and Guidelines. In addition, they were developed at a time of "tremendous mistrust of the land management agencies to implement the concepts they were intended. There are elements of the plan that reflect that mistrust and have, I think, crippled the Forest Service and BLM implementing the plan” (Interviewee T). The interviewees from the land management agencies have expressed a consistent disappointment with the nature of the Standard and Guidelines. The process orientation of the rules has limited the land management agencies in their ability to implement adaptive management and respond to specific conditions on the ground that require actions not specified in the ROD. As a BLM planner explained, "Much of these are processes rather than land management, telling us steps to go through before we take an action, prepare this kind of analysis, do this type of assessment, have it reviewed by these people...That's policy, that's guidance, which belongs in internal documents. You build that into something that's in the management plan and you want to change that process later, you've got to amend your plan. You've got to do an analysis under NEPA for that” (Interviewee T).

The structure of the Standard and Guidelines and the addition of Survey and Manage have limited the management actions for the land management agencies in a way that the FEMAT team did not imagine for the NWFP. The conservative nature of the approach taken by the EIS team based on the desire for greater certainty took the EIS and 
ROD in a direction that hindered the development of adaptive management, flexibility to manage to conditions on the ground and a level of creativity that the FEMAT team had hoped. One academic scientist who worked on the FEMAT plan expressed the transition from the FEMAT plan to the EIS as follows:

“Everybody wanted certainty, in terms of outcomes. Certainty doesn't allow for adaptability. The adaptive management areas that we created in FEMAT, were so scary to the agency biologists that they did everything they could, but to eliminate them...By the time the B team, who took the FEMAT and converted it into the final environmental impact statement, were done with it, you couldn't do anything in adaptive management areas until you had a comprehensive plan...They removed all opportunity and all incentive for anybody to use those, because they were the most difficult areas to get anything done in" (Interviewee X).

The issue of uncertainty and the limits to scientific certainty has a history in environment regulation and has been described as the "regulator's dilemma” (Weinberg 1985, 60). Weinberg defines the regulator's dilemma as the situation when science is unable to provide answers, "yet the regulator by law, is expected to regulate even though science can hardy help him” (Weinberg 1985, 60). Weinberg suggests that regulators need to re-evaluate the expectations when scientists are unable to provide certainty in regard to the available science. "Instead of asking science for answers to unanswerable questions, regulators should be content with less far-reaching answers. For example, where the ranges of uncertainty can be established, regulate on the basis of uncertainty; 
where the ranges of uncertainty are so wide as to be meaningless, recast the question so the regulation does not depend on answers to the unanswerable” (Weinberg 1985, 68). The solution Weinberg proposes for the regulator's dilemma is to accept uncertainty as part of management and if need be, redefine the question. This proposal provides a similar solution as does adaptive management. Management needs to move forward knowing and accepting the limits of the science.

As a means to address uncertainty in decision-making in matters of environmental regulation, the precautionary principle was first endorsed by the second international North Sea conference in 1987 (Bodansky 1991, 4). The precautionary principle has been described as "'when an activity raises threats of harm to human health or the environment, precautionary measures should be taken even if some cause and effect relationships are not fully established scientifically’” (Kriebel 2001, 871). The precautionary principle has been interpreted as favoring a regulatory approach "with respect to the environment, we should err on the side of caution; we should resolve uncertainties in favor of the environment” (Bodansky 1994, 203). What does it mean that we should side in favor of the environment?

Prior to the enactment of the major environmental laws in the 1970s, US regulatory agencies used an "environmental quality" approach to environmental management (Bodansky 1994, 217). This approach was based on the premise that an "acceptable" level of pollution could be calculated and then discharges could be allocated among pollution sources. This approach "depends on having accurate scientific information about the 'assimilative capacity' of the environment, that is, about the level 
of discharges that can be safely absorbed” (Bodansky 1994, 217). With the 1972 Federal Water Pollution Control Act the "assimilative” approach was replaced with a precautionary approach which assumes that the scientific certainty required for the former approach was not always possible and "attempts to replace standards that focus on the tolerable effects of water pollution with standards that focus on pollution's preventable causes” (Bodansky 1994, 217). With the application of the precautionary principle, "regulators need not show that an activity or product is dangerous; instead, proponents of the activity or product have the burden of establishing 'safety'” (Bodansky 1994, 210). In order to address the uncertainty aspect of being able to quantify the harm from environmental pollution, the 1972 Act calls for a goal of zero discharge. The assumption here is that all discharges are harmful, hence, they must be curtailed. The impact to management actions as a result of the precautionary principle has then some unintended consequences, the possibility of no management action. "According to the precautionary principle, if environmental impacts are uncertain, then our management strategies should not depend on being able to predict environmental harm, but instead should seek to reduce the risk of harm by reducing the overall impact of human activities on the environment” (Italics mine, Bodansky 1994, 217).

Sunstein (2003) makes a similar argument as that of Bodansky, that as the precautionary principle does not provide any direction for management, it "threatens to be paralyzing, forbidding regulation, inaction and every step in between” (Sunstein 2003, 1004). Sunstein presents two versions of the precautionary principle. The weak version can be summarized as the "lack of decisive evidence of harm should not be grounds for 
refusing to regulate" and regulation should be weighed in relation to the potential costs and benefits. This form of the precautionary principle Sunstein argues, was the foundation of the principle first used by the European Commission. In this weak version, the precautionary principle states "a truism, one that is uncontroversial and necessary only to combat public confusion or the self-interested claims of private groups demanding unambiguous evidence of harm, which no rational society requires” (Sunstein 2003, 1016).

It is the strong version of the precautionary principle that Sunstein argues leads to inaction. The strong version of the precautionary principle holds "the threshold burden is minimal and once it is met, there is something like a presumption in favor of stringent controls" (Sunstein 2003, 1018). One form of stringent control is identified as the "mythical benevolence of nature," a form that is evident in the direction management actions were taken with the NWFP. Sunstein defines this as "the belief that nature is essentially benign and that human intervention is likely to carry risks...Processes that interfere with nature seem, on the part of many, to be taken as troubling 'degradation' whereas gains or improvements seem, other things being equal, far less significant” (Sunstein 2003, 1038). Sunstein makes the argument that the analysis of risk with regulation and management action needs to consider systemic interactions, not just single point solutions. This is evident in the issues raised by both academic and land management interviewees in regard to the risks related to the halting of active management on many parts of federal forests. Management actions taken to arrest the 
forest disturbance cycle have implications for potential catastrophic disturbance unless active management is taken to mimic less severe disturbance routines. Sunstein explains, "The conclusion is that the precautionary principle often seems helpful because analysts focus on the 'target' risk and not on the systemic, riskrelated effects of being precautionary, or even on the risk-related consequences of risk reduction. Rational regulators, of course, think about systems, not snapshots. And once we see that risks are inevitably part of systems, the precautionary principle will become far less helpful” (Sunstein 2003, 1054).

The distinction Sunstein makes between snapshot and system is analogous to the goal of ecosystem management to manage at the landscape level, not at the site level. It is the same issue as applying a coarse filter approach as opposed to a fine filter approach.

\section{Social Constructs of Nature}

The NWFP established the transition of the federal forests in the Pacific Northwest from a dominant timber harvest paradigm to a new paradigm of "ecosystem management" whose objective is "promote the long-term sustainability of ecosystems by ensuring their health, diversity, and productivity” (Thomas 2004b, 267-268). This definition expresses the goals of ecosystem management, not the practice of how ecosystem management is to be achieved. What the FEMAT plan proposed, going back to the original ISC task force, was to divide the federal forests in the range of the NSO 
into a system of reserves to maintain biodiversity objectives and the Matrix areas where timber harvest could continue to support social, economic and land management agency objectives. The EIS and ROD establishing the NWFP went further to identify the rules and regulations that define the implementation of the plan. The separation of reserves and Matrix is but one way to accomplish the goals of ecosystem management and in the case of the NWFP, was the articulation of a history of a conflict between conservation and preservation.

As one interviewee expressed, "the NWFP came along at the end of what I would call the Golden Era of Zoning type forest planning...and everything was going to be zoned out, planned out and outcomes guaranteed" (Interviewee N). The federal land management agencies zoned the forest on a functional basis, the dominant function being timber harvest, in response to the Multiple Use Act of 1960 requirement to manage federal forests for timber, water, grazing, recreation and wildlife. (Hayes 2007, 4). The management technique was to assign forest functions to forest zones. Two main categories emerged, timber harvest (plantation) and wilderness (wildlife reserve, recreation). The timber harvest zone was defined, in the ideal to be the development of a sustained-yield managed forest, a plantation. This delineation of forest management was an expression of the split between conservation and preservation. Preservation, in this case, defined the forest as functions related to wilderness, natural processes (water, wildlife) or human enjoyment of the forest (recreation). The NWFP focus on a network of reserves can be seen as an extension of functional zoning. The boundaries of the latesuccessional reserves were drawn around "significant chunks of old forest” and these 
boundaries have remained fixed over the past twenty-four years (Interviewee K). The outcome of the NWFP has been a fixing in time and space of the federal forests in the Pacific Northwest in regard to (1) late-successional reserves, (2) a focus on old-growth at the expense of other forest stages, i.e., early seral, and (3) a halt to active management on most federal forest land.

Lee (2009) sheds light on this outcome with what he considers the symbolic meaning of old-growth forests in the Pacific Northwest as "sacred trees". His discussion addresses the symbolic meaning of old-growth forests in relation to the Progressive Movement which defined the development of professional forestry and management of forests for sustained-yield harvest early in the twentieth century. The development of professional forestry was based on "rational methods to bringing order not just to forests, but, the extent possible, to the local communities depending on forests for their livelihood" (Lee 2009, 96). The model of sustained yield forest harvest "epitomizes the rational thinking of the modernist era. The messiness of natural forests was to be ordered by forest regulation. Manipulation of both time and space was fundamental to bringing order to forests” (Lee 2009, 98). The order of the modern era is expressed as time as "duration" and space as "interchangeable”. The model of the forest was defined by a "national forest planning [that] treated all available acres as having the same potential value," i.e., commercial value (Lee 2009, 98). Lee proposes that “the modern world we knew for most of the twentieth century failed to accept the truth that the messiness of the world is part of the human condition" (Lee 2009, 96). The "postmodern society" reflects the "re-enchantment of the natural world" and this "found expression in a sudden shift in 
the cultural meanings associated with old trees” (Lee, 2009, 96 - 97). Lee (2009) addresses the idea of "bringing order to forests." In the case of what he defines as the modern era, that order is defined by the commercial value of the forest. His argument is that the postmodern era is a reaction to the lens of commercial value for federal forests and new lens of symbolism rejects the commercial focus, "a symbolic refuge from an increasingly commercialized world” (Lee 2009, 99).

The FEMAT plan of a network of late-successional reserves for maintaining biodiversity and ecosystem processes was based on the principles of conservation biology. The plan is an ordering of the federal forests in the range of the NSO between maintaining wilderness areas for species that are dependent on old-growth habitat and commercially zoned areas for timber harvest. The FEMAT plan flipped the priorities of previous forest plans but maintained the separation in regard to management goals. The network of late-successional reserves became the ordering of the federal forest to "grow owls” instead of growing trees. In Lee's terms, the shift in priorities for the federal forests with ecosystem management was to move from a utilitarian or commercial valuation of the forest to a symbolic valuation based on the goals of species and oldgrowth preservation. The reordering of the forest was from a sustained-yield of timber to “sustained-yield” of biodiversity and old-growth trees.

Different organizations have interpreted this reordering of the forest in conflicting ways. The scientists from the FEMAT team based their plan on the understanding that the uncertainties of the scientific knowledge at the time meant that further understanding of ecological processes and of species will require future evaluations of the plan; this is 
the basis for adaptive management. In addition, the recognition of the disturbance prone nature of the Pacific Northwest meant that the boundaries created with the plan would need to be addressed with potential future events. "Because of things like fire, windstorms, and global warming, and all these things that impact these systems and to make them very dynamic, that in the long run we need to be moving towards a plan that is also very dynamic and does allow us to manage the entire landscape in a way that - to the best of our ability - to not just conserve species diversity but also respond to things like fire, insect outbreaks, things like that” (Interviewee P). The goal for ecosystem management was to manage at the landscape level and to focus on ecosystem processes rather than at the individual species or at the stand level. The boundaries established for the late-successional reserves not meant to be permanent. As one interviewee explained, "let your habitat types move around, you need some of all kinds so we know they change, so let them change and just re-designate" (Interviewee $\mathrm{N}$ ).

In the research, the meaning of the symbolic valuation of the network of latesuccessional reserves as a means to preserve old-growth forests and biodiversity was expressed with the environmental community. One of the primary goals of the environmental community was to stop all harvest of old-growth forests, regardless of the location in the reserves or the Matrix. "And so in terms of the conservation community's goals at the time on the NWFP which was still to protect all remaining old-growth, ancient forest. That wasn't being met because - that, the full breadth of that wasn't reflected in the NWFP" (Interviewee C). Subsequent lawsuits by the environmental community stopped all harvest of old-growth in the Matrix, convincing the court that 
such harvest was detrimental to recovery of the NSO. The goal according to one interviewee is to move away from the concept of the Matrix: "I think the goal that I see and what I think makes sense is everything is a reserve. So in other words, you don't have any Matrix. Because the Matrix is basically saying, 'This is what we're giving to the timber industry.' Well, the public doesn't care about the timber industry" (Interviewee O).

The federal land management agency interviewees expressed the recognition that environmental disturbance and the need for better management for biodiversity are at odds with a system of fixed reserves. "The challenge with the NWFP and the latesuccessional reserves are fixed on the landscape. Once they burn up, they're gone. Being able to have a mosaic of reserves that moves across the landscape depending on your current ecological condition is much more important that a fixed boundary because owls...no species recognizes the fixed boundary of a reserve" (Interviewee AH). Similar to the issues discussed earlier regarding the difficulties with changing standards and guidelines in the NWFP, changing the fixed boundaries of the late-successional reserves have met with similar resistance from the environmental community. As one retired USFS regional forester explained, “And then you would probably ask is if that's true, why is it that you're not more aggressive about moving off of fixed land allocations and standards and guidelines that lack flexibility? And the answer to that is maybe what folks said to me is, 'They don't trust you. As imaginative as you may be, as well intentioned, we don't trust that future administrations will provide the degree of protection what we believe is appropriate’" (Interviewee $\mathrm{AB}$ ). The resistance to making any changes to the 
reserve structure of the NWFP continues in light of any new scientific information that would suggest otherwise. A USFS scientist noted that "in spite of the new information we have gathered in that time frame through monitoring and other things...we're trying to do that now but there's a lot of opposition to any sort of revision of the NWFP. Because of fear that it's going to - based on very little fact in my opinion - the fear is that it's going to do this or it's going to do that depending on which side of the issue you're on. It's based on speculation” (Interviewee K).

The desire of the environmental community to preserve all old-growth forests reflects a broader cultural phenomenon as Lee (2009) relates in regard to the valuation of these forests for their symbolic value. The desire for a "wilderness" is an ideal of "nature which is separate from visible social influence and is experienced in an individual, often spiritual way” (Hobbs 2011, 121). The meaning of these late-successional reserves as a symbolic refuge from the demands of social life is not in any way less "real" than the silviculturist's timber focused view of them as “decadent” due to their minimal annual growth rates (Hirt 1994, 17). The science of conservation biology provided the basis for the environmental community to argue in court that the proposals put forth by the land management agencies prior to the FEMAT plan were inadequate to meet the requirements for maintaining a viable NSO population. In discussing the Australian urban environmentalist community, Davison (2008) notes "many environmentalists rely on science to prove the reality of the human-nature interdependence while also relying on it to place nature out of the reach of human subjectivity, out of the reach of politics, by describing the incontrovertible facts of nature” (Davison 2008, 1286). The concept of a 
reserve network defines the nature - culture separation. Conceptually free from the subjective influence of human social activity, the reserve defines a wilderness in which nature is free from human intervention and can be rediscovered by the individual.

In addition to the fixing of the reserve network in time and space, a second consequence of the NWFP has been the focus on the preservation of late-successional forests at the expense of other seral stages, primarily the early seral stage. A number of FEMAT scientists have recognized that the plan did not provide a balanced view of all seral stages found across the landscape. One FEMAT participant noted, “we've focused on the mature and the old because that's where the crisis was. We neglected the very young. And you have to look at the whole sere. You have to go back to managing the whole sere. And get that accepted and that includes patches with the diverse early seral vegetation and with biological legacies. And those areas can be large as long as they're structurally complex. So it is to go back to looking at the entire - all structural stages. And that it turns out there's actually biodiversity in the very young to the very old and so we need to stop thinking of this in terms of black and white" (Interviewee $\mathrm{H}$ ). The focus on old-growth forests and the populations of species associated that that habitat came at the expense of biological diversity associated with other forest conditions. " $[T]$ his period, lacking the dominance of evergreen conifer forest, is the period when we have the greatest array of biological diversity...It's not just weeds, it's really a very, very rich system. Because you're going to have such a long period of time of dominance by evergreen conifers, that makes this period really important” (Interviewee X). 
The BLM developed its new forest plan with the recognition of the need to maintain a balance between all seral stages of forest conditions. The BLM "identified how out of whack those seral stages are. It's not the typical curve you would associate with two and a half million acres. We're overburdened in certain seral stages, and we're deficient in others. Part of what we're trying to do is get back to that normal regime" (Interviewee W). The BLM is "creating early seral habitat by doing modification to stand replacement harvest with large amounts, like up to 30 to $40 \%$ of leave, either as pockets or as scattered" (Interviewee AD). The BLM has targeted this work in their harvest base, 40 to 60 year old plantations.

The focus on old-growth habitat and associated biodiversity from a cultural perspective has a symbolic value that early seral habitat does not. This points to the symbolic value Lee (2009) presents in regard to old-growth forests as it pertains to humans. "The reversibility of 'old-growth' time provides the cultural template and social legitimization of efforts at forest restoration. From a postmodernist perspective, forest restoration can be viewed as a symbolic event to restore the beginnings - often imagined in the United States as the landscapes that prevailed at the time of European conquest. In this sense, forest restoration is about myth-making in a world in which the rich meanings provided by myths have been supplanted by the one-dimensional world of moneymaking” (Lee 2009, 101). The idea Lee presents is that forest restoration symbolically provides humans with new beginnings in a human time scale, away from the everyday social world dominated by commercial activity. New beginnings from an ecosystem management perspective rests with early seral habitat as it relates to the ecosystem time 
scale. The stage of early seral habitat has become to be recognized as an important stage in forest structural development as part of the historical disturbance cycle. " $[T]$ he historical structural fabric of the northwest forests did include openings. Different kinds of openings than we make now. They were really patches with this diverse early seral vegetation and biological legacies" (Interviewee $\mathrm{H}$ ).

One of the unintended consequences of the NWFP has been the halting of active management on most federal forests, especially in the moist forests of the western region of the plan area. The implications to active management with the introduction of Survey and Manage as well as the application of the precautionary principle to the size of riparian areas and harvest in the Matrix have limited not only the timber harvest potential but also the ability for the land management agencies to do any sort of active management. The ability of environmental organizations to bring legal action against any proposed management activity, and the success these litigants have achieved, has made, especially the USFS very conservative in its approach to active management. USFS personnel both retired and active expressed frustration with the process by which environmental organizations can bring suit against proposed management actions. Thinning of plantations on federal lands is one area where the land management agencies have support from the environmental community. The goal of thinning in plantations is to increase to the likelihood that these forest stands will take on the structural and compositional complexity of old-growth forests. These forests are between 40 to 60 years of age and are the result of extensive clear cutting of old-growth forests after the demand for timber from federal forests during the late 1950s through the 1970s housing 
demand. As one environmental interviewee stated, "younger forests that are very plastic, especially the plantations, these are much more in need of and have room for interventions" (Interviewee D). He continues, "I think once a forest has gotten to be about 80 years old, we are sort of trusting in natural processes taking over and sort of moving it from 80 years to 200 years without much intervention" (Interviewee D).

The quotation above provides two insights into the symbolic meaning of oldgrowth forests. First, a forest stand below the age of 80 has a "plasticity" which is amenable of manipulation by humans in order to provide it with a pathway to becoming an old-growth forest in its structural and compositional complexity. However, once a forest reaches the age of 80 , it moves into a new category where human management is replaced with management by "natural” forces. The separation of management agents from human to nature follows the guideline provided by Lee (2009) of the "otherness" of the old-growth forest as "sacred" from its biological existence. "Visiting old growth is not required to appreciate its meaning, because this place is first of all a refuge for the imagination, not a material condition. It is a place of power because natural processes are free to function unimpeded by human demands. As such, it opens a door to different experiences of space and time” (Lee 2009, 99).

The federal land management agencies find themselves in a position caught between the demands of the environmental community for increased preservation of federal forests and reduced agency management and the demands of the timber community and Oregon counties for increased timber harvest from federal lands. These are the same demands that existed prior to the NWFP with the federal land management 
agencies trying to balance their activities to meet both demands. The NWFP did not solve the social conflict on the demands of the federal forests, it reversed the dominance of one community, the timber community, with the environmental community. The failure of the federal land management agencies to rebuild trust with both communities and the ability for the environmental community to direct land management decisions from the federal courts has limited the freedom of action of the agencies, especially the USFS.

\section{The US Land Management Agencies Moving Forward}

Clarke and McCool (1996) write about seven federal natural resource agencies with the goal to "examine what accounts for the performance differences that exist among federal agencies," what they refer to as "'differentials in agency power”" (Clarke and McCool 1996, 3). They define successful performance as "that which makes one agency rich, powerful, and influential in the government process” (Clarke and McCool 1996, 3). Clarke and McCool propose that a successful federal agency is one with a dominant "scientifically-based profession" (Clark and McCool 1996, 10) and the important factors for high performance is "a set of organizational and political conditions” (Clarke and McCool 1996, 5). They define performance to be based on two resources; first, "expertise and control of information" and second, "political support" (Clarke and McCool 1996, 6). The USFS and BLM are described in their book as having quite different performance levels, the USFS is described as "bureaucratic superstar" while the BLM is classified as an "organizational shooting star." However, since the 
second edition of their book, changes as a result of the influence of court mandated management direction, the impact of litigation from the environmental community and in the Pacific Northwest, the NWFP, and these classifications do not hold up.

In their analysis of the federal resource agencies, Clarke and McCool take an agency focused approach to their analysis. They look at the history of each agency and empirically identify traits of each, concluding that these traits are the explanation for the levels of performance and success or failure. They are looking at each agency in isolation, not as part of an organizational field where agency performance is expressed as a result of the cultural milieu, interpretations of federal statutes, the state of scientific professionalism, other agencies and private interests. Clarke and McCool do discuss the "iron triangle" of the specific agency, congressional committee and industry organizations, but the sides of the triangle are viewed as independent entities and the relations between them are described in economic terms. The USFS has a relationship with the timber industry and the revenue contributions to the federal treasury. The BLM has a relationship with the ranching industry. This is not to say that these relations are not, or were not, important. The issue is that they are but a subset of the larger organizational field. The iron triangle cannot begin to bring insight into the changes that have been brought on these two federal land management agencies.

The analysis of each federal land management agency Clarke and McCool present does not align with the current state of these agencies in the Pacific Northwest. Clarke and McCool classify the USFS as a bureaucratic superstar based on its focus on "the scientific and technical management of the timber resource according to the principles of 
wise use and sustained yield” (Clarke and McCool 1996, 52). The agency's focus on silviculture as a profession, the belief in the core principles of scientific management, the rejection of political interference in the agency and the economic contribution of the USFS, define its status as bureaucratic superstar. What Clarke and McCool describe is an agency of "organizational zeal or esprit de corps" that "exude[s] a sense of selfconfidence in their relationships with others” (Clarke and McCool 1996, 10). Unlike the USFS, the BLM is classified as an organizational shooting star, having a "variegated history...their development is characterized by more ups and downs...Unpredictability and uncertainty are almost built into the character of these organizations” (Clarke and McCool 1996, 175-76). The BLM’s “variegated history” is presented as a captured agency of the livestock industry and chronically underfunded to successfully meet its management mandate. The professionalism of the agency is described as not as robust as the USFS due to the lack of range management university programs and "agency personnel have been subject to more pronounced local pressures” due to the lack of a personnel rotation policy (Clarke and McCool 1996, 163).

The conditions that led to one agency's success in the past can lead to an unsuccessful transition to a future defined by a new articulation of the organizational field. The discussion here is limited to the USFS and the BLM in the Pacific Northwest, but, what are the requirements for these federal land management agencies to be successful in the future? One insight into this is to look at how these land management agencies have fared since the implementation of the NWFP. Is the future performance of 
an agency dependent upon its organizational DNA as described by Clarke and McCool? Clarke and McCool (1996) elaborates:

"We thus see bureaucracies as entities, even organisms, that are constantly changing and adapting to their environments, which also are in a state of flux. Some agencies are better equipped to make the necessary changes to secure their continued influence, and even survival, than are others. This former group, those which compete better than the others, is blessed with a potent combination of resources. In the case of the Corps and the Forest Service, these include: a pro-development, multiple-use mission; a pragmatic or utilitarian ideology; a clear beginning...; a scientific and/or military basis of expertise; internal recruitment to leadership positions; a coherent, well-defined public image; and unusually strong support from Congress... as well as from large, well-organized constituencies outside the formal institutions of government” (Clarke and McCool 1996, 67-68). What Clarke and McCool present is a model for organizations that fixes them in time and ignores the relations articulated by the organizational field. The organic model proposed by Clarke and McCool does not stand the test of time with the changes the USFS has seen since the NWFP. The consensus of interviewees across all categories is that the USFS has lost its direction and has found itself unable to actively manage in any of the forest classifications, Matrix or Reserve. It has limited its harvest activities to thinning of plantations, an activity supported by the environmental community. The shift to ecosystem management has forced the agency to defund timber harvest activities and 
increase the staff of scientific specialists. One area where the agency has seen growth is in forest firefighters. The practice of timber harvest that defined the technical expertise of the past and mission has been replaced and with it the very foundation of agency success which Clarke and McCool attribute to the agency. As one interviewee stated, "You've got a whole new cadre of people, who are fundamentally uncomfortable with the idea of cutting down trees. They've lost not only the capacity to do active management, but the will to do active management. It's stunning. You end up with a Forest Service that does nothing but thin forests, if anything” (Interviewee X).

Clarke and McCool see the BLM as a less successful agency when compared to the USFS. However the BLM in Oregon has shown success in areas where the USFS has failed. First, the BLM completed its "Resource Management Plans of Western Oregon” in 2016, succeeding the NWFP. Second, the BLM is engaged in select areas with the institution of new silvicultural techniques based on the work of Franklin and Johnson (2012) termed “ecological forestry” (Wheeler 2012). Ecological forestry concepts "incorporate principles of natural forest development, including the role of natural disturbances in the initiation, development, and maintenance of stands and landscape mosaics” (Franklin and Johnson 2012, 432). Ecological forestry is a silvicultural technique meant to bridge the arbitrary separation between Matrix and Reserve.

The BLM has been successful in the Pacific Northwest by taking innovative approaches to both planning and timber management. The success of the 2016 planning effort was the result of recognizing the role the regulatory agencies play in the 
organizational field. By working with the regulatory agencies the BLM was able to establish a relational-based plan that brought the fundamentals of the science to bear on providing a court approved plan. The difference in this plan when compared to previous BLM planning efforts was the recognition that the effort cannot be won based on the argument of who has the better science. Second, the 2016 Plan rejected the process orientation of the NWFP and focused on outcomes.

The interviewees from the BLM spoke about the conflict in management goals between the O\&C Act and the ESA. They expressed the desire for senior BLM officials or Congress to provide clear direction on which of these two was dominant. However, the desire for a resolution would destroy a dynamic between the O\&C Act and the ESA that has been the source for creative solutions for the agency. The O\&C Act requires the BLM to provide a sustainable level of timber revenues to the Oregon O\&C counties. The ESA requires the BLM to maintain old-growth forest habitat for the NSO and the marbled murrelet. The dynamic between these two have defined that level of sustainable timber harvest and the demands for ecosystem management. One interviewee expressed what they saw as the manner in which the BLM has adapted to the post-NWFP era in a way the USFS has not. "Lo and behold, this organization has become, they are the most innovative forestry organization in the Pacific Northwest. Why is that? Because they are actually trying to do integrated management for environmental and economic values. Their habitat conservation plan requires them to do serious kinds of things. When you're actually obligated to meet multiple goals like that, you work and you learn. If you're the 
Forest Service and you don't have any economic goals anymore, you don't innovate and you don't learn" (Interviewee X).

The USFS is in process of revising its forest plans based on the requirement from the NFMA to revise forest plans at least every fifteen years. In total there are 127 land management plans within the USFS and of these, 68 are due for revision as most were developed between 1983 and 1993 (Federal Register 2016, 90724). The 2012 Planning Rule and amendments provides the framework for developing these plan revisions. The process is depicted in Figure 3. Region 6 and Region 5 have just completed the Northwest Forest Plan Science Synthesis, whose "synthesis is intended to support upcoming management planning and forest management on all federal lands in the NWFP area, but is expected primarily to serve impending revisions of forest and resource management plans that apply to land managed by the Forest Service” (Spies 2018, 3). It represents the pink section of Figure 3. 


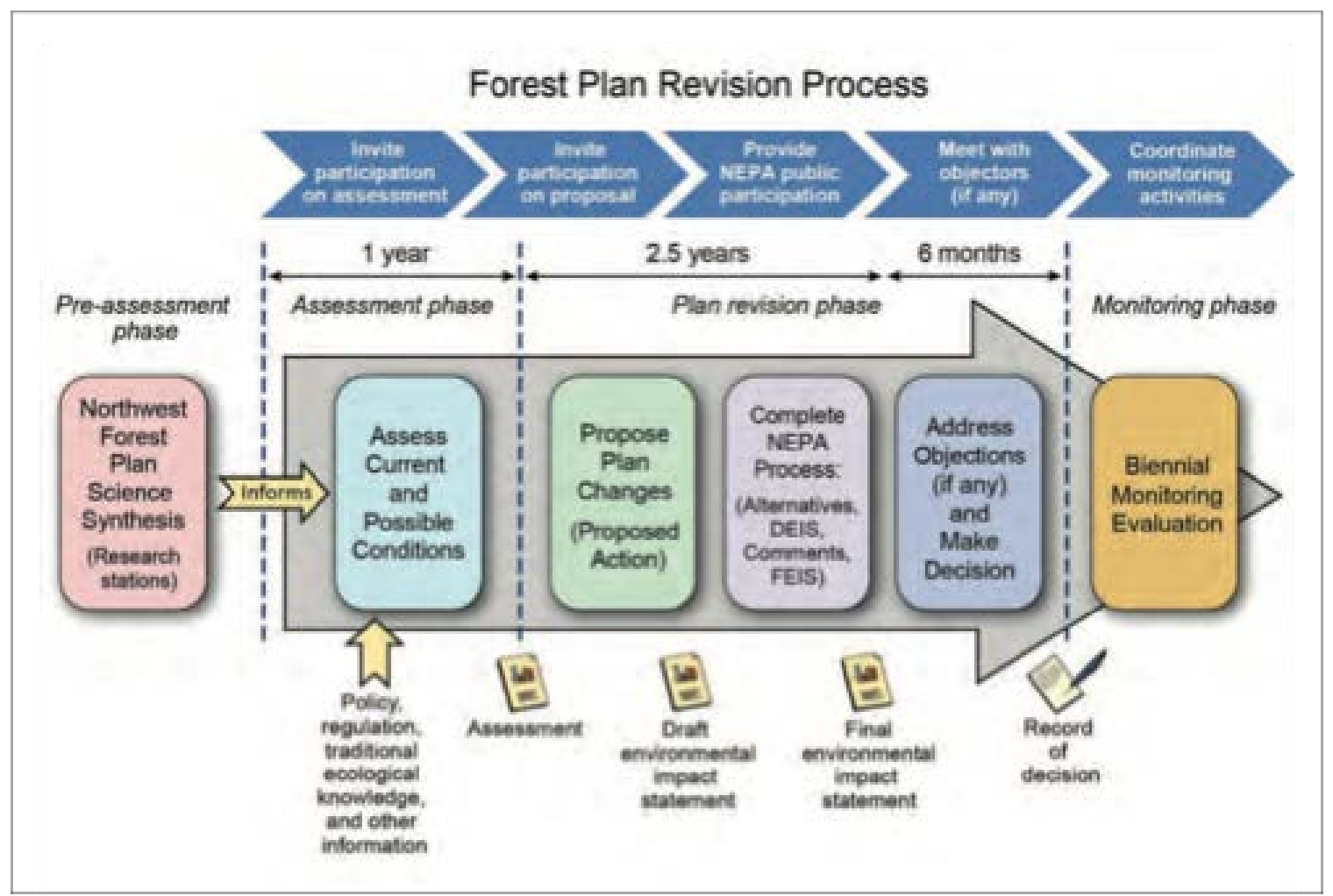

Figure 3. Forest Plan Revision Process from Spies 2018.

The 2012 Planning Rule supports adaptive management “an integrated approach to management of resources and uses, incorporates a landscape-scale context for management and is intended to help the Forest Service adapt to changing conditions and improve management based on new information and monitoring” (Federal Register 2016, 90724). To date, the USFS has not successfully implemented an adaptive management regime. From this research, the issue has been the process-oriented NWFP and the inability of the agency to successfully modify the plan due to litigation from the environmental community and a court which supports them. The intent of the 2012 Planning Rule is to “encourage and support the more regular use of amendments to update plans between revisions” (Federal Register 2016, 90724). If the intent of the 
USFS is to amend and update plans based on process requirements, does it not face the same roadblocks with the current NWFP? The lesson learned from the NWFP, as well articulated by the BLM planning team, is to focus on outcomes, leaving process requirements out of the plan. Adaptive management is based on the understanding that learning is an ongoing part of management. The acceptance of uncertainty driving adaptive management of federal forests means that process should not be codified in a NEPA document.

A second lesson from the implementation of the NWFP is that the science informing a plan does not stand on its own. The scientific expertise informing any plan is articulated by the scientists and each federal agency will have its level of risk and set of directives that inform those scientists. As the USFS is more deeply embedded in the relations between federal regulatory agencies than in the past, the USFS should take a cooperative approach as evidenced by the BLM. The final determination of whether a forest plan meets federal guidelines will ultimately be adjudicated in court. The USFS needs to have the support of the federal regulatory agencies backing the science of the plan. That would be the first level of participation.

The second level of participation would be to reach out to relevant state agencies, tribal entities, the environmental community and the timber industry in order to try to bring them into the planning process. This second level of participation is more difficult to manage given the wide range of interests. However, public opinion and activism will remain part of the process as the NWFP shows. One of the BLM interviewees involved with the development of the 2016 BLM plan provides some guidance here: “What I tried 
to do was get folks in the room and see if reasonable thinking could help find places where they overlap. Where those bubbles overlapped is where we stayed. We let go of a few issues on both sides, be we tried to stay in the overlap zone. That's where we were for four years" (Interviewee W). 


\section{Chapter 6: Discussion and Conclusion \\ Implications of the Research}

The USFS is in the early stages of revisiting its forest plans in the Pacific Northwest. The Northwest Forest Plan Science Synthesis is the beginning of the process

as outlined in Figure 3. The intention of this section is to address the implications of the research and what it can bring to this planning process.

It is unfortunate for this research that Jack Ward Thomas passed away in 2016, his perspective would have added a great deal. Fortunately, Dr. Thomas provided his thoughts about the NWFP and its implementation in a number of journal articles, book chapters and a journal published in 2004. In a book chapter entitled "Learning from the Past and Moving into the Future,” Dr. Thomas identifies lessons learned from his experience with FEMAT:

"First among these is that an ecosystem management approach is more appropriate than a species-by-species approach triggered by the application of ESA, NFMA, and NEPA. Second, an assessment should include an evaluation of social and economic effects along with ecological considerations. Third, it is inappropriate to consider only one option, and scientists should not make decisions. Fourth, instead, scientists should provide decision makers with potential management alternatives and appropriate information on which to base a decision. Fifth, all the agencies involved with the application of the myriad pertinent laws should be involved from the beginning. Sixth, it is essential to include an 
adequate array of technical specialists - including economists and social scientists. Seventh, it is important to remember that ecosystem management is as much about people as anything else. Eighth, managers should be involved in the process. And, ninth, there should be opportunity for elected officials to be informed along with the public - i.e., the process should be 'transparent'”(Thomas 1999, 17).

Dr. Thomas touches on a number of topics that have been raised with this research. First, the role of the scientist should focus on providing decision makers a number of options with consequences of each in order for them to make informed decisions. The research has borne out in addition, decision makers need to shift their focus from taking the technical answer and bringing in a broader political lens. This speaks to the second and seventh lesson Dr. Thomas proposes, that ecosystem management must include the human elements with regards to economic and social elements. By limiting our thinking and planning around the idea of ecosystem management as the domain of ecological processes, decision makers will continue to make the same mistakes by defining the need for an answer that addresses fundamental social issues couched in technical solutions. As the history of the NWFP shown, public opinion will continue to define management actions adjudicated through the courts.

We have seen that with the separation between nature and culture in our philosophical tradition, we need to re-evaluate these two spheres in order to redefine the management of federal forests. The organizational field expresses the social wants and thinking of what becomes defined as the "federal forest." That definition is not a 
consensus. It is unlikely that in the end, one viewpoint will dominate. Given the current configuration of the organizational field, the notion of federal forests as "reserves" has the dominant position given the current set of environmental laws and judicial interpretation. However, the separation of the concept of the reserve and the Matrix is one based on this nature/culture dichotomy. In order to address Dr. Thomas’s seventh lesson, the separation of the reserve and the Matrix needs to be redefined as a management technique. One interviewee expressed this in reference to maintaining biological diversity, "The classic conservation biologist view of the world was black and white, islands of habitat embedded in non-habitat, and that doesn't work. Both the enviros and the timber industry would like it to be that way, but it doesn't work. What we've talked about is we really need to be managing landscapes as shades of gray, where essentially you're sustaining biota and processes to varying degrees everywhere” (Interviewee X).

It has been the practice of federal land management agencies to associate the goals of multiple-use into separate land parcels, what one interviewee termed, "the Golden Era of zoning type forest planning” (Interviewee N). The federal forest was divided up into functional areas and as with the NWFP, the zoning of reserves and Matrix have become fixed. These boundaries do not change, regardless of the changes due to disturbance. The question is, does forest planning need to follow the zoning model? Is it possible to actively manage the landscape based on the existing forest conditions and allow for changes as a result of disturbance? By managing at the landscape level the federal land management agency will be able to work with changes due to natural 
disturbances to make sure the various types of successional stages are distributed across the landscape.

One implication from this research is that the USFS should address the social and economic goals for federal forest management to incorporate levels of timber harvest balanced with the needs for maintaining ecosystem processes. Franklin and Johnson (2012) propose what they refer to as "ecological forestry" which "incorporates principles of natural forest development, including the role of natural disturbances in the initiation, development, and maintenance of stands and landscape mosaics” (Franklin and Johnson 2012, 432). Ecological forestry is a silvicultural approach and proposes an integrated active management for both timber harvest and ecosystem maintenance. With their new plan, the BLM incorporates an uneven age management regime with retention levels in their regeneration harvests that follow in line with ecological forestry (Interviewee T).

The fifth item on Dr. Thomas's list concerns enlisting all federal agencies involved with the application of relevant federal laws at the beginning of the USFS forest planning process. This research has shown how the BLM was successful in developing their 2016 plan with the inclusion of the federal regulatory agencies at the initial stages of the planning process. The USFS should begin the second phase of its forest planning process similarly. By bringing in the appropriate federal regulatory agencies the USFS can address finding common ground regarding federal regulatory statues. The ability for the USFS to present a forest plan, or series of forest plans, that will meet federal court and public approval will rest on a unified federal agency plan. 
The USFS’s 2012 Planning Rule states that adaptive management is “an integral part of the 2012 rule” (Federal Register 2016, 90724). For implementing adaptive management, the 2012 rule provides for the use of amendments to the plan between revisions (Federal Register 2016, 90724). This allows "the Forest Service adapt to changing conditions and improve management based on new information and monitoring” (Federal Register 2016, 97024). Amendments do not require an EIS as would a plan revision. The intent is to develop a plan process which can not only be amended as new information is available, but also provide agency management the discretion to apply amendments when deemed necessary. "The 2012 rule gives the responsible official the discretion to determine whether and how to amend a plan, including determining the scope and scale of an amendment based on a specific need to change the plan” (Federal Register 2016, 90726). There are a series of clarifications as to the responsibility of the responsible official, but the goal here is to allow the USFS to begin to make changes to a plan where the NWFP did not allow. Any change to the NWFP requires an EIS (Interviewee T) and this meant, as this research has shown, modifications are difficult to implement.

The 2012 Planning Rule provides a means for addressing the process associated with adaptive management. However, as this research has shown, the underlying assumptions of adaptive management are, one, a fundamental recognition that our scientific knowledge is incomplete and two, an acceptance of uncertainty in regard to management actions or experiments. The importance of the latter is the need to move away from the risk-averse position of the precautionary principle and adapt a more active 
management position. The success of adaptive management will require the USFS to accept greater risk taking and seek creative solutions. The 2012 Planning Rule requires the USFS to use the best available science with the amendment process (Federal Register 2016, 90726). The best available science should always inform management decision making. However, the application of the precautionary principle with the NWFP has led to a situation where active management of the federal forests has been severely limited. The success of adaptive management will require a shift in thinking for the USFS and other organizations in the organizational field. As one interviewee explained, “Everybody wanted certainty, in terms of outcomes. Certainty doesn't allow for adaptability” (Interviewee X).

\section{Dynamics of Organizational Fields}

The concept of the organizational field was introduced in Chapter 5. The organizational field is defined "as a set of interdependent populations or organizations participating in the same cultural or social sub-system” (Scott 2008, 434). It was established earlier in this document that social structures or social relations are not static but need to be viewed as being continuously constructed and negotiated by social actors (Scott 2008, 431). The USFS or BLM do not exist or act independently of the sociopolitical context which comprises other organizations, commercial interests and laws and regulations governing their behavior. The federal land management agencies are part of an organizational field with an ongoing “complex process of negotiation and contestation over cultural meanings” (Mohr 1998, 350). An organizational field should not be 
viewed as the "organizations in environments but on the organization of the environment” (Scott 2008, 434). The organizational field of the federal land management agencies exists as a dynamic process and defines the interdependent relations between the organizations over time. The continuous process of the contestation and negotiation of meaning will reconfigure the relations within the organizational field. The following discussion address the changes in the organizational field of the federal land management agencies prior to the NWFP, at the introduction of the plan and the current status.

The organizational field for the federal land management agencies prior to the introduction of the NWFP is represented in Figure 4. As has been established, the land management agencies were established based on the principles of conservation. Conservation starts with the assumption of the forest as comprised of renewable resources, timber, and seeks the efficient use of those resources, known as sustained yield. The land management agencies operated with an agricultural model for the harvest and planting of trees to maintain a sustained yield forest and simultaneously seeking to achieve sustained timber communities. 
Organizational Field for Land Management Agencies Prior to NWFP

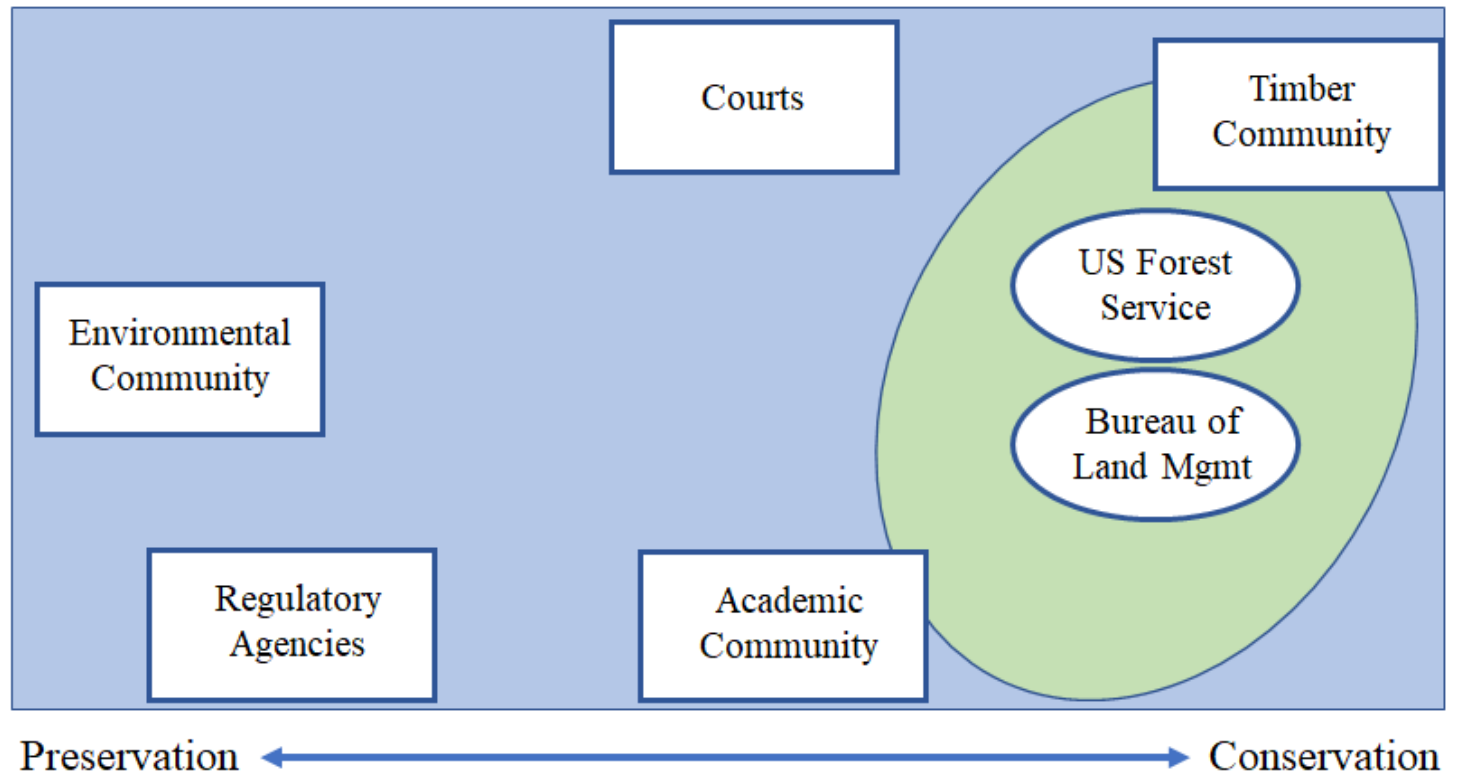

Figure 4. Organizational Field for Land Management Agencies Prior to NWFP

The focus on timber harvest, road building and local mills brought the land management agencies in alignment with the interests of the timber community, represented by the green oval in Figure 4. The land management agencies shared a common perspective with the commercial timber interests, supporting local mills and providing larger commercial firms with timber after the end of World War II in order to support the growing demand for housing. The land management agencies were employers of local residents for timber harvest and road building, supporting the local communities.

The academic community has always influenced the federal land management agencies. Professional programs in silviculture, economics and biological sciences were training future agency personnel and providing consultation for the management of federal forests since the introduction of the agencies. In the early twentieth century 
through the 1980s, the academic community was focused on forest research in silviculture, game management and economic modeling. The academic community and land management agencies were both operating under the sustained yield model of forest resources for federal forests.

Prior to the shutdown of federal timber sales by Judge Dwyer, the federal land management agencies were viewed by the courts as providing the expertise for the interpretation of federal laws pertaining to the management of federal forests. The federal land management agencies were able to implement management actions and the courts did not interfere with setting management policy. The regulatory agencies were less influential with the land management agencies prior to the listing of the NSO. The environmental community was active in opposing timber harvest in federal forests and raising the visibility of biodiversity, but it was not until the listing of the NSO that they began to have an impact on forest management through the intervention of the court.

Two events led to the reordering of the relations in the organizational field for the federal land management agencies, both as the result of the environmental laws passed in 1970s. These events eventually led to the Clinton Forest Conference and the NWFP. The first event was the listing of the NSO by the USFWS in June 1990 based on the ESA. With the listing of the NSO the USFWS took on the role of defining the architecture for the federal lands in the range of the NSO. In addition, the USFWS was now in a position to review management actions of the USFS and BLM to determine the impact of these actions to the habitat of the NSO. The land management agencies were now required to 
consult with the USFWS, providing the regulatory agency with a position of authority previously absent.

The second event was the shutting down of federal timber sales in the range of the NSO. The environmental community successfully argued that the USFS and BLM we out of compliance with the NFMA, FLPMA, the ESA and NEPA. The central argument the environmental community made was that the reserves set aside by the land management agencies were insufficient to maintain the viability of the NSO and as a result violated the "viability clause" of the NFMA. Their claim was based on the work of academic scientists showing that the configuration of the reserves and the amount of reserves was insufficient based on the principles of conservation biology and the ever improving research into the hunting and roosting requirements for the NSO. The land management agencies were provided multiple opportunities to prove to the District Court of Western Washington that their plans met the standard of best available science and would successfully meet the NFMA requirement. When the land management agencies failed to meet this standard as defined by the court, timber sales were halted.

The NWFP was initiated with the intent to provide a plan for the federal forests in the range of the NSO to meet the social and economic goals as defined by the Forest Conference and to meet the interpretation of the "viability clause" of the NFMA held by the District Court. The court had become the arbiter of contested meanings held by the environmental community and the land management agencies as to how the NFMA would be interpreted. In the past the courts had deferred to the land management agencies for the interpretation. However in this case, the court viewed the actions of the 
land management agencies as based on economic and political grounds and the USFS and BLM lost credibility with the court. In their place, the court looked to academic and regulatory agency scientists as credible scientific actors. With the final ROD, the court agreed that the plan met the requirements of the NFMA and reopened the federal forests for timber sales. The shift in the organizational field at the introduction of the NWFP is expressed in Figure 5.

\section{Organizational Field for Land Management Agencies at Introduction of NWFP}

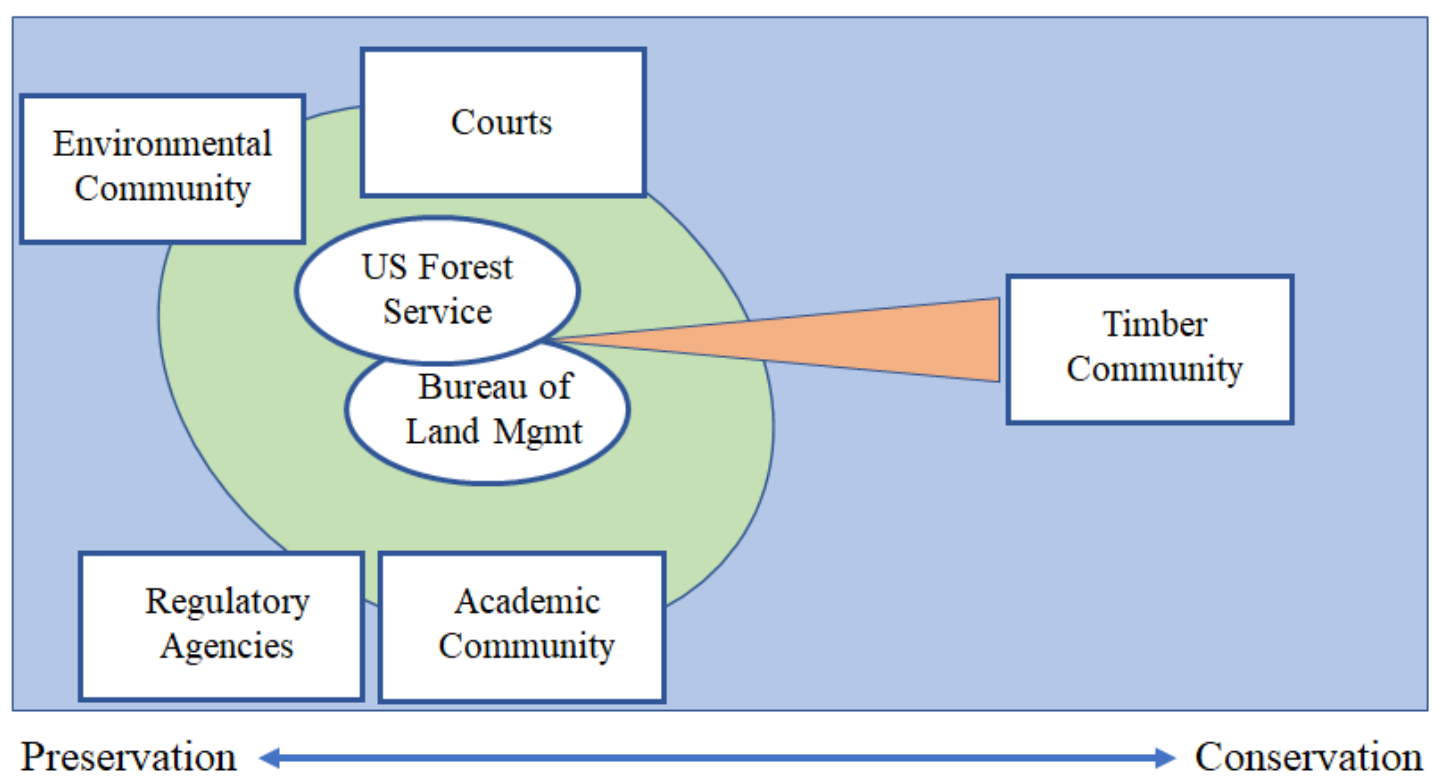

Figure 5. Organizational Field for Land Management Agencies at Introduction of NWFP

The USFS and BLM were signatories to the final ROD for the NWFP. This was the first time that the land management agencies shared a common forest plan. As was expressed by the BLM interviewees, with the NWFP, the BLM was held to the standards defined by the NFMA, which was enacted to apply only to the USFS. With the NWFP the land management agencies were now managing federal forests under the guidelines set out for ecosystem management, away from the previous agricultural model. This shift 
in management direction is represented by the movement of the USFS/BLM in Figure 5 towards the Preservation side of the figure. Figure 5 shows the land management agencies under greater influence from the academic community, regulatory agencies, environmental community, and most important, the courts. The regulatory agencies and courts provided more involvement with land management agency decision making and management actions. The regulatory agencies began to define the landscape architecture for the federal forests in the range of the NSO. The court is provided direction for management actions through the contestation of meaning between the land management agencies and the environmental community. The academic community continued to train future agency personnel, to provide interpretations of forest management direction such as through the development of the NWFP and scientific expertise in the eyes of the court. The timber community had less influence on the land management agencies but continued to apply political pressure and litigation against the agencies in order to ensure the 1.2 billion board feet projected in the NWFP is harvested and that the funding is continued to timber communities.

The current organizational field for the federal land management agencies is expressed in Figure 6. Since the introduction of the NWFP there has been two major shifts. First, leading academics involved with the development of the FEMAT plan have begun to shift further toward the Conservation side with the recognition that the work accomplished with preserving the old-growth forests, although necessary, is not sufficient in order to maintain the ecological processes and resiliency of the Pacific Northwest federal forests and also to meet the economic and social goals for all stakeholder in the 
region. New thinking involving the importance of early seral habitat, disturbance cycles and ecological forestry have been addressed in new directions for forestry management.

Current Organizational Field for Land Management Agencies

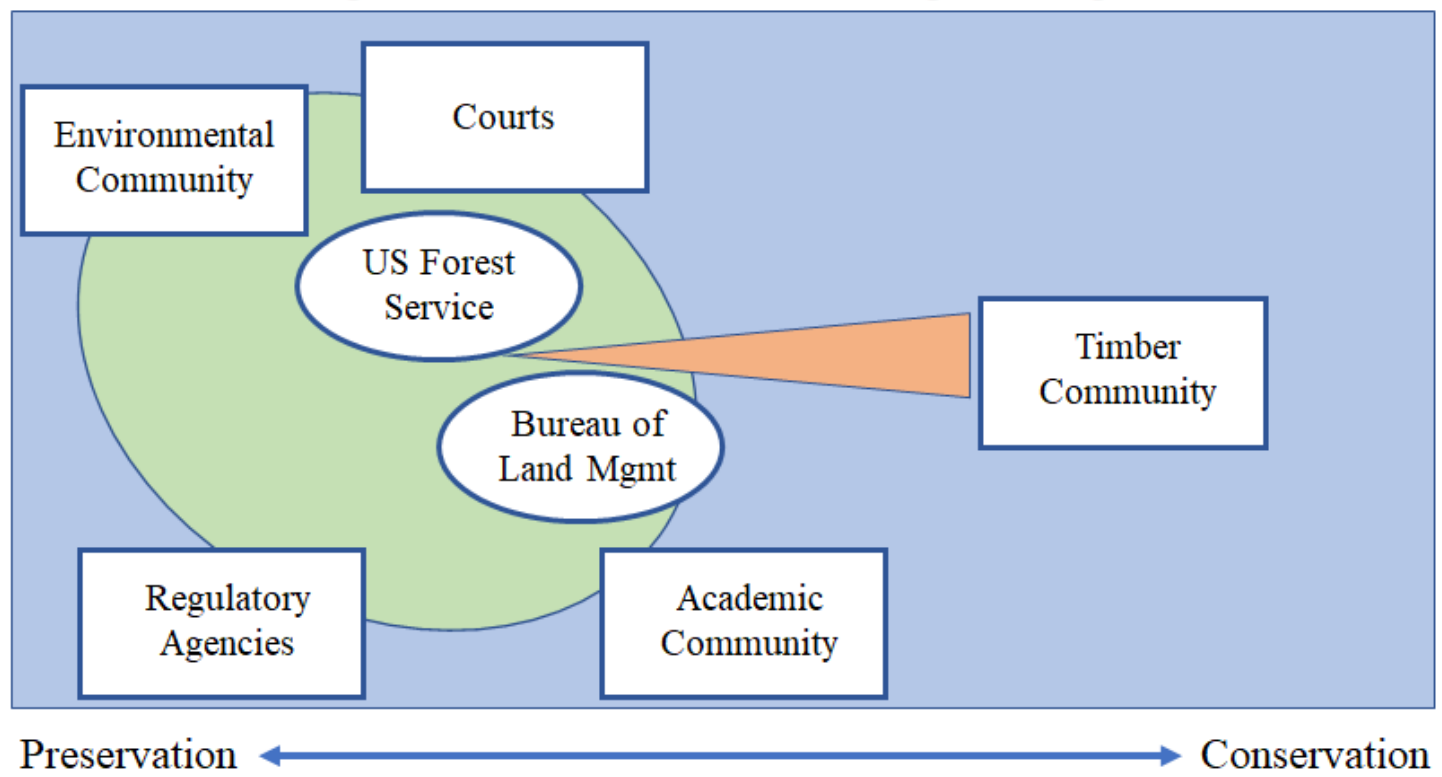

Figure 6. Current Organizational Field for Land Management Agencies

Second, the BLM is now operating under a new forest plan superseding the NWFP called the "Resource Management Plans of Western Oregon” since 2016. With this new plan the BLM is no longer operating in conjunction with the USFS under the NWFP. The timber community continues to address timber harvest levels with the BLM and the USFS with continued litigation and political pressure.

\section{Directions for Future Research}

The thirty-eight interviews that make up the primary sources for this research have provided a number of topics that could not be addressed in one dissertation. This dissertation represents an expression of some of the powerful themes that were articulated 
by the interviewees. There are additional themes addressing forest management issues that were expressed in this research that are rich for future research and writing. Two topics related to a fundamental principle behind ecosystem management, the conflicting management techniques of coarse filter versus fine filter management. Ecosystem management is premised on applying a coarse filter approach to the landscape management of federal forests. The NWFP as defined by the FEMAT team was based on a coarse filter approach and the subsequent implementation of the plan through the ROD shifted that approach to apply a fine filter with programs such as Survey and Manage.

The first topic addresses the experiment the USFWS is preforming with removing barred owls from historical NSO habitat. Given the threatened status of the NSO, the ESA requires the USFWS to take actions to maintain NSO habitat and populations. The USFWS has implemented a plan with the support of many organizations in the organizational field and should be commended for its work to gain a strong consensus for their barred owl removal experiments. However, there are a number of questions that have been raised in regard to what constitutes a workable plan for removal moving forward. Assuming the current experiment is shown successful in providing a cost effective means for NSO to re-inhabit historical habitat, two questions can be raised. First, how long would the USFWS need to maintain the removal of barred owls? Second, how is the USFWS to determine what defines a suitable range of habitat for the NSO? In discussions with the USFWS, they are prepared to remove barred owls for a long period of time into the future (Interviewee Y). However, by definition, the NWFP defined the range of habitat for the continued survival of the subspecies to be the entire range from 
northern Washington to northern California. If the USFWS is not able, and states they are not able, to remove barred owls throughout the historical range of the NSO, then how can the subspecies continue? Did the USFWS miss the tipping point for removal of the barred owl? Given the greater adaptive ability of the barred owl, was there anything the USFWS could have done to change the course of events? This line of potential research would address some of the fundamental questions regarding the fine filter approach of the ESA and how it does or does not align with ecosystem management.

The second line of inquiry concerns the federal regulatory and environmental laws that define federal agency guidelines for both regulatory and land management actions. The majority of these laws were written prior to the development of ecosystem management and some go back to the turn of the twentieth century. The interviewees, especially from the federal land management agencies, expressed their frustration with the inconsistencies between these federal laws with the mandate they express and the underlying assumptions they make regarding appropriate land management. One example is the inconsistencies for the land management goals for the BLM based the dictates of the O\&C Act and the ESA. The BLM would prefer to have a court ruling as to which law takes precedent, but this has not happened (Interviewee W). What looks like a source of frustration for the BLM is according to one interviewee, actually a source of positive conflict that has resulted in creative solutions on the part of the BLM (Interviewee X). Another source of conflict with current guidelines for ecosystem management are the environmental laws written in the 1970s that take a fine filter approach to forest management. Like many of the environmental laws written during this 
period, the perspective taken was on point sources of pollution or point sources of threatened biodiversity and solution was based on "command-and-control regulation" (Rosenbaum 2014, 182). The focus of such regulation tends towards point source solutions and does not take into consideration broader, landscape thinking as expressed by ecosystem management (Interviewee AB). This can be seen with the very point source solution of shooting barred owls. Thomas (2009) suggested the need for a new "Public Land Review Commission" to address the laws governing natural resource management (Thomas 2009, 197). Future research on this topic would focus on interviewing federal land managers, regulatory agency personnel, environmental legal scholars and political figures.

\section{Conclusion}

The NWFP was developed to address the political conflict in the Pacific Northwest between two competing visions of what the federal forests should be. The conflicting ideas of preservation and natural resource management have a long history with federal forest management. Although they provided much different pictures, they both stem from the same source in contemporary thought regarding the separation of Nature and Culture. The plan set out to be a compromise to address the concerns of the timber industry, labor leaders, Oregon counties and the environmental community. That compromise was Option 9 from the series of options developed by the FEMAT team chosen by the Clinton White House. The goals of the plan were to maintain old-growth 
forest habitat for old-growth dependent species and to sustainably harvest 1.2 billion board feet of timber from the federal forests in the range of the NSO.

The implementation of the plan produced a much different outcome. The original FEMAT plan was taken through the NEPA process by the USFS and BLM with an EIS and a final ROD. The final ROD established the NWFP as an amendment to the existing individual forest plans. The ROD deviated from the FEMAT plan in a number of significant ways. First, the ROD was highly process oriented which meant that the land management agencies became captive to these processes when they were not working with conditions on the ground. Any change to the ROD would require a new EIS. Second, the ROD contained Survey and Manage which required that before any management action could be taken that survey of old-growth species would need to be completed and a plan put in place to secure these populations should they be found. This process essentially shut down active management in the Matrix and a reduction in timber harvest. Third, the ROD was adjudicated in federal court with the environmental community essentially shutting down any timber harvest of old-growth in the Matrix and cutting back active management by the land management agencies throughout the federal forests.

There are three themes which run through the narratives in this research. First, as a means to resolve the social conflict regarding how the federal forests should be managed, the federal courts and the White House look to scientists to provide a solution based on the best available science. This is consistent with previous attempts to address the conflict between ecological preservation and demands of timber harvest from the 
federal forests. The solution provided by FEMAT was primarily a landscape perspective informed by conservation biology, applying the principles of adaptive management. The subsequent adjudication of the ROD showed that the political and economic aspects of the plan were absent. The loss of credibility of the land management agencies with the public and the federal court sidelined the agency managers and planners.

Secondly, the final ROD took on a perspective that was contrary to the original FEMAT plan with a process orientation meant to guide land managers and planners. The FEMAT plan was based on the central acceptance of the uncertainty associated with the level of scientific knowledge of the complexity of the federal forest ecosystems. The FEMAT plan was based on the concept of adaptive management, through experimental management efforts, the land managers would garner new information for the ecosystem management of federal forests. The ROD and subsequent NWFP did not embrace adaptive management and instead applied the precautionary principle that sought certainty in management actions and a subsequent loss active management. The precautionary principle was also adopted by the federal courts in matters pertaining to old-growth forests and listed species. Survey and Manage is an example of the application of the precautionary principle.

Third, the historical conflict between the thinking behind preservation and conservation has continued to guide federal forest management both at the level of legal mandates and scientific thought. The separation between nature and society has defined our ideas about wilderness and the role of active management for federal forests. Two opposing ideas of how to manage federal forests have been found. First, the preservation 
ideology sees federal forests as wilderness, best managed with as little human interaction as possible. Here Nature is seen as the best steward as natural processes will take over. The opposing agricultural model for federal forests best seen with private forestry management takes the position that forests can be planned and controlled to maximize timber harvest through rotations for the most efficient use of land. Here, Nature is managed out of the process and up until the NWFP, was the dominant model for federal forests.

The USFS is currently beginning its planning process for the federal forests in the Pacific Northwest and Northern California to supersede the NWFP. The BLM finalized their new plan in 2016 and many of the actions the BLM took to accomplish this should be adopted by the USFS. In addition, the USFS should look to the three themes identified in this dissertation in order to address the aspects of the NWFP that have failed to meet the social and ecosystem management goals that were originally desired. The NWFP has left the USFS with little room for active management in all aspects of federal forest stewardship. A new plan must provide a means not only for timber harvest but also the means for land managers to implement the goals of ecosystem management as intended by the FEMAT team. 


\section{References}

Blumm, M.C. (1991). Ancient Forest, Spotted Owls, and Modern Public Law. Environmental Affairs 18: 605-621.

Blumm, M.C. and Wigington, T. (2013). The Oregon and California Railroad Grant Lands' Sordid Past, Contentious Present, and Uncertain Future: Century of Conflict. Environmental Affairs 40(1): 1-76.

Bodansky, D. (1991). Scientific Uncertainty and the Precautionary Principle. Environment 33(7): 4-5 and 43.

Bodansky, D. (1994). The Precautionary Principle in US Environmental Law. In O’Riordan, T. and Cameron, J. (eds.) Interpreting the Precautionary Principle. London: Earthscan Publications, Ltd.

Bonnett, M. and Zimmerman, K. (1991). Politics and Preservation: The Endangered Species Act and the Northern Spotted Owl. Ecology Law Quarterly 18: 105-171.

Braun, V. and Clarke, V. (2006). Using Thematic Analysis in Psychology. Qualitative Research in Psychology 3: 77-101.

Burch, W. (1971). Daydreams and Nightmares. New York: Harper \& Row.

Charnley, S., McLain, R.J. and Donoghe, E.M. (2008). Forest Management Policy, Amenity Migration, and Community Well-Being in the American West: Reflections from the Northwest Forest Plan. Human Ecology 36: 743-761.

Clarke, J.N. and McCool, D.C. (1996). Staking Out the Terrain (2 ${ }^{\text {nd }}$ ed.). Albany, NY: State University of New York Press.

Corbin, J. and Strauss, A. (1990). Grounded Theory Research: Procedures, Canons, and Evaluative Criteria. Qualitative Sociology 13(1): 3-21.

Coyne, I.T. (1997). Sampling in Qualitative Research: Purposeful and Theoretical Sampling; Merging or Clear Boundaries. Journal of Advanced Nursing 26: 623-630.

Creswell, J.W. and Miller, D.L. (2000). Determining Validity in Qualitative Inquiry. Theory Into Practice 39(3): 124-130.

Cronon, W. (1995). The Trouble with Wilderness. In Cronon, W. (ed.) Uncommon Ground: Toward Reinventing Nature. New York: W.W. Norton \& Company. 
Daniels, S.E. and Merrill, K. (1992). The Committee of Scientists: A Forgotten Link in the National Forest Planning History. Forest \& Conservation History 36: 108-116.

Davison, A. (2008). The Trouble with Nature: Ambivalence in the Lives of Urban Australian Environmentalists. Geoforum 39: 1284-1295.

Diller, L. (2013). To Shoot or Not to Shoot. The Wildlife Professional, Winter: 54-57.

DiMaggio, P.J. and Powell, W.W. (1983). The Iron Cage Revisited: Institutional Isomorphism Collective Rationality in Organizational Fields. American Sociological Review 48: 147-160.

DiMaggio, P.J. and Powell, W.W. (1991). The Iron Cage Revisited: Institutional Isomorphism and Collective Rationality in Organizational Fields. In Powell, W.W and DiMaggio, P.J. (eds.) The New Institutionalism in Organizational Analysis. Chicago: The University of Chicago Press.

FEMAT (Forest Ecosystem Management Assessment Team). (1993). Forest Ecosystem Management: An Ecological, Economic, and Social Assessment. Report of the Forest Ecosystem Management Assessment Team. Washington, DC: U.S. Government Printing Office.

Federal Register. (2016). Department of Agriculture, Forest Service, 36 CFR Part 219. National Forest System Land Management Planning. 81(241): 90723-90739.

Franklin, J.F. (1995). Scientists in Wonderland. BioScience 45: S74-S78.

Franklin, J.F. and Johnson, K.N. (2012). A Restoration Framework for Federal Forests in the Pacific Northwest. Journal of Forestry 110(8): 429-439.

Freeman, R. (2002). The United States Forest Service and the Political Construction of Ecosystem Management. Environmental History 7(4): 632-658.

Gordon, J. (1999). History and Assessments: Punctuated Nonequilibrium. In Johnson, K.N., Swanson, F.J., Herring, M. and Greene, S. (eds.) Bioregional Assessments: Science at the Crossroads of Management and Policy. Washington, DC: Island Press.

Gunderson, L.H. (1999). Stepping Back: Assessing for Understanding in Complex Regional Systems. In Johnson, K.N., Swanson, F.J., Herring, M. and Greene, S. (eds.)

Bioregional Assessments: Science at the Crossroads of Management and Policy. Washington, DC: Island Press.

Hays, S.P. (1959). Conservation and the Gospel of Efficiency. Pittsburgh, PA: The University of Pittsburg Press. 
Hays, S.P. (2007). The Rise of Ecological Forestry in America. Pittsburgh, PA: The University of Pittsburg Press.

Hirt, P.W. (1994). A Conspiracy of Optimism: Management of the National Forests Since World War Two. Lincoln, NE: University of Nebraska Press.

Hobbs, E. (2011). Performing Wilderness. Political Geography 26: 250-267.

Hoberg, G. (1997). From Localism to Legalism: The Transformation of Federal Forest Policy. In David, C. (ed.) Western Lands and Environmental Politics. Boulder, CO: Westview Press.

ISC (Interagency Scientific Committee to Address the Conservation of the Northern Spotted Owl). (1990). A Conservation Strategy for the Northern Spotted Owl. USDA Forest Service; USDI Bureau of Land Management, Fish and Wildlife Service, and National Park Service, Portland, OR. Washington, DC: U.S. Government Printing Office.

Johnson, K.N., Franklin, J.F., Thomas, J.W., and Gordon, J. (1991). Alternatives for Management of Late-Successional Forests of the Pacific Northwest. A Report to the Agriculture Committee and the Merchant Marine Committee of the U.S. House of Representatives.

Kirk, J. and Miller, M.L. (1986). Reliability and Validity in Qualitative Research. Newbury Park, CA: Sage Publications.

Kreibel, D., Tickner, J., Epstein, P., Lemons, J., Levins, R., Loechler, E.L., Quinn, M., Rudel, R., Schettler, T, and Stoto, M. (2001). The Precautionary Principle in Environmental Science. Environmental Health Perspectives 109(9): 871-876.

Lee, R.G. (2009). Sacred Trees. In Spies, T.A. and Duncan, S.L. (eds.) Old Growth in a New World - A Pacific Northwest Icon Reexamined. Washington, DC: Island Press.

Marcot, B.G. and Thomas, J.W. (1997). Of Spotted Owls, Old Growth, and New Policies: A History Since the Interagency Scientific Committee Report. United States Department of Agriculture, Forest Service, Pacific Northwest Research Station, General Technical Report PNW-GTR-408.

Maser, C. (1994). Sustainable Forestry, Philosophy, Science, and Economics. Delray Beach FL: St. Lucie Press.

Maxwell, J.A. (1992). Understanding and Validity in Qualitative Research. Harvard Educational Review 62(3): 279-300. 
Meslow, E.C. (1993). Spotted Owl Protection: Unintentional Evolution Toward Ecosystem Management. Endangered Species UPDATE: School of Natural Resource and Environment, The University of Michigan, January/February 10 (3/4): 34-38.

Miles, M.B. and Huberman, A.M. (1994). Qualitative Data Analysis. Thousand Oaks, CA: Sage Publications.

Mohr, J.W. (1998). Measuring Meaning Structures. Annual Review of Sociology 24: 345-370.

Nishishiba, M., (2014) Research Methods and Statistics for Public and Nonprofit Administrators. Los Angeles: Sage Publications.

Patton, M.Q. (1999). Enhancing the Quality and Credibility of Qualitative Analysis. Health Services Research 34(5) Part II: 1189-1208.

Pottast, T. (1996). Genetics, Evolution, and Environmental Ethics. Bioloisches Zentralblatt 115: 177-183.

Rosenbaum, W.A. (2104) Environmental Politics and Policy, ninth edition. Los Angeles: CQ Press/Sage Publications.

Rule, L.M. (2000). Enforcing Ecosystem Management Under the Northwest Forest Plan: The Judicial Role. Fordham Environmental Law Review 12(1): 211-252.

Satterfield, T. (2002). Anatomy of a Conflict. Vancouver, BC: University of British Columbia Press.

Scott, W.R. (1995). Institutions and Organizations. Los Angeles: Sage Publications.

Scott, W.R. (2008). Approaching Adulthood: The Maturing of Institutional Theory. Theoretical Sociology 37: 427-442.

Shinn, C. (1996). Taking Stock of Institutional Thought: Institutions, Institutionalization, and Institutional Effects. Administrative Theory and Praxis 18(2): 31-41.

Skillen, J.R. (2015). Federal Ecosystem Management: Its Rise, Fall, and Afterlife. Lawrence, KS: University of Kansas Press.

Spies, T.A., Stine, P.A., Gravenmier, R., Long, J.W., Reilly, M.J., and Mazza, R. (2018) Synthesis of Science to Inform Land Management Within the Northwest Forest Plan Area: Executive Summary. U.S. Department of Agriculture, Forest Service, Pacific Northwest Research Station, Portland, OR. 
Sunstein, C. (2003). Beyond the Precautionary Principle. University of Pennsylvania Law Review 151: 1003-1058.

Tackas, D. (1996). The Idea of Biodiversity. Baltimore, MD: The Johns Hopkins University Press.

Thomas, J.W., Raphael, M.G., Anthony, R.G., Forsman, E.D., Gunderson, A.G., Holthausen, R.S., Marcot, B.G., Reeves, G.H., Sedell, J.R., and Solis, D.M. (1993). Viability Assessments and Management Considerations for Species Associated with LateSuccessional and Old-Growth Forests of the Pacific Northwest. The Report of the Scientific Analysis Team. Portland, OR: USDA Forest Service.

Thomas, J.W. (1999). Learning from the Past and Moving to the Future. In Johnson, K.N., Swanson, F.J., Herring, M. and Greene, S. (eds.) Bioregional Assessments: Science at the Crossroads of Management and Policy. Washington, DC: Island Press.

Thomas, J.W. (2004a). Sustainability of the Northwest Forest Plan: Still to be Tested. In Arabas, K. and Bowersox, J. (eds.) In Forest Futures: Science, Politics, and Policy for the Next Century. Lanham, MD: Rowman \& Littlefield Publishers.

Thomas, J.W. (2004b). Jack Ward Thomas: The Journals of a Forest Service Chief. (Ed. Harold K. Sheen). Seattle, WA: The University of Washington Press.

Thomas, J.W. (2009). Increasing Difficulty of Active Management on National Forests Problems and Solutions. In Spies, T.A. and Duncan, S.L. (eds.) Old Growth in a New World - A Pacific Northwest Icon Reexamined. Washington, DC: Island Press.

Thomas, J.W., Franklin, J.F., Gordon, J., and Johnson, K.N. (2006). The Northwest Forest Plan: Origins, Components, Implementation Experience and Suggestions for Change. Conservation Biology 20(2): 277-287.

Tuchmann, E.T., Connaughton, K.P., Freedman, L.E., and Moriwaki, C.B. (1996). The Northwest Forest Plan. A Report to the President and Congress. Portland, OR: USDA Forest Service.

USDA (United States Department of Agriculture) Forest Service and BLM (Bureau of Land Management). (1994). Record of Decision for Amendments to Forest Service and Bureau of Land Management Planning Documents Within the Range of the Northern Spotted Owl and Standards and Guidelines for Management of Habitat for LateSuccessional and Old-Growth Forest Related Species Within the Range of the Northern Spotted Owl. USDA Forest Service, Portland, OR and BLM, Moscow, ID. 
USDA (United States Department of Agriculture) Forest Service and BLM (Bureau of Land Management). (2007). Record of Decision to Remove the Survey and Measure Mitigation Measure Standards and Guidelines from Forest Service Land and Resource Management Lands Within the Range of the Northern Spotted Owl. USDA Forest Service, Portland, OR.

USFWS (United States Fish \& Wildlife Service). (2011). Revised Recovery Plan for the Northern Spotted Owl (Strix occidentalis caurina). Portland, OR: U.S. Fish \& Wildlife Service.

Weinberg, A.M. (1985). Science and Its Limits: The Regulator's Dilemma. Issues in Science and Technology 2(1): 59-72.

Wheeler, A. (2012). Roseburg District Pilot Project. Journal of Forestry 110(8): 439441.

Yaffee, S.L. (1994). The Wisdom of the Spotted Owl: Policy Lessons for a New Century. Washington D.C.: Island Press. 
Appendix: List of Interviewees

\begin{tabular}{|c|c|c|}
\hline Interviewee & Date of Interview & Classification \\
\hline Interviewee A & February 27, 2017 & Academic \\
\hline Interviewee B & March 17, 2017 & Regulatory \\
\hline Interviewee C & March 24, 2017 & Environmental \\
\hline Interviewee D & April 6, 2017 & Environmental \\
\hline Interviewee E & April 6, 2017 & Environmental \\
\hline Interviewee F & April 18, 2017 & Regulatory \\
\hline Interviewee G & April 21, 2017 & Regulatory \\
\hline Interviewee H & April 26, 2017 & Academic \\
\hline Interviewee I & April 27, 2017 & Academic \\
\hline Interviewee J & April 27, 2017 & Regulatory \\
\hline Interviewee K & June 2, 2017 & US Forest Service \\
\hline Interviewee L & June 8, 2017 & Other \\
\hline Interviewee M & June 16, 2017 & Other \\
\hline Interviewee N & June 27, 2017 & Academic \\
\hline Interviewee $\mathrm{O}$ & June 28, 2017 & Environmental \\
\hline Interviewee P & June 29, 2017 & Academic \\
\hline Interviewee Q & June 29, 2017 & Academic \\
\hline Interviewee $\mathrm{R}$ & June 30, 2017 & Industry \\
\hline Interviewee S & July 10, 2017 & Other \\
\hline Interviewee T & July 11, 2017 & Bureau of Land Management \\
\hline Interviewee U & July 12, 2017 & US Forest Service \\
\hline Interviewee V & July 13, 2017 & Other \\
\hline Interviewee W & July 20, 2017 & Bureau of Land Management \\
\hline Interviewee X & July 21, 2017 & Academic \\
\hline Interviewee Y & July 24, 2017 & Regulatory \\
\hline Interviewee Z & July 25, 2017 & US Forest Service \\
\hline Interviewee AA & July 28, 2017 & US Forest Service \\
\hline Interviewee $\mathrm{AB}$ & August 7, 2017 & US Forest Service \\
\hline Interviewee AC & August 9, 2017 & US Forest Service \\
\hline Interviewee AD & August 10, 2017 & Industry \\
\hline Interviewee AE & August 15, 2017 & Bureau of Land Management \\
\hline Interviewee AF & August 16, 2017 & Industry \\
\hline Interviewee AG & August 18, 2017 & Industry \\
\hline Interviewee AH & August 18, 2017 & US Forest Service \\
\hline Interviewee AI & August 24, 2017 & Industry \\
\hline Interviewee AJ & August 24, 2017 & Industry \\
\hline Interviewee AK & September 12, 2017 & Bureau of Land Management \\
\hline Interviewee AL & September 17, 2017 & Bureau of Land Management \\
\hline
\end{tabular}

